Aus der Abteilung Präventive Zahnmedizin,

Parodontologie und Kariologie

(Komm. Leiter: Prof. Dr. med. dent. M. Hülsmann)

im Zentrum Zahn-, Mund- und Kieferheilkunde

der Medizinischen Fakultät der Universität Göttingen

\title{
LPS-bindendes Protein an humanem Myokard unter Berücksichtigung der parodontalen Gesundheit und \\ des IL-1-Polymorphismus
}

Eine klinisch-experimentelle Untersuchung bei Patienten mit kardialer Insuffizienz

\author{
INAUGURAL-DISSERTATION \\ zur Erlangung des Doktorgrades \\ für Zahnheilkunde \\ der Medizinischen Fakultät \\ der Georg-August-Universität zu Göttingen
}

vorgelegt von

Elske Semper

aus

Göttingen

Göttingen 2012 
Dekan:

I. Berichterstatter:

II. Berichterstatter/in:

III. Berichterstatter/in:

Tag der mündlichen Prüfung:
Prof. Dr. rer. nat. H. K. Kroemer

Prof. Dr. med. dent. R. F. Mausberg

Prof. Dr. med. Meyer

Prof. Dr. rer. nat. Lüder 


\section{Inhaltsverzeichnis}

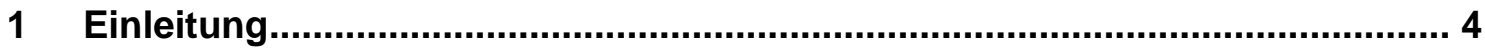

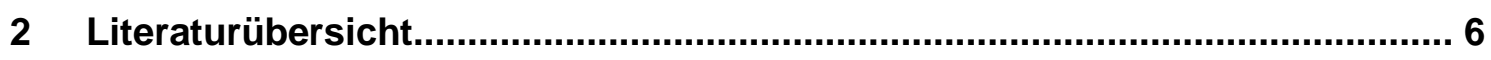

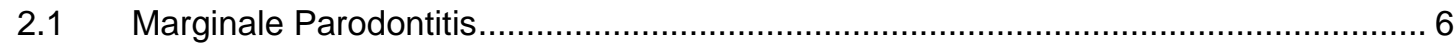

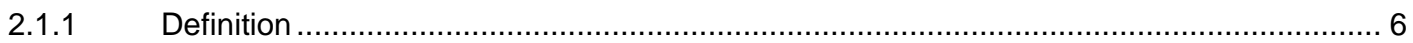

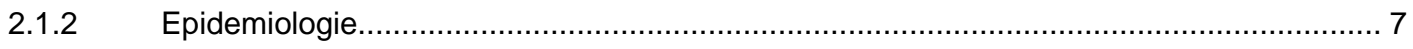

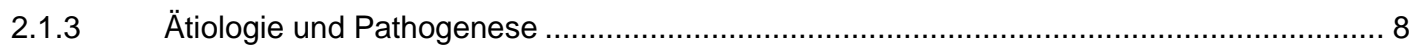

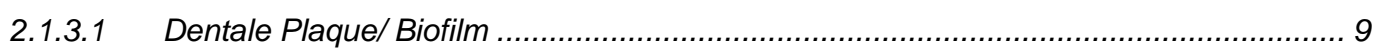

2.1.3.2 Parodontopathogene Mikroorganismen .......................................................... 10

2.1.3.3 Parodontitis als multifaktorielles Geschehen ......................................................... 11

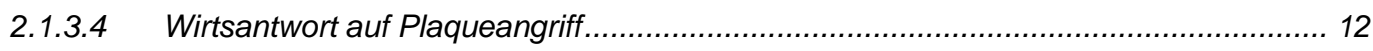

2.1.3.5 Lipopolysaccharid (LPS) und Lipopolysaccharid-bindendes Protein (LBP) ................ 13

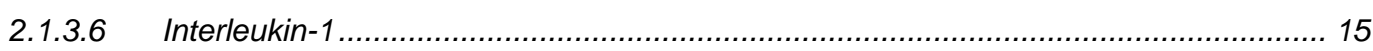

2.1.3.7 Pathohistologische Betrachtung der parodontalen Gewebedestruktion...................... 17

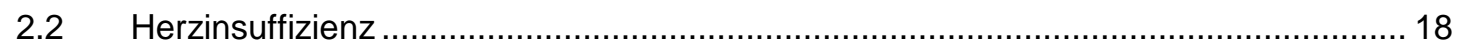

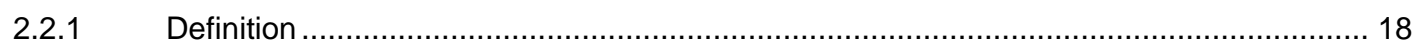

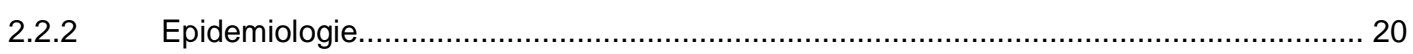

2.2.3 Ätiologie und Pathogenese .............................................................................................. 20

2.3 Bekannte Assoziationen zwischen Parodontitis und Herzerkrankungen .................... 24

3 Material und Methoden ..............................................................................28

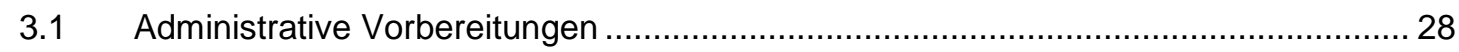

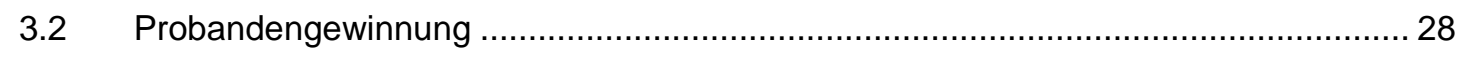

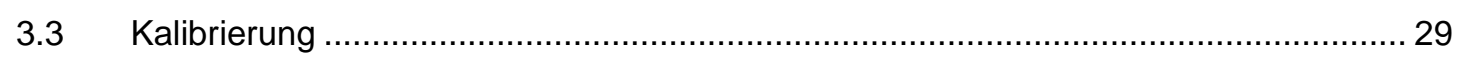

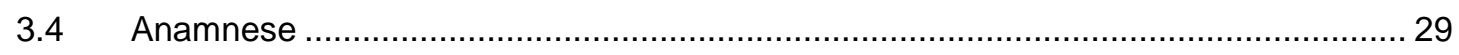

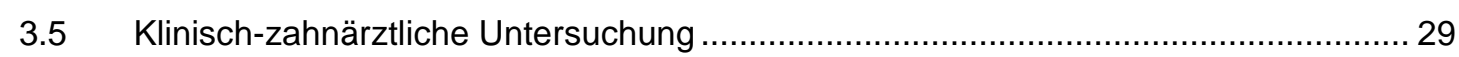

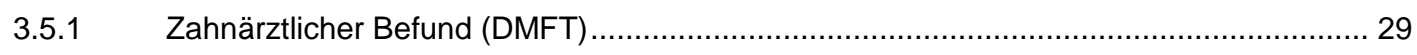

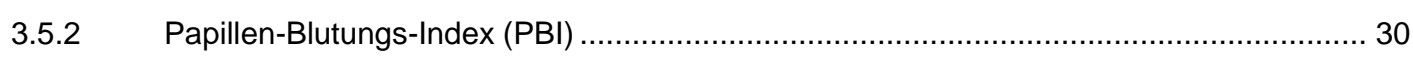

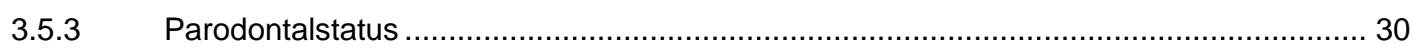

3.6 Gewinnung der Blut- und Herzgewebeproben .................................................. 31

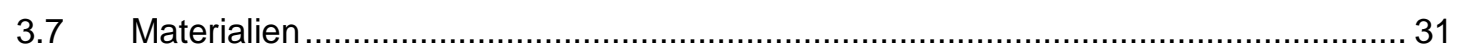

3.8 Aufbereitung der Herzgewebeproben durch Proteinaufreinigung mit Lysispuffer ....... 32

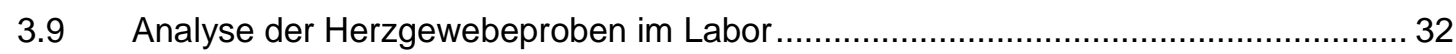

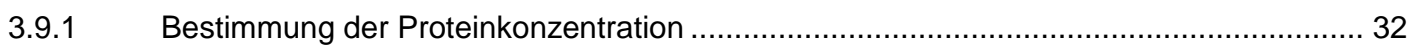

3.9.2 SDS-Polyacrylamid-Gelelektrophorese (SDS-Page)................................................... 33

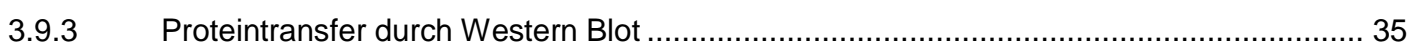

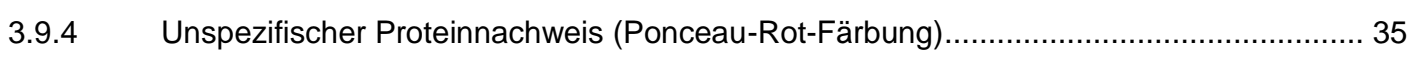

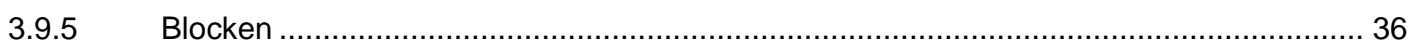




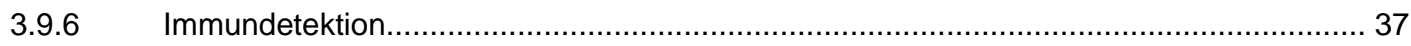

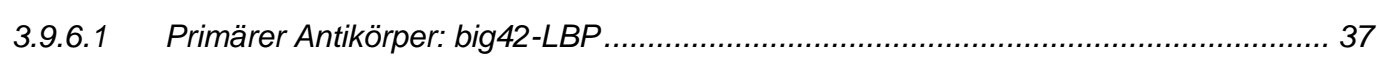

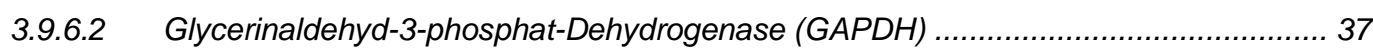

3.9.6.3 Sekundärantikörper: goat anti-mouse HRP ................................................... 37

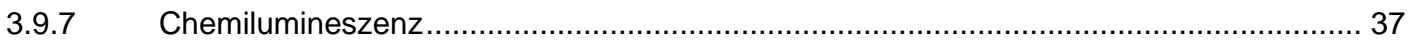

3.9.8 Auswertung der Banden für big42-LBP und GAPDH .......................................... 38

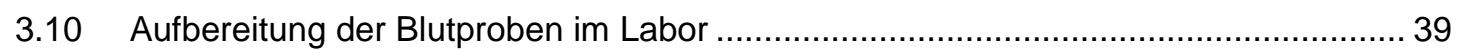

3.10.1 Isolierung und Aufreinigung der Leukozytenfraktion (Buffy Coat) ................................. 39

3.10.2 DNA-Isolierung mit QIAamp ${ }^{\circledR}$ DNA Mini Kit ............................................................. 39

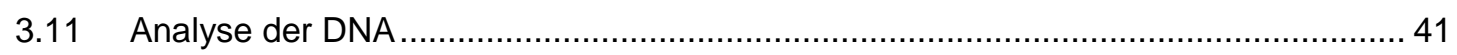

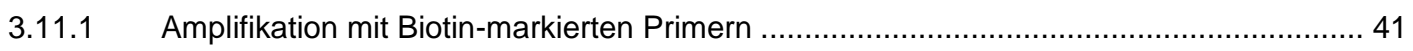

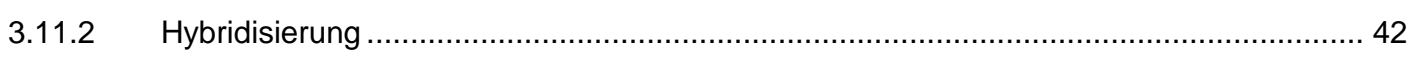

3.11.2.1 Denaturierung der Amplifikationsprodukte................................................... 42

3.11.2.2 Hybridisierung an membrangebundene Sonden .............................................. 42

3.11.2.3 Entfernen aller unspezifisch gebundenen Amplifikate ...................................... 42

3.11.2.4 Zugabe eines Streptavidin/Alkalische Phosphatase-Komplexes.......................... 42

3.11.2.5 AP-vermittelte Farbreaktion................................................................. 42

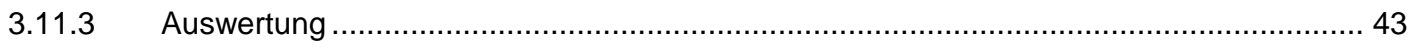

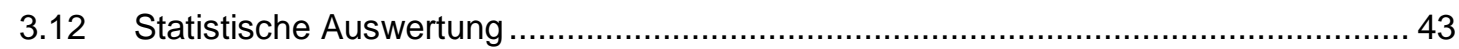

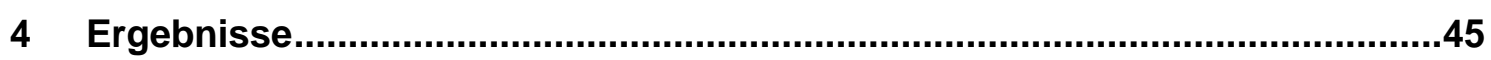

4.1 Beschreibung des Patientenkollektivs..................................................... 45

4.2 Zahnärztlicher Befund (DMFT) und Papillen-Blutungs-Index ...............................50

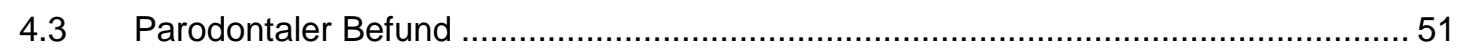

4.4 Laborergebnisse für Lipopolysaccharid-bindendes Protein bzw. big42-LBP............. 53

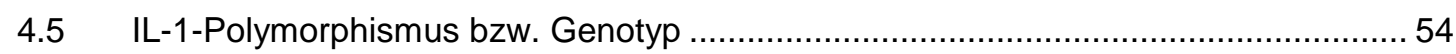

4.6 Statistische Auswertung im Zusammenhang mit dem Papillen-Blutungs-Index (PBI) 56

4.6.1 Einfluss von Geschlecht und Rauchverhalten auf den PBI ...................................... 56

4.6.2 Assoziation zwischen Genotyp und PBI .......................................................... 56

4.7 Statistische Auswertung im Zusammenhang mit dem Schweregrad der Parodontitis 56

4.7.1 Einfluss von Geschlecht und Rauchverhalten auf den Schweregrad der Parodontitis ..... 56

4.7.2 Assoziation zwischen Genotyp und Schweregrad der Parodontitis................................ 57

4.8 Statistische Auswertung im Zusammenhang mit big42-LBP ................................ 57

4.8.1 Assoziation zwischen big42- LBP und dem Papillen-Blutungs-Index............................ 57

4.8.2 Assoziation zwischen big42-LBP und dem Schweregrad der Parodontitis .................... 57

4.9 Assoziation zwischen big42-LBP und dem Genotyp .............................................. 59

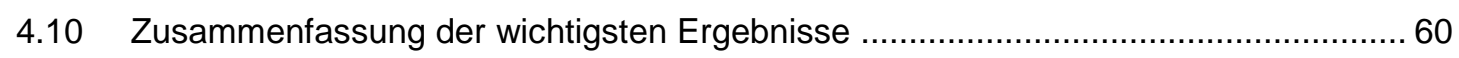

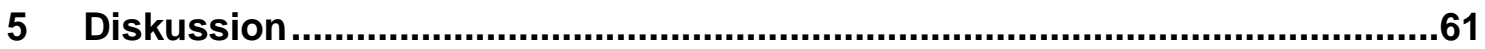

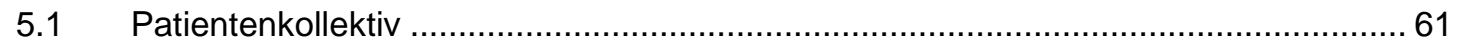

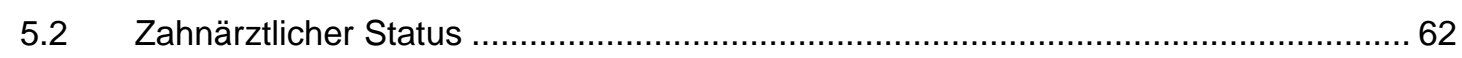

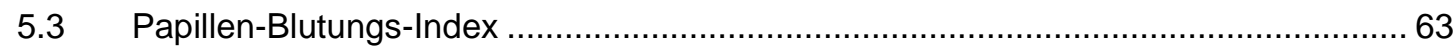

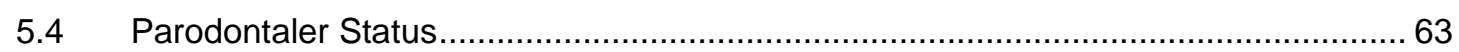




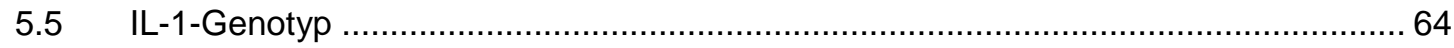

5.6 Untersuchung möglicher Einflussfaktoren auf den Parodontalstatus ......................... 69

5.7 Lipopolysaccharide und Lipopolysaccharid-bindendes Protein ................................. 70

5.8 Zusammenhang zwischen LBP und Schweregrad der Parodontitis ........................... 71

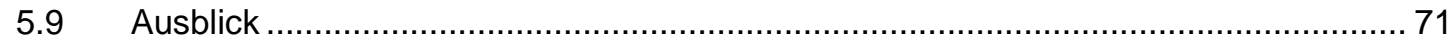

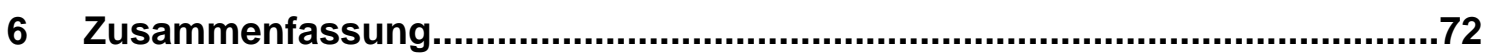

$7 \quad$ Anhang

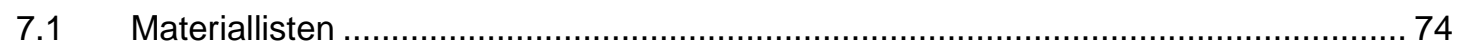

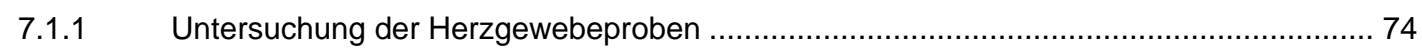

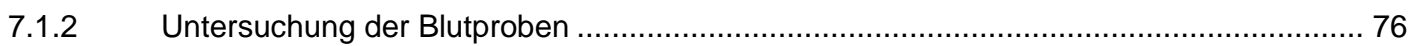

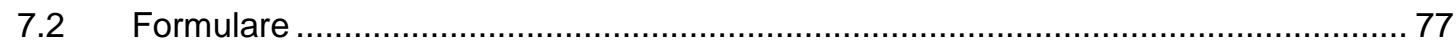

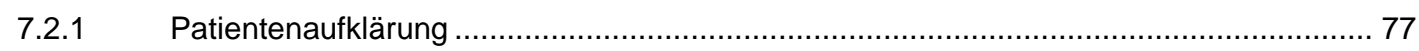

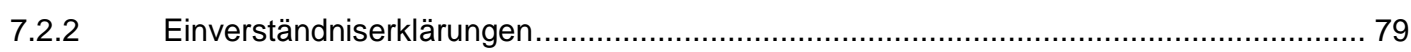

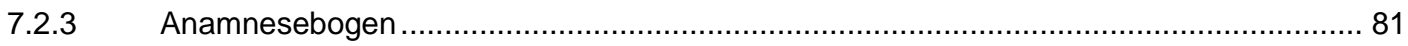

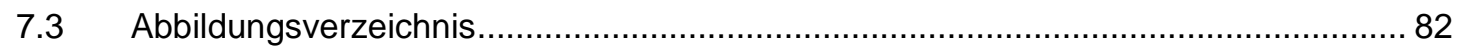

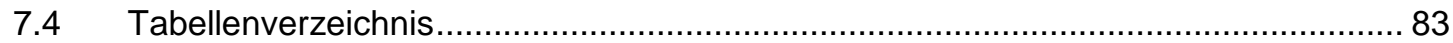

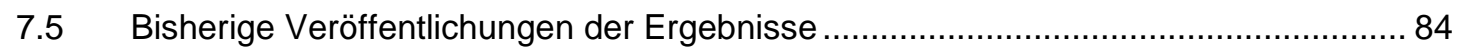

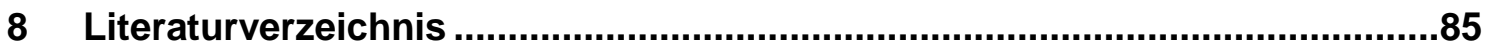




\section{$1 \quad$ Einleitung}

Kardiovaskuläre Erkrankungen werden derzeit als häufigste Todesursache weltweit gewertet (WHO 2011). Patienten versterben vor allem an chronisch ischämischen Herzerkrankungen, akutem Myokardinfarkt sowie Herzinsuffizienz (Statistisches Bundesamt 2011).

Die Pathogenese dieser Erkrankungen wird maßgeblich von verschiedenen Risikofaktoren beeinflusst. Eine Reihe dieser Faktoren, z.B. Rauchen, Übergewicht oder Hypertonie konnte bereits identifiziert werden (Lederhuber und Lange 2010). Bis heute werden jedoch weitere mögliche Risikofaktoren zum Teil kontrovers diskutiert. Auch das Vorliegen einer Parodontitis könnte das Auftreten kardiovaskulärer Erkrankungen beeinflussen.

Bereits 1990 berichtete Syrjänen von zwei Fallkontrollstudien, die auf einen Zusammenhang zwischen oraler Infektion und Gefäßerkrankungen schließen ließen (Syrjänen 1990). Seitdem wurde in verschiedensten Studien eine Assoziation zwischen Parodontitis und dem Auftreten von Herzerkrankungen wie Myokardinfarkt oder Koronarer Herzerkrankung untersucht. Vielfach konnte ein Zusammenhang zwischen dem Vorhandensein einer Parodontitis und der Entstehung einer Herzerkrankung gezeigt werden (DeStefano et al. 1993; Joshipura et al. 1996; Arbes et al. 1999; Pussinen et al. 2003; Tang et al. 2011). Jedoch konnte der genaue Mechanismus bis heute nicht geklärt werden (Tang et al. 2011). Das Vorhandensein gemeinsamer Risikofaktoren, eine gesteigerte Entzündungsneigung des Patienten oder das Eindringen von parodontopathogenen Bakterien in arteriosklerotische Plaque werden diesbezüglich diskutiert (Haynes und Stanford 2003).

Eine mögliche Wirkung des Lipopolysaccharids (LPS) parodontopathogener Bakterien auf die Pathogenese von Herzerkrankungen wurde bis dato nicht untersucht. Ausgehend von der Annahme, dass die Parodontitis in Zusammenhang mit der Pathogenese und Progression einer Koronaren Herzerkrankung steht, wurde die Hypothese aufgestellt, dass parodontopathogene Mikroorganismen und ihr LPS eine Rolle bei der Entstehung einer Herzinsuffizienz spielen könnten.

Ziel eines umfassenden Pilotprojektes am selben Patientenkollektiv war es, in unterschiedlichen Einzelprojekten nachzuweisen, ob parodontopathogene Bakterien am Myokard nachweisbar sind und ob deren LPS in der Lage ist, am Myokard zu binden, um so möglicherweise Entzündungsreaktionen in den Myokardzellen auszulösen. Beispielsweise befassten sich Einzelprojekte mit der Bestimmung der Bakterienlast an Parodontopathogenen im Mund und am Myokard mittels PCR sowie der Auswertung histologischer Schnitte des Herzgewebes zur Erhebung eines 
Inflammations-Scores sowie zur Bestimmung verschiedener immunhistochemischer Parameter (Jahn 2012).

Ziel der vorliegenden Studie des Pilotprojektes war es, auf Proteinebene nachzuweisen, ob Lipopolysaccharid-bindendes Protein (LBP) an Atrium, Ventrikel und Klappe vorhanden ist und LPS somit in der Lage ist, am Myokard zu binden. Hierzu wurde mittels Proteinaufreinigung und Western-Blot-Verfahren eine quantitative Bestimmung von LBP an Atrium, Ventrikel und Klappe von menschlichem Myokard, das im Rahmen von Aortenklappenersatz-Operationen entnommen wurde, durchgeführt. Am Patienten wurden eine Anamnese sowie ein zahnärztlicher und parodontaler Befund erhoben, um den Schweregrad der vorliegenden Parodontitis bestimmen zu können. Zusätzlich wurde DNA der Patienten, die aus Blutproben gewonnen wurde, auf einen IL-1-Polymorphismus (Genotyp) untersucht. 


\section{$2 \quad$ Literaturübersicht}

\subsection{Marginale Parodontitis}

\subsubsection{Definition}

Als marginale Parodontitis wird eine bakteriell bedingte entzündliche Erkrankung des Zahnhalteapparates bezeichnet. Diese geht mit zunehmender Destruktion der Tiefenproliferation des Epithels, der Desmodontalfasern sowie des alveolären Knochens und daraus resultierender Bildung von Zahnfleischtaschen einher. Bleibt die marginale Parodontitis unbehandelt, kommt es zu einem Attachmentverlust von 0,1-0,3 mm pro Jahr (Brown und Löe 1993), im weiteren Verlauf ist ein Zahnverlust möglich.

Im Rahmen des „International Workshop for a Classification of Periodontal Diseases and Conditions" in Oak Brook, Illinois wurde 1999 die aktuell gültige, von der American Academy of Periodontology (AAP) empfohlene Einteilung der Parodontopathien in folgende acht Gruppen erarbeitet:

- Gingivale Erkrankungen

- Chronische Parodontitis

- Aggressive Parodontitis

- Parodontitis als Manifestation einer Systemerkrankung

- Nekrotisierende Parodontalerkrankungen

- Parodontalabszesse

- Parodontitis im Zusammenhang mit endodontalen Läsionen

- Entwicklungsbedingte oder erworbene Deformationen und Zustände.

Die häufigste Form der marginalen Parodontitis ist die chronische Parodontitis (Kinane und Lindhe 2003). Deren klinische Eigenschaften und eine mögliche Subklassifizierung wurden ebenfalls im Rahmen des Workshops in Oak Brook festgelegt (Lindhe et al. 1999). Demnach hat die chronische Parodontitis die größte Prävalenz bei Erwachsenen, tritt aber seltener auch bei Kindern und Jugendlichen auf. Eine Korrelation zwischen dem Ausmaß der Destruktion und lokalen Faktoren, auch iatrogener Art, ist zudem bekannt. Häufig sind Konkremente vorhanden, das subgingivale Erregerspektrum stellt sich uneinheitlich dar. Die Progredienz der Erkrankung wird als leicht bis mäßig beschrieben, wobei Phasen starker Progredienz möglich sind. Der Krankheitsverlauf kann sowohl durch systemische Erkrankungen wie Diabetes mellitus oder AIDS, als auch durch exogene Einflüsse wie Rauchen oder Stress beeinflusst werden (Krejci und Bissada 2000; Persson 2006). 
Eine Subklassifizierung wird anhand der Ausbreitung des Attachmentverlustes in lokalisierte und generalisierte chronische Parodontitis vorgenommen (Tab. 1).

\begin{tabular}{|l|l|}
\hline Iokalisierte chronische Parodontitis & generalisierte chronische Parodontitis \\
\hline$<30 \%$ der approximalen und vestibulooralen & $>30 \%$ der approximalen und vestibulooralen \\
Wurzeloberflächen weisen & Wurzeloberflächen weisen \\
Attachmentverluste auf & Attachmentverluste auf \\
\hline
\end{tabular}

Tab. 1: Subklassifizierung der chronischen Parodontitis nach Ausbreitung des Attachmentverlustes (Lindhe et al. 1999)

Außerdem ist eine Unterteilung nach Ausmaß der Attachmentverluste in drei Schweregrade der Parodontitis möglich (Tab. 2).

\begin{tabular}{|l|l|}
\hline Attachmentverlust & Schweregrad \\
\hline 1 bis $2 \mathrm{~mm}$ & leichte Parodontitis \\
\hline 3 bis $4 \mathrm{~mm}$ & moderate Parodontitis \\
\hline $5 \mathrm{~mm}$ und mehr & $\begin{array}{l}\text { Schwere/fortgeschrittene chronische } \\
\text { Parodontitis }\end{array}$ \\
\hline
\end{tabular}

Tab. 2: Subklassifizierung der chronischen Parodontitis nach Ausmaß des Attachmentverlustes (Burgemeister und Schlagenauf 2003; Lang 2003)

\subsubsection{Epidemiologie}

Die Daten zur Parodontitisprävalenz in Deutschland werden in den Deutschen Mundgesundheitsstudien (DMS) des Instituts der deutschen Zahnärzte (IDZ) ermittelt (Micheelis 2011). Um einen internationalen Vergleich zu ermöglichen, werden diese Studien in den üblichen Alterskohortenabgrenzungen der Weltgesundheitsorganisation (WHO) durchgeführt. In der aktuellsten DMS aus dem Jahr 2005 (DMS IV: Micheelis und Schiffner 2006) wiesen entsprechend dem CPI-Indexsystem, ein von der WHO favorisierter Gruppen-Index zur Beurteilung des parodontalen Zustandes (Ainamo et al. 1982), ca. $73 \%$ der Erwachsenen (35-44 Jahre) und ca. 88\% der Senioren (65-74 Jahre) mindestens einen Zahn mit Sondierungstiefen von mehr als $4 \mathrm{~mm}$ auf. Im Vergleich zu der letzten DMS des Jahres 1997 liegt ein Anstieg der Sondierungstiefen von etwa $27 \%$ bei den Erwachsenen und etwa $24 \%$ bei den Senioren vor. Die Prävalenz des Attachmentverlustes zeigte, dass 2005 bei ca. 86\% der Erwachsenen und etwa $98 \%$ der Senioren an mindestens einem Zahn Attachmentverluste von mehr als $3 \mathrm{~mm}$ gemessen werden konnten.

Kombiniert man die Ergebnisse für Sondierungstiefen und Attachmentverlust entsprechend dem CDC/AAP-Indexsystem $(C D C=$ Center of Disease Control; $A A P=$ American Academy of Periodontology) und unterscheidet nach Schweregrad der Parodontitis (Page und Eke 2007), ergeben sich für 1997 und 2005 die in Tabelle 3 aufgeführten Daten. 


\begin{tabular}{|l|l|l|l|l|}
\hline & \multicolumn{2}{|l|}{$\begin{array}{l}\text { Erwachsene } \\
\text { (35-44 Jahre) }\end{array}$} & \multicolumn{2}{l|}{$\begin{array}{l}\text { Senioren } \\
\text { (65-74 Jahre) }\end{array}$} \\
\hline & 1997 & 2005 & 1997 & 2005 \\
\hline $\begin{array}{l}\text { keine oder milde } \\
\text { Parodontitis }\end{array}$ & $48,0 \%$ & $46,9 \%$ & $36,2 \%$ & $24,0 \%$ \\
\hline $\begin{array}{l}\text { moderate } \\
\text { Parodontitis }\end{array}$ & $40,4 \%$ & $45,3 \%$ & $42,4 \%$ & $54,1 \%$ \\
\hline $\begin{array}{l}\text { schwere } \\
\text { Parodontitis }\end{array}$ & $11,6 \%$ & $7,8 \%$ & $21,4 \%$ & $21,9 \%$ \\
\hline
\end{tabular}

Tab. 3: Parodontitislast in Deutschland nach CDC/AAP-Einteilung für ausgewählte Altersgruppen (DGP 2011, S. 16)

Sowohl bei den Erwachsenen als auch bei den Senioren konnte 2005 ein etwas geringerer Anteil an Patienten mit schwerer oder keiner/milder Parodontitis und ein Anstieg der Patienten mit moderater Parodontitis festgestellt werden.

\subsection{3 Ätiologie und Pathogenese}

Primäre Ursache einer Parodontitis ist die Besiedlung der Mundhöhle mit parodontopathogenen Mikroorganismen. Zudem wird die Ätiologie und Pathogenese der Parodontitis aber auch von verschiedenen endogenen Faktoren (genetisch) und exogenen Faktoren (umweltbedingt und erworben) beeinflusst (Page und Kornman 1997). Abbildung 1 zeigt eine Übersicht über die Ätiologie und Pathogenese der Parodontitis unter Berücksichtigung der verschiedenen Einflussfaktoren.

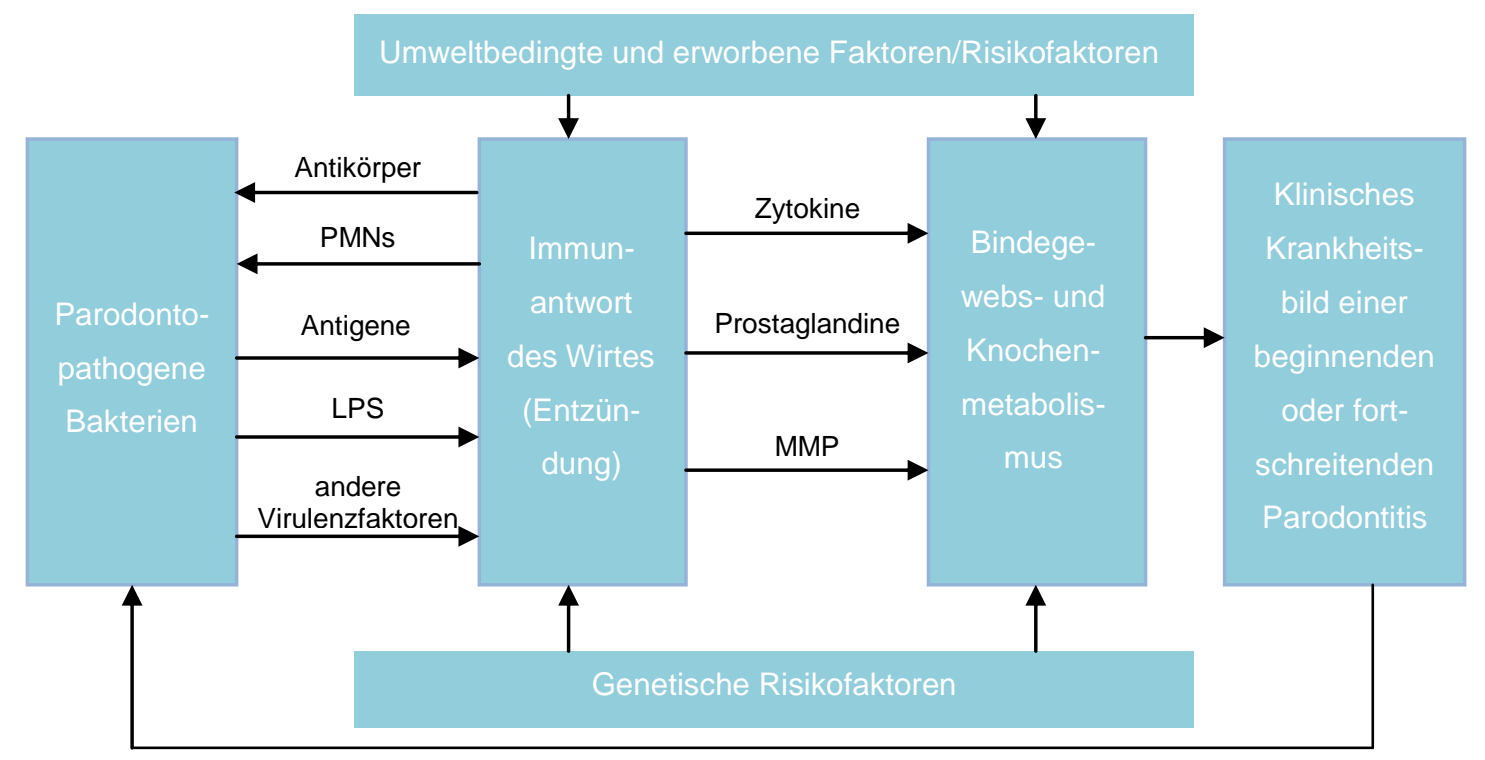

Abb. 1: Ätiologie und Pathogenese der Parodontitis (nach Page und Kornman 1997, S. 10) (PMN=Polymorphkernige , LPS= Lipopolysaccharide , MMP= Matrixmetalloproteinasen) 


\subsubsection{Dentale Plaque/ Biofilm}

Eine Parodontitis folgt üblicherweise einer Gingivitis. Primärer Auslöser für die Entstehung einer Gingivitis bzw. Parodontitis ist die Plaque. Dabei handelt es sich um einen strukturierten, zähen, gelb-gräulichen Zahnbelag, zusammengesetzt aus Bakterien, deren Stoffwechselprodukten und Speichelproteinen (Rateitschak et al. 1989). Die Mikroorganismen der dentalen Plaque sind in einem Biofilm organisiert (Marsh und Bradshaw 1995; Kolenbrander et al. 2002), einer Bakterienpopulation, die in einer selbst produzierten extrazellulären Matrix aus polymeren Molekülen eingebettet ist, auf Oberflächen oder lebendem Gewebe haftet (Kayser 2001) und den Bakterien einen genetischen Austausch ermöglicht (Marsh 2005). Bakterien in der Tiefe eines Biofilms sind weitestgehend vor Immunzellen, Antikörpern oder Antibiotika geschützt (Kayser 2001).

Wird nach Reinigung der Zahnoberfläche keine weitere Mundhygiene durchgeführt, vollzieht sich die Plaquebildung nach einem wiederkehrenden Muster (Plagmann 1998): Nach wenigen Minuten bis Stunden bildet sich auf der gereinigten Zahnoberfläche das so genannte frühe Pellikel (Zahnoberhäutchen), in dem erste grampositive Kokken und Stäbchen aus dem Speichel vorhanden sind. Es wird vermutlich durch Adsorption von Speichelproteinen gebildet (Plagmann 1998) und entwickelt sich durch Auf- und Einlagerungen von Bakterienprodukten sowie Bestandteilen der Sulkusflüssigkeit zum reifen Pellikel.

In der sich anschließenden etwa zwei Tage dauernden ersten Phase der eigentlichen Plaquebildung kommt es zur Anlagerung von ersten gramnegativen Bakterien, und die Matrixbildung aus extrazellulären Polysacchariden beginnt. Zu diesem Zeitpunkt liegt eine etwa 10-20 Zelllagen dicke Bakterienschicht vor, die zu ca. 90\% aus grampositiven Kokken und wenigen Stäbchen besteht (Theilade et al. 1966). Die Gingiva erscheint klinisch noch gesund, es kann jedoch eine erhöhte Sulkusflüssigkeitsfließrate gemessen werden (Plagmann 1998).

In den folgenden Tagen kommt es durch Zellteilung zu einer Massenzunahme der Plaque und der Ausbildung einer deutlich komplexeren Flora. Grampositive Kokken und Stäbchen machen nur noch einen Anteil von ca. $45 \%$ aus, fakultativ und obligat anaerobe Actinomyceten nehmen auf $25 \%$ und gramnegative anaerobe Kokken auf 20\% zu. Gramnegative anaerobe Stäbchen machen in dieser Phase ca. 5\% der Masse aus. Auch Filamente und fusiforme Bakterien sind zu finden (Theilade et al. 1966). Klinisch kann ein Bluten auf Sondieren festgestellt werden. Nach etwa 7-10 Tagen liegt eine $0,2 \mathrm{~mm}$ bis $0,5 \mathrm{~mm}$ dicke, voll pathogene supragingivale Plaque aus 200-300 Zelllagen vor (Plagmann 1998). Zusätzlich zu den oben beschriebenen Mikroorganismen sind nun auch Spirillen und Spirochäten zu finden (Theilade et al. 1966) 
und durch die Dickenzunahme bildet sich ein günstiges Milieu für anaerobe Mikroorganismen. Die Gingiva erscheint als Zeichen für die vorliegende Entzündung gerötet und geschwollen (Plagmann 1998).

Die Rolle der Plaque als Hauptursache für die Gingivitis bewiesen Löe et al. 1965 in einer experimentellen Studie, für die Probanden mit niedrigem Plaqueindex und gesunder Gingiva die Mundhygiene einstellten (Löe et al. 1965). Nach 2-3 Wochen konnte bei allen Probanden eine Gingivitis diagnostiziert werden (Löe et al. 1965). Nach detaillierten Mundhygieneinstruktionen und Wiederaufnahme der Mundhygiene konnte ein Rückgang der Entzündung der Gingiva innerhalb eines Tages verzeichnet werden; der Plaque-Index war nach 7 bis 11 Tagen wieder auf seinem Ausgangswert (Theilade et al. 1966). Daraus schlossen Löe et al., dass die Gingivitis ein reversibles Ereignis darstellt.

Verläuft die Plaquebildung ungehindert, kann sich die Plaque im Laufe der Zeit langsam nach subgingival ausbreiten. Aufgrund des dort herrschenden anaeroben Milieus, dem Schutz vor mechanischem Abtrag und dem Nährstoffangebot aus der Sulkusflüssigkeit kommt es hier zusätzlich zu der adhärenten am Zahn haftenden Plaque zur Ausbildung einer nicht adhärenten Plaque („swimmers plaque“) mit hoher Parodontopathogenität (Plagmann 1998).

\subsubsection{Parodontopathogene Mikroorganismen}

In der subgingivalen Plaque konnten bis dato über 500 Bakterienarten nachgewiesen werden, jedoch ist nur eine geringe Anzahl an der Ätiologie und Pathogenese der Parodontitis beteiligt (Paster et al. 2001).

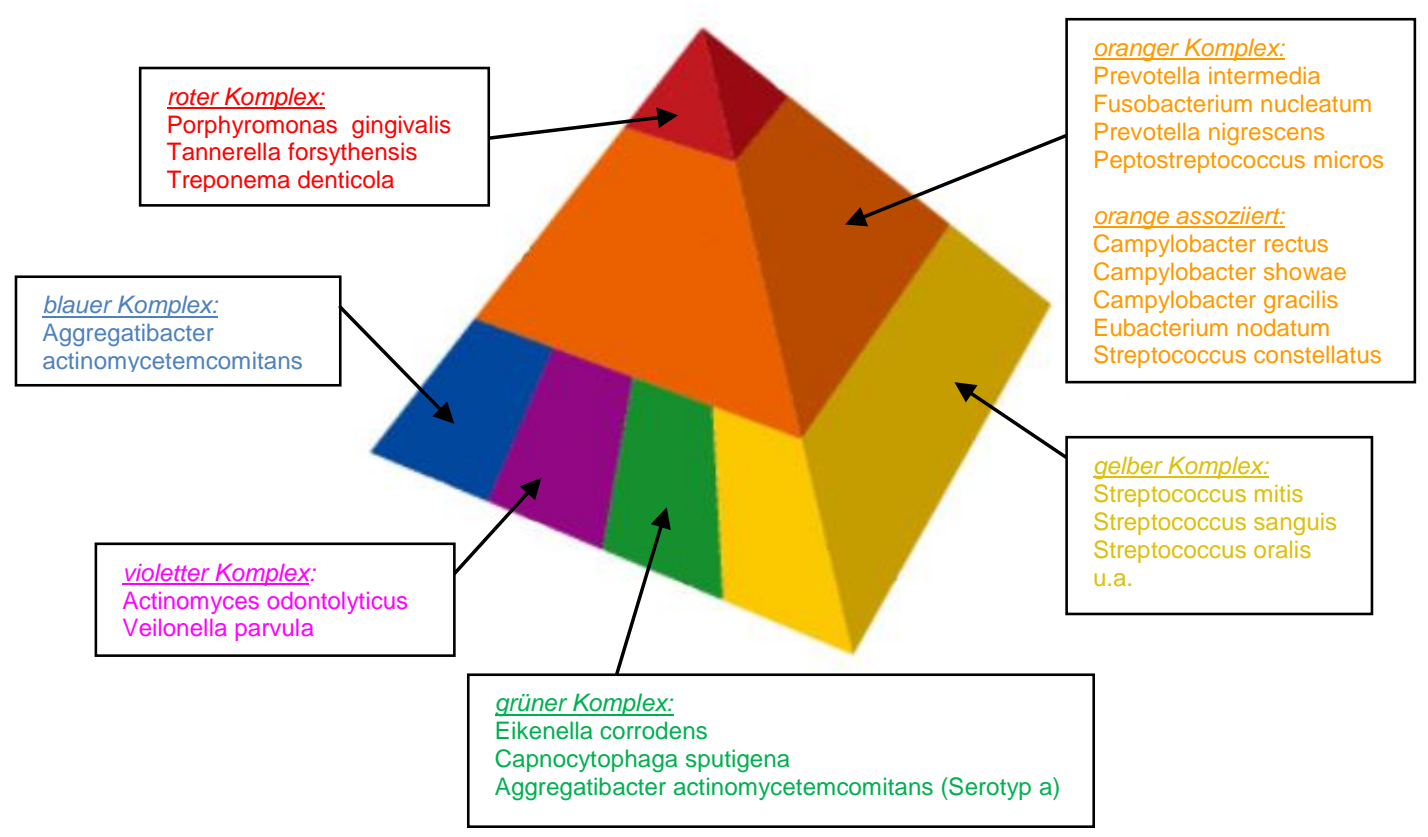

Abb. 2: Parodontopathogene Mikroorganismen (nach Socransky und Haffajee 2002, S. 19) 
Socransky et al. (1998) haben die parodontopathogenen Mikroorganismen in sechs Komplexe eingeteilt (Abb. 2). Die Bakterien des orange-assoziierten, des gelben, des grünen und des violetten Komplexes bilden die Frühbesiedler (Socransky und Haffajee 2002). Der orange Komplex umfasst die so genannten „Brückenspezies“, die Bindungsrezeptoren sowohl für die Frühkolonisierer als auch für die stark parodontopathogenen Bakterien des roten Komplexes aufweisen (Kolenbrander et al. 2002). Socransky et al. (1998) zeigten auf, dass vor Besiedlung mit Bakterien des roten Komplexes in der Regel schon Bakterien des orangen Komplexes vorhanden waren.

\subsubsection{Parodontitis als multifaktorielles Geschehen}

Auch wenn die dentale Plaque die Hauptursache einer Gingivitis bzw. marginalen Parodontitis darstellt, ist die Entstehung und Progression der Parodontitis ein multifaktorielles Geschehen. Es spielen verschiedene exogene und endogene Risikofaktoren eine entscheidende Rolle (van Dyke und Sheilesh 2005; Persson 2006; Salvi et al. 1997). Zu den exogenen bzw. veränderbaren Faktoren gehören Rauchen (Albandar et al. 2000), der Ernährungszustand bzw. BMI (Pischon et al. 2007), Alkoholkonsum und der sozioökonomische Status (van Dyke und Sheilesh 2005) sowie Stress (Hugoson et al. 2002; Pistorius et al. 2002; Wimmer et al. 2002). Weiterhin spielen systemische Erkrankungen wie Diabetes mellitus (Kinane und Chestnutt 1997) und rheumatische Arthritis (Mercado et al. 2003) sowie Herzerkrankungen (Persson 2006) und HIV (Murray 1994; Yeung et al. 1993) eine Rolle.

$\mathrm{Zu}$ den endogenen Faktoren gehören genetische Einflüsse und als wichtigster modulierender Faktor die Immunabwehr. In Zwillingsstudien und Untersuchungen zur familiären Häufung von Parodontopathien konnte ein genetischer Einfluss auf die Pathogenese der Parodontitis festgestellt werden (van der Velden et al. 1993; Michalowicz 1994; Michalowicz et al. 2000). Es wurden bereits verschiedene Gene untersucht, die eine Rolle in der Pathogenese der Parodontitis spielen. Dabei sind vor allem Genvarianten betroffen, die die proinflammatorische Wirkung der Zytokine verstärken oder die Affinität der Immunglobulin-Rezeptoren verändern und die Infektabwehr beeinflussen (Kocher und Meisel 2011).

So wurden Genpolymorphismen des Interleukin-1, des Tumornekrosefaktors TNF-a, verschiedener anderer Interleukine (IL) sowie IgG-Rezeptoren, CD14 und Vitamin-DRezeptoren als mögliche Risikofaktoren für Parodontitis untersucht (Laine et al. 2010). Im Rahmen der vorliegenden Arbeit wurde der Interleukin-1-Polymorphismus der Probanden ermittelt. 


\subsubsection{Wirtsantwort auf Plaqueangriff}

Wie beschrieben spielt die Immunabwehr eine entscheidende Rolle bei der Entstehung und Progression einer Parodontitis (van Dyke und Serhan 2003).

Man kann drei Anteile der Wirtsreaktion auf die Besiedlung mit bakterieller Plaque unterscheiden (Plagmann 1998). So gibt es einen chemischen Abwehrmechanismus durch antibakterielle Bestandteile der Sulkusflüssigkeit und des Speichels, mechanischen Schutz durch die Spülwirkung des Speichels sowie Dichtigkeit und Zellumsatz des Epithels und als dritte und entscheidende Komponente gilt die Entzündungsreaktion des Immunsystems (Plagmann 1998). Hierbei unterscheidet man die Reaktion des angeborenen Immunsystems in Form von vaskulären und zellulären Reaktionen und die Reaktion des erworbenen oder spezifischen Immunsystems, das bei länger anhaltender Schädigung oder Anwesenheit von Antigenen in Wirkung tritt (Campbell et al. 2003).

Die Gefäße reagieren auf einen schädlichen Angriff mit Gefäßerweiterung und Steigerung der Permeabilität, wodurch es zu einem Austritt von Plasma ins Gewebe und einem resultierenden Ödem kommt (Campbell et al. 2003). Gelangt das Blutplasma vom Gewebe über das Saumepithel in den Sulkus und in die Mundhöhle, spricht man von der so genannten Sulkusflüssigkeit (Plagmann 1998). Sie enthält Elektrolyte, Immunglobuline und Komplementfaktoren zur Unterstützung der Immunabwehr, dient jedoch gleichzeitig als Substrat mit Wachstumsfaktoren für Porphyromonas gingivalis, Fusobacterium nucleatum und Treponema denticola (van Palenstein Helderman 1981).

Zu der Immunabwehr gehört außerdem das Komplementsystem, das über Signalwege von bestimmten Proteinen Opsonierung, Zellaktvierung und Zelllyse auslösen kann (Schütt und Bröker 2011). Aktiviert wird das Komplementsystem spezifisch durch Antigen-Antikörper-Komplexe („klassischer Weg“) oder unspezifisch durch Bakterienenzyme, lysosomale Enzyme von Granulozyten und durch Endotoxine (Lipopolysaccharide) der gramnegativen Mikroorganismen (Plagmann 1998).

Die zelluläre Komponente der angeborenen Immunabwehr bilden neutrophile Granulozyten und Makrophagen, die aus den Gefäßen austreten und durch Chemotaxis an den Infektionsort gelangen (Janeway 2002). Die neutrophilen Granulozyten haben keine Wirkung auf nicht-adhärente Plaquebakterien (Williams 1992).

Das spezifische Immunsystem greift unterstützend und ergänzend ein, wenn der Angriff anhält und nicht vom angeborenen Immunsystem abgefangen werden kann (Janeway 2002). Es läuft zum einen auf humoraler Ebene, hauptsächlich getragen durch Plasmazellen, die zur Antikörperproduktion fähig sind, und zum anderen auf 
zellulärer Ebene mittels T-Lymphozyten ab. Diese sind in der Lage, zu verschiedenen Subklassen zu differenzieren: Die T-Helferzellen unterstützen B-Lymphozyten bei der Antikörperbildung, die regulatorischen T-Zellen hemmen und regulieren die Funktion der T-Helfer- und B-Zellen, zytotoxische T-Zellen bewirken die Lyse der Zielzelle und T-Memoryzellen sind für das immunologische Gedächtnis des Körpers verantwortlich (Schütt und Bröker 2011). Die Kommunikation zwischen den Zellen zwecks Aktivierung, Differenzierung, Proliferation etc. erfolgt über so genannte Zytokine, die von humoralen Effektorsystemen oder aus Zellen freigesetzt werden. Die wichtigsten Zytokine im Zusammenhang mit der Pathogenese der Parodontalerkrankungen sind Interleukin-1, -4, -6 und -8, Tumornekrosefaktor- $\alpha$ (TNF- $\alpha$ ), Interferon- $\gamma$ (IFN- $\gamma)$ und Matrixmetalloproteinasen (Alexander und Damoulis 1994).

\subsubsection{Lipopolysaccharid (LPS) und Lipopolysaccharid-bindendes Protein (LBP)}

Das Lipopolysaccharid (LPS) stellt einen wichtigen Stimulator der angeborenen Immunabwehr dar (Liu et al. 2008). Es ist in der äußeren Zellwand gramnegativer Bakterien verankert und besteht aus einer nach extrazellulär zeigenden Polysaccharidkette, dem so genannten O-Antigen, einem Kernpolysaccharid, zusammengesetzt aus äußerer und innerer Kernregion, sowie dem Lipid A (Raetz 1990) (Abb. 3).

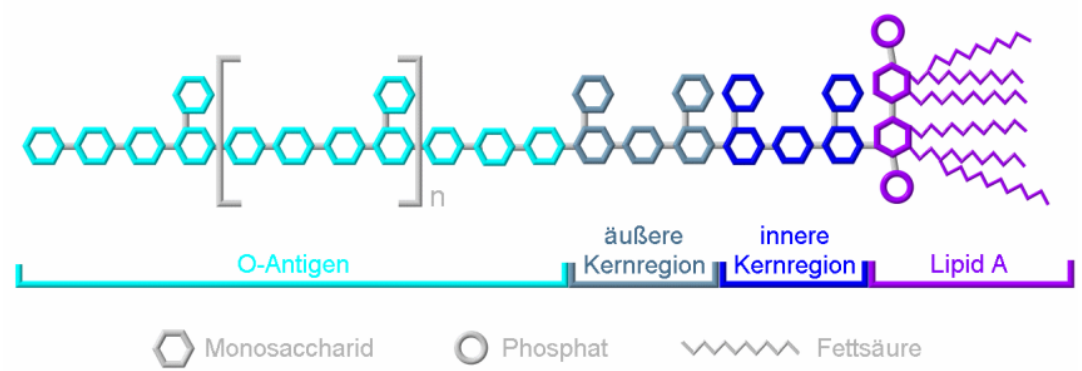

Abb. 3: Struktur des LPS (http://edoc.hu-berlin.de/dissertationen/hallatschek-werner-2004-10-20/HTML/)

In früheren Publikationen wurde das Lipopolysaccharid als Endotoxin bezeichnet, inzwischen ist man jedoch zu der Erkenntnis gelangt, dass das Lipid A für die Endotoxinwirkung verantwortlich ist (Rietschel et al. 1994). LPS fördert die Immunabwehr, indem es Monozyten und Makrophagen zur Sekretion von Zytokinen wie IL-1, IL-6, IL-8, TNF- $\alpha$ und anderen Mediatoren anregt (Rietschel et al. 1994). Gelangt LPS in das Blut, wird es entweder vom Lipopolysaccharid-bindenden Protein (LBP) gebunden oder es erfolgt eine unspezifische Bindung an Lipoproteine im Serum. Apolipoproteine sind ebenfalls in der Lage, LPS zu binden, wodurch dieses neutralisiert wird. 
Es wurde gezeigt, dass die Wirkung des LPS durch Bindung an das Lipopolysaccharidbindende Protein (LBP) gesteigert werden kann (Tapping und Tobias 1997). LBP ist ein Akute-Phase-Protein, das von Hepatozyten und intestinalen Epithelzellen synthetisiert wird (Grube et al. 1994). Die Plasmakonzentration beträgt etwa 5 - $15 \mu \mathrm{g} / \mathrm{ml}$ (Zweigner et al. 2001) und steigt im Falle einer Entzündung oder Gewebeschädigung drastisch an (Gallay et al. 1994; Opal et al. 1999).

LBP geht über Erkennung des Lipid A eine Bindung mit LPS ein (Lamping et al. 1996). Der LPB-LPS-Komplex bindet über CD14 an Makrophagen (Wright et al. 1990), die dadurch zur Ausschüttung von IL-1 $\beta$, IL-6, IL-8 und TNF- $\alpha$ stimuliert werden. Als signalübertragender Faktor hierbei wurde der Toll-like-Rezeptor 4 identifiziert (Qureshi et al. 1999).

LBP hat eine konzentrationsabhängige Wirkung auf LPS. Bei niedriger Konzentration wird die LPS-induzierte Aktivierung von Makrophagen gesteigert. Eine hohe LBPKonzentration hemmt die LPS-induzierte Zellstimulation. Die Produktion von LBP wird durch Interleukin-6 angeregt (Tapping und Tobias 1997), Interleukin-1 wirkt synergistisch (Schumann et al. 1996). Ein Nachweis von LBP kann mit einem MausAnti-Mensch-LBP-monoklonalen Antikörper erfolgen (Ren et al. 2004).

Ein weiteres Protein, das in der Lage ist, LPS spezifisch zu binden, ist das „Bactericidal Permeabilitiy Increasing Protein" (BPI) (Marra et al. 1992). BPI konnte eine 45\%ige strukturelle Homologie zu LBP nachgewiesen werden (Schumann et al. 1994), jedoch wirkt es im Gegensatz zu LBP hemmend auf die LPS-Effekte, da es anscheinend keine Bindung an den CD14-Rezeptor vermitteln kann (Elsbach und Weiss 1993). Der Wirkmechanismus der Lipopolysaccharide ist in Abbildung 4 schematisch dargestellt.

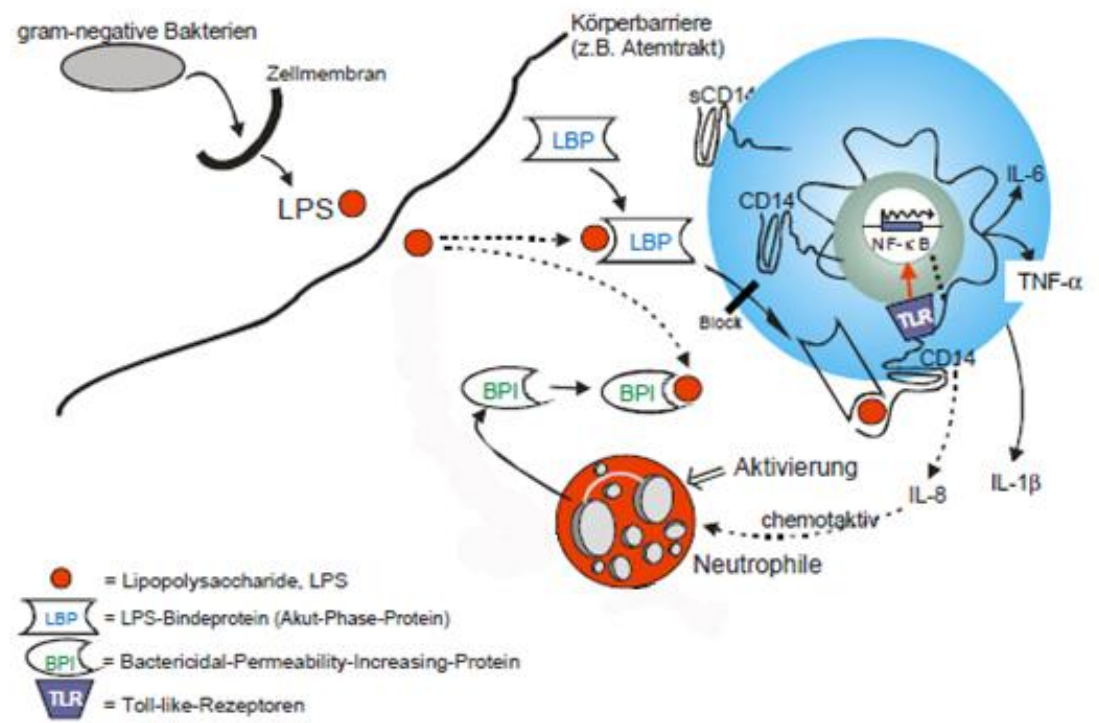

Abb. 4: Wirkmechanismus von Lipopolysacchariden (Ausschuss für Biologische Arbeitsstoffe 2005, S. 2) 


\subsubsection{Interleukin-1}

Interleukin-1 (IL-1) wird vor allem von LPS-stimulierten Makrophagen und Monozyten produziert (Matsuki et al. 1991). Zu der IL-1-Familie gehören die zwei Untereinheiten IL-1 $\alpha$ und IL-1 $\beta$, die als Agonisten wirken, sowie ein IL-1-Rezeptorantagonist (IL-1RN), der an IL-1-Rezeptoren bindet und als Antagonist die Signaltransduktion hemmt (Granowitz et al. 1992). Untersucht wurden bisher zwei IL-1-Rezeptoren (IL-1-R I und IL-1-R II), wobei eine Signaltransduktion anscheinend nur über Bindung des IL-1-R I ausgelöst werden kann. Das IL-1 $\beta$ ist zwar in der Lage, an IL-1-R II zu binden, es findet dabei jedoch kein Signalumsatz statt (Sims et al. 1994). Graves und Cochran (2003) stellten fest, dass IL-1 neben TNF- $\alpha$ für die parodontalen Gewebedestruktionen im Verlauf einer marginalen Parodontitis hauptverantwortlich ist.

IL-1 regt die Bildung von Adhäsionsmolekülen auf Fibroblasten, endothelialen Zellen und Zellen der Immunabwehr (z.B. Lymphozyten und Monozyten) an. Dadurch erfolgt die Regulation der Leukodiapedese (Takahashi et al. 1994). Weitere Funktionen von IL-1 sind die Anregung von Monozyten und Fibroblasten zu erhöhter Freisetzung von Prostaglandin $\mathrm{E}_{2}\left(\mathrm{PGE}_{2}\right)$, das die Knochenresorption steigert, und Matrixmetalloproteinasen (MMP) (Birkedal-Hansen 1993) sowie die Hemmung der Kollagensynthese und Förderung der Kollagenaseproduktion. Matrix-Metalloproteinasen sind fähig, Proteine der extrazellulären Matrix abzubauen (Sorsa et al. 2006).

IL-1 $\beta$ ist weiterhin in der Lage, Osteoklasten zu aktivieren, und dadurch den Knochenabbau zu fördern (Stashenko et al. 1987). Heath et al. (1985) konnten zeigen, dass es bei Zugabe von IL-1 zu Knochenzellkulturen zu Resorptionsprozessen und Verlust an Knochenmatrix kommt (Heasman et al. 1993). Verschiedene Studien stellten einen signifikanten Zusammenhang zwischen dem IL-1ß-Spiegel und Parodontitis fest (Preiss und Meyle 1994; Jandinski et al. 1991; Masada et al. 1990). Agrawal et al. wiesen einen Effekt von IL-1 auf parodontale Ligamentzellen (PDLZellen) nach (Agrawal et al. 2006).

Man kann also schlussfolgern, dass eine Parodontitis bei erhöhter Sekretion von IL-1 einen schnelleren und schwerwiegenderen Verlauf nehmen wird (Becker et al. 2000). Wie oben erwähnt, lassen Zwillings- und Familienstudien auf eine genetische Komponente bei der Pathogenese der Parodontitis schließen. Die IL-1-Produktion wird auf genetischer Ebene durch die Regulierung der Genexpression bestimmt. Die Gene für IL-1A, IL-1B und IL-1RN sind lokalisiert auf Chromosom 2q13 (Nothwang et al. 1997).

Kornman et al. konnten zuerst zeigen, dass bei nichtrauchenden Kaukasiern Variationen einzelner Basenpaare der DNA (single nucleotid polymorphism (SNP)), die Expression und damit die Produktion des IL-1 beeinflussen können (Kornman et al. 
1997). Untersucht wurden verschiedene Polymorphismen des IL-1-Genclusters in Assoziation zum Schweregrad der Parodontitis. Es wurde festgestellt, dass eine Kombination aus Polymorphismen in Form von Cytosin-Thymin-Basenaustauschen an Position -889 in der Promotor-Region des IL-1A-Gens und an Position +3953 (heute: +3954 (Kornman et al. 1999)) im Exon 5 des IL-1B-Gens mit einer raschen Progredienz der Parodontitis einhergehen (Kornman et al. 1997). Liegt an der jeweiligen Position ein Thymin $(T)$ statt Cytosin $(C)$ vor, wird diese Veränderung in der DNA-Basensequenz als Allel 2 definiert (Sakellari et al. 2003). Träger, die mindestens eine Kopie von Allel 2 sowohl an IL-1A-889 als auch an IL-1B+3953/4 aufweisen, werden im Folgenden nach Kornman et al. (1997) als Genotyp-positiv bezeichnet. Bei Nachweis dieses „positiven Genotyps“ und Vorhandensein subgingivaler parodontopathogener Mikroorganismen konnte eine erhöhte IL-1-Produktion festgestellt werden. McGuire und Nunn stellten fest, dass Raucher mit positivem IL-1-Genotyp ein 7,7-fach erhöhtes Risiko zur raschen Progredienz einer Parodontitis und einem daraus resultierenden Zahnverlust haben (McGuire und Nunn 1999).

Andere Untersuchungen konnten zeigen, dass ein IL-1-Polymorphismus, also ein positiver Genotyp, mit dem Vorhandensein von Bakterien des roten und orangen Komplexes assoziiert ist (Socransky et al. 2000).

Ein weiterer Polymorphismus, der im Zusammenhang mit der Pathogenese und Progression der Parodontitis untersucht wurde, betrifft das Gen des IL-1-Rezeptorantagonisten (IL-1RN). Es konnte festgestellt werden, dass beim Vorhandensein des Allel 2 des Gens IL-1RN die Konzentration an IL-1RN signifikant abnimmt, woraus eine verminderte Entzündungshemmung resultiert (Andus et al. 1997). Beim Allel 2 des ILRN ist an Position +2018 das Thymin durch Cytosin ersetzt (IL-1RN+T2018C) (Schütt 2011).

Laine et al. (2001) untersuchten die drei genannten IL-1-Polymorphismen auf einen Zusammenhang mit Parodontitis, dem Vorhandensein von $P$. gingivalis und $A$. actinomycetemcomitans in der Mundhöhle sowie dem Rauchverhalten. Sie stellten fest, dass nicht-rauchende Parodontitis-Patienten, bei denen $P$. gingivalis und $A$. actinomycetemcomitans nicht nachgewiesen werden konnten, signifikant häufiger Träger des Allel 2 an den Genen IL-1A, IL-1B und IL-1RN waren (Laine et al. 2001).

Auf Grundlage der beschriebenen Erkenntnisse wurden kommerzielle Tests zur Bestimmung eines individuellen Parodontitisrisikos anhand des IL-1-Polymorphismus, wie der in dieser Studie verwendete GenoType ${ }^{\circledR} \mathrm{IL}-1$ der Firma Hain Lifescience, entwickelt.

Einige Studien stützen die Theorie von Kornman et al., jedoch konnten viele Veröffentlichungen keine Assoziation zwischen dem IL-1-Polymorphismus und 
marginaler Parodontitis feststellen. Laine et al. (2010) veröffentlichten ein Review über verschiedene Genpolymorphismen im Zusammenhang mit chronischer Parodontitis. Sie stellten fest, dass von 15 Studien, die sich mit der Assoziation zwischen IL-1Polymorphismus und Parodontitis befassten, zwei Studien bei Kaukasiern (López et al. 2005; McDevitt et al. 2000), eine Studie bei indischen Probanden (Agrawal et al. 2006) sowie eine Studie bei kaukasischen Rauchern (Meisel et al. 2003) eine Assoziation zeigen konnten. Eine Vielzahl anderer Studien (u.a. in China, Thailand, Japan, Indien und Brasilien durchgeführt) konnte die Theorie nicht stützen. Daraus schloss man, dass der IL-1-Polymorphismus nicht für die gesamte Weltbevölkerung als Risikofaktor für chronische Parodontitis festgelegt werden darf, aber auch für kaukasische Personen keine eindeutige Aussage getroffen werden kann (Laine et al. 2010). Auch Huynh-Ba et al. stellten kontroverse Aussagen in verschiedenen Studien zu diesem Thema fest und empfahlen, positive Assoziationen kritisch zu bewerten (Huynh-Ba et al. 2007). Die Ergebnisse kommerziell erwerblicher IL-1-Genotyp-Tests sollten mit Vorsicht betrachtet werden und nur im Zusammenhang mit Rauchverhalten, Systemerkrankungen, mikrobiellem Erregerspektrum u.a. zu einer umfassenden Risikoeinschätzung hinzugezogen werden (Huynh-Ba et al. 2007).

\subsubsection{Pathohistologische Betrachtung der parodontalen Gewebedestruktion}

Eine unbeeinflusste Plaquebildung vorausgesetzt kann man pathohistologisch verschiedene Stadien der parodontalen Gewebedestruktion unterscheiden.

Nach zwei bis vier Tagen stellt sich das Stadium der Initialläsion einer Gingivitis ein, das durch lokale vaskuläre Reaktionen in Form von Gefäßerweiterung und -permeabilitätssteigerung gekennzeichnet ist (Page und Schroeder 1976). Dadurch können Serum und neutrophile Granulozyten in das Gewebe austreten, die das Bindegewebe und das Saumepithel durchwandern und die Plaque umlagern, wodurch es zu Auflockerung und Einreißen des koronalen Saumepithelanteils kommt. Aufgrund der zusätzlichen ödematösen Schwellung kommt es zur Vertiefung des Sulkus (Plagmann 1998). Die supragingivale Plaque beginnt, sich zur subgingivalen Plaque zu entwickeln. Innerhalb von ein bis zwei Wochen folgt das Stadium der Frühläsion, in dem es zur Verstärkung der klinischen Symptome kommt. In Nachbarschaft zu Sulkusboden und Saumepithel bildet sich ein zelluläres entzündliches Infiltrat, das überwiegend aus Lymphozyten (70-90\%) v.a. des T-Zell-Typs, und einigen Makrophagen (7-16\%) besteht (Plagmann 1998). In der Infiltratregion kommt es zu 60-70\% Kollagenverlust (Attström und Lindhe 1986), im koronalen Saumepithel beginnt die Ausbildung von Epithelzapfen ins angrenzende Bindegewebe (Page 1986). 
Nach etwa sechs Wochen hat sich das Stadium der etablierten Läsion einer Gingivitis eingestellt. Eine ausgereifte subgingivale Plaque ist vorhanden und eine gingivale Tasche mit zum Teil ulzerierendem Taschenepithel hat sich ausgebildet. Der Bindegewebsverlust schreitet voran und eine deutliche Epithelzapfenbildung der ursprünglich glatten Basalmembran des Saumepithels ist sichtbar (Plagmann 1998). Das entzündliche Infiltrat besteht zu diesem Zeitpunkt überwiegend aus BLymphozyten und Plasmazellen (Attström und Lindhe 1986). Entscheidend ist, dass die Veränderungen auf die marginale Gingiva beschränkt sind und der Zahnhalteapparat nicht betroffen ist (Plagmann 1998). Dieses Stadium der etablierten Gingivitis kann über mehrere Jahre persistieren, es herrscht ein Gleichgewicht zwischen Plaqueangriff und Abwehrreaktion des Wirts (Plagmann 1998).

Wird dieses Gleichgewicht gestört, tritt das Stadium der fortgeschrittenen Läsion, die Parodontitis, ein. Die Destruktion greift auf den Zahnhalteapparat über, das Saumepithel verlagert sich nach apikal und es kommt zur Ausbildung echter parodontaler Taschen. Das Infiltrat enthält vor allem Plasmazellen und wenige BLymphozyten (Attström und Lindhe 1986). Die kollagenen Faserbündel der marginalen Gingiva sind aufgelöst, lediglich transseptale Fasern sind noch vorhanden. Der Großteil des Saumepithels wird zu dünnem Taschenepithel umgebaut, das nicht in der Lage ist, einen Epithelansatz auszubilden. Durch ein schmales Band des ursprünglichen Saumepithels ist der Taschenboden versiegelt. Das benachbarte Knochenmark bildet sich zu fibrösem Bindegewebe um (Plagmann 1998).

\subsection{Herzinsuffizienz}

\subsubsection{Definition}

Als Herzinsuffizienz wird das Unvermögen des Herzens, bei normalen Füllungsbedingungen und ausreichendem Volumenangebot das vom Organismus benötigte Herzzeitvolumen zu fördern, bezeichnet (Rickenbacher 2001).

Man unterscheidet anhand der Verlaufsform die akute von der chronischen Herzinsuffizienz. Entsprechend der Lokalisation spricht man von einer Rechtsherzoder Linksherzinsuffizienz bzw. bei konsekutiver Insuffizienz des jeweils anderen Ventrikels von einer Globalinsuffizienz (Lederhuber und Lange 2010). Die Rechtsherzinsuffizienz tritt insgesamt eher selten (z.B. bei pulmonaler Hypertonie (Cor pulmonale), Herzklappenfehler (z.B. Pulmonalstenose) etc.), meist in Folge einer Linksherzinsuffizienz auf.

Beruht die verminderte Auswurfleistung des Herzens auf einer Kontraktionsstörung des Myokards, liegt eine systolische Herzinsuffizienz vor (Lederhuber und Lange 2010). 
Hierbei unterscheidet man Low-output-failure, ein Vorwärtsversagen mit vermindertem Herzzeitvolumen, von High-output-failure, wobei ein erhöhter Bedarf (z.B. bei Anämie, Hyperthyreose, AV-Fistel) trotz physiologischer Ejektionsfraktion nicht gedeckt werden kann. Ist der Grund für die verminderte Auswurfleistung eine herabgesetzte diastolische Dehnbarkeit (Compliance) und Relaxation des Ventrikels bei erhaltener systolischer Pumpfunktion, spricht man von einer diastolischen Herzinsuffizienz. Die Herzinsuffizienz lässt sich in verschiedene Schweregrade einteilen. Weit verbreitet ist die Klassifikation der New York Heart Association (NYHA) entsprechend der Leistungsfähigkeit des Patienten (Tab. 4).

\begin{tabular}{|c|l|}
\hline Stadium & Merkmale \\
\hline I & $\begin{array}{l}\text { Herzerkrankung ohne körperliche Limitation. Alltägliche körperliche Belastung verursacht } \\
\text { keine inadäquate Erschöpfung, Rhythmusstörungen, Luftnot oder Angina pectoris }\end{array}$ \\
\hline \multirow{2}{*}{ II } & $\begin{array}{l}\text { Herzerkrankung mit leichter Einschränkung der körperlichen Leistungsfähigkeit. Keine } \\
\text { Beschwerden in Ruhe. Alltägliche körperliche Belastung verursacht Erschöpfung, } \\
\text { Rhythmusstörungen, Luftnot oder Angina pectoris }\end{array}$ \\
\hline \multirow{2}{*}{ III } & $\begin{array}{l}\text { Herzerkrankung mit höhergradiger Einschränkung der körperlichen Leistungsfähigkeit bei } \\
\text { vewohnter Tätigkeit. Keine Beschwerden in Ruhe. Geringe körperliche Belastung } \\
\text { Bettlägerigkeit }\end{array}$ \\
\hline
\end{tabular}

Tab. 4: Herzinsuffizienzklassifikation der NYHA (vgl. Hoppe et al. 2005, S. 490)

Eine weitere anerkannte Klassifikation ist die der American Heart Association (AHA), die Pathogenese und Progredienz der Erkrankung berücksichtigt (Hoppe et al. 2005) (Tab. 5).

\begin{tabular}{|c|l|}
\hline Stadium & Merkmale \\
\hline A & $\begin{array}{l}\text { Hohes Herzinsuffizienzrisiko, da Faktoren vorliegen, die stark mit der Entstehung einer } \\
\text { Herzinsuffizienz assoziiert sind; keine strukturelle Herzerkrankung, noch nie Herz- } \\
\text { insuffizienzsymptome }\end{array}$ \\
\hline B & $\begin{array}{l}\text { Strukturelle Herzerkrankung, die eng mit der Entstehung einer Herzinsuffizienz assoziiert } \\
\text { ist, bisher keine Herzinsuffizienzsymptome }\end{array}$ \\
\hline C & Frühere oder derzeitige Herzinsuffizienzsymptome bei struktureller Herzerkrankung \\
\hline D & $\begin{array}{l}\text { Fortgeschrittene strukturelle Herzerkrankung und schwere Herzinsuffizienzsymptome in } \\
\text { Ruhe trotz maximaler medikamentöser Therapie (spezielle Therapie erforderlich) }\end{array}$ \\
\hline
\end{tabular}

Tab. 5: Herzinsuffizienzklassifikation der AHA (vgl. Hoppe et al. 2005, S. 490)

Als Leitsymptome der Herzinsuffizienz gelten Dyspnoe, Müdigkeit und Flüssigkeitsretention (Ödeme) (Dickstein et al. 2008). 


\subsubsection{Epidemiologie}

Schätzungen zufolge leiden etwa 1,5 Mio. Menschen in Deutschland und mehr als 10 Mio. der europäischen Bevölkerung an Herzinsuffizienz (Hoppe et al. 2005; http://www.kardionet.de/krankheiten/herzinsuffizienz.html). Inzidenz und Prävalenz der Erkrankung sind altersabhängig. Zwischen dem 45. und 55. Lebensjahr ist weniger als $1 \%$ der Bevölkerung betroffen, zwischen dem 65 . und 75 . Lebensjahr bereits $2-5 \%$ und ab dem 80. Lebensjahr sind etwa 10\% der Menschen an Herzinsuffizienz erkrankt (Hoppe et al. 2005). Männer sind 1,5-mal so häufig betroffen wie Frauen (Roger et al. 2004), wobei bei älteren Menschen kein geschlechtsspezifischer Unterschied mehr festgestellt werden konnte (Dickstein et al. 2008). Im Jahr 2010 war laut statistischem Bundesamt die Herzinsuffizienz mit 5,6\% der Verstorbenen nach chronisch ischämischen Herzerkrankungen und akutem Myokardinfarkt die dritthäufigste Todesursache insgesamt (Statistisches Bundesamt 2011). Bei Männern steht sie an vierter Stelle und bei Frauen an zweiter Stelle der häufigsten Todesursachen (Statistisches Bundesamt 2011).

\subsection{3 Ätiologie und Pathogenese}

In $80-90 \%$ der Fälle liegt den Symptomen eine ventrikuläre Dysfunktion zugrunde, wobei bei $60 \%$ eine systolische Funktionsstörung mit einer Ejektionsfraktion $\leq 40 \%$ vorliegt (Hoppe et al. 2005). Häufigste Ursache für eine Herzinsuffizienz in westlichen Ländern ist die koronare Herzerkrankung (54-70\%), die in 35-42\% der Fälle von einer arteriellen Hypertonie begleitet wird (Hoppe et al. 2005). Eine arterielle Hypertonie als alleinige Ursache der chronischen Herzinsuffizienz findet man bei 9-20\% der Erkrankten (McMurray und Stewart 2000; Cleland et al. 2003; Hoppe et al. 2005). Weitere mögliche Ursachen sind Kardiomyopathien (v.a. dilatative), Herzklappenfehler (Stenosen/Insuffizienzen), Rhythmusstörungen (Tachykardie/Bradykardie) sowie Alkohol- und Drogenabusus (Lip et al. 2000).

Als Auslöser der Herzinsuffizienz kommen wie beschrieben Herzmuskelschädigungen durch Verlust an Myokard oder durch erhöhte Druck- bzw. Volumenbelastung in Frage. Direkte Folge ist eine eingeschränkte kardiale Pumpleistung und daraus resultierend eine Unterversorgung der Organe mit sauerstoffreichem Blut.

Um die verminderte Kontraktilität des Herzens zu kompensieren, werden funktionale, morphologische und neurohumorale Kompensationsmechanismen in Gang gesetzt (Lederhuber und Lange 2010).

$\mathrm{Zu}$ den funktionalen Kompensationsmechanismen gehören der Frank-StarlingMechanismus, eine autoregulatorische Anpassung der Kammertätigkeit an kurzfristige Veränderungen der Vor- und/oder Nachlast, und das Treppenhaus- oder Bowditch- 
Phänomen, wonach das Herz auf eine gesteigerte Herzfrequenz mit Steigerung der Kontraktiliät reagiert (Weil und Schunkert 2006). Sowohl der Frank-StarlingMechanismus als auch das Bowditch-Phänomen sind bei Herzinsuffizienz herabgesetzt (Weil und Schunkert 2006).

Bei den morphologischen Kompensationsmechanismen, dem kardialen Remodeling (Cohn et al. 2000), kann man makroskopische und mikroskopische Veränderungen unterscheiden (Weil und Schunkert 2006). Makroskopisch kommt es durch Druckbelastung des Herzens, z.B. in Folge arterieller Hypertonie oder einer Aortenklappenstenose, zur Zunahme der Wanddicke (konzentrisches Remodeling) und Entstehung einer konzentrischen Hypertrophie (Weil und Schunkert 2006). Aorteninsuffizienz, schwere Anämien oder Shuntvitien führen über eine erhöhte Volumenbelastung zur Zunahme des linksventrikulären Durchmessers (exzentrisches Remodeling), es entsteht eine exzentrische Hypertrophie (Weil und Schunkert 2006). Abbildung 5 zeigt eine schematische Darstellung der makroskopischen Veränderungen beim kardialen Remodeling.

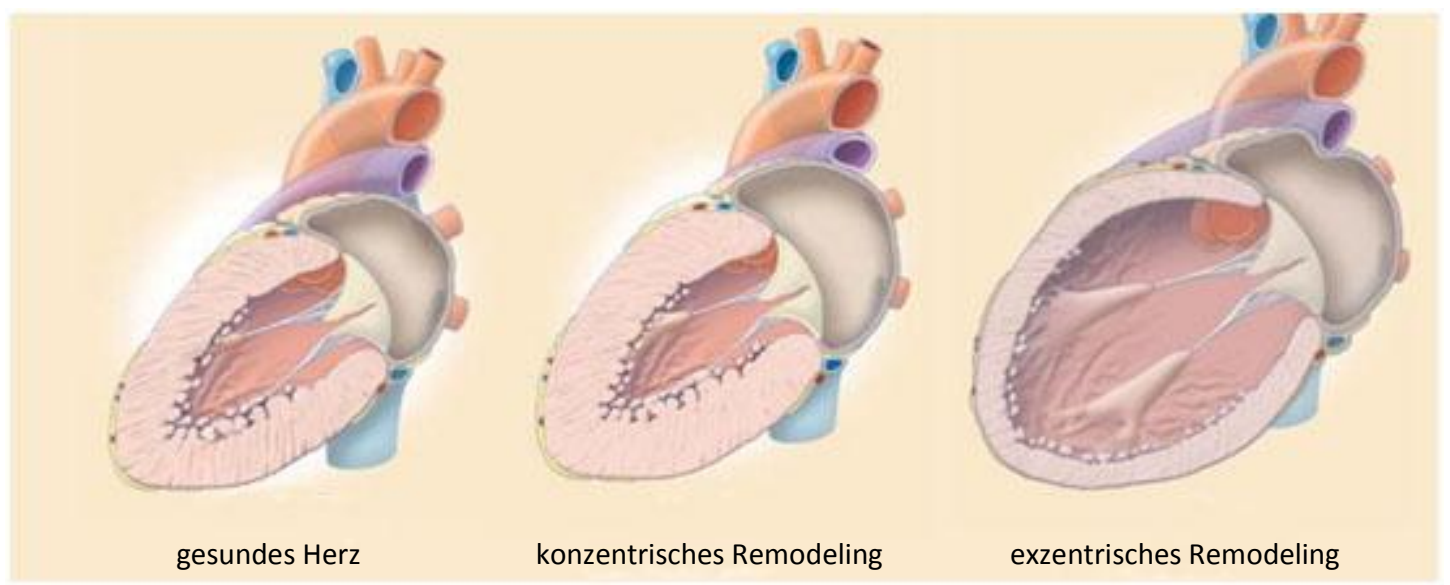

Abb. 5: Kardiales Remodeling (modifiziert nach Jessup und Brozena 2003, S. 2011)

Mikroskopisch kann zum einen eine Kardiomyozytenhypertrophie beobachtet werden, bei gesteigerter Wandspannung kommt es jedoch auch vermehrt zum aktiven Zelltod (Apoptose) (Weil und Schunkert 2006). Gleichzeitig erfolgt eine Umstrukturierung der Bindegewebszellen im insuffizienten Herzen; vor allem durch Zunahme des kollagenen Netzwerkes wird die passive Dehnbarkeit des Myokards herabgesetzt (Weil und Schunkert 2006).

Die neurohumoralen Adaptationsmechanismen führen durch Flüssigkeitsretention zur Erhöhung der Vorlast und durch Erhöhung des peripheren Widerstands zur Erhöhung der Nachlast (Classen et al. 2004). Zu den Mechanismen gehören u.a. die Aktivierung des sympathischen Nervensystems, dessen Katecholamine durch Bindung an den $\beta 1$ - 
Rezeptor positiv inotrop, chronotrop und lusitrop wirken und so eine erhöhte Kontraktilität bewirken (Classen et al. 2004). Bei chronischer Herzinsuffizienz liegt jedoch eine ständige adrenerge Stimulation vor, so dass es über eine negative Rückkopplung zur Abnahme der $\beta 1$-Adrenorezeptoren-Dichte kommt (Weil und Schunkert 2006). Außerdem wird das Renin-Angiotensin-Aldosteron-System aktiviert, das mittels renaler, vaskulärer und kardialer Mechanismen zu Flüssigkeitsresorption, Steigerung des peripheren Widerstands und Myokardhypertrophie führt (Classen et al. 2004). Vasopressin (synonym: Antidiuretisches Hormon ADH) und Endothelin, deren Produktion bei Herzinsuffizienz gesteigert wird (Weil und Schunkert 2006), begünstigen Flüssigkeitsretention bzw. Nachlasterhöhung.

Gleichzeitig kommt es zur Aktivierung regulierender Mechanismen, z.B. durch natriuretische Peptide, Bradykinin, Prostaglandine und Stickstoffmonoxid, die Volumen eliminierend und vasodilatatorisch wirken (Classen et al. 2004). Diese Mechanismen haben eher gegenregulatorische als kompensatorische Wirkung und fallen quantitativ nicht ins Gewicht (Classen et al. 2004).

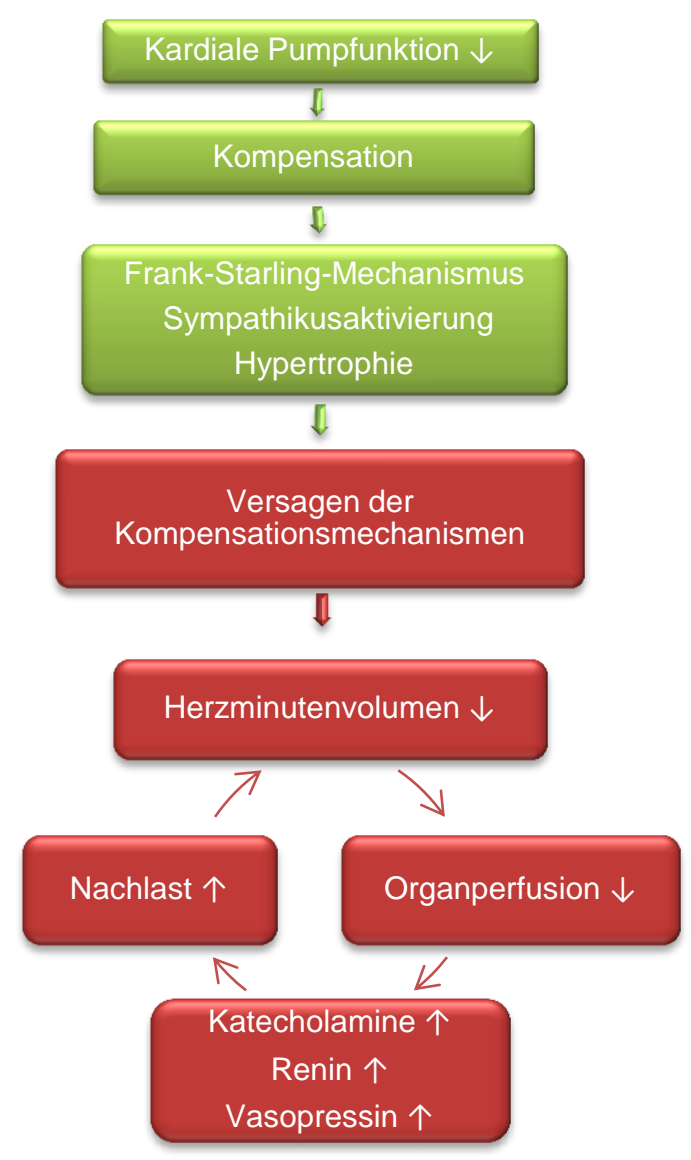

Abb. 6: Circulus vitiosus der Herzinsuffizienz (nach Classen et al. 2004, S. 213) 
Die kompensatorischen Mechanismen erlauben zwar eine kurzfristige Stabilisierung der Myokardfunktion und der Perfusion lebenswichtiger Organe, tragen jedoch bei chronischer Aktivierung zur Progression der Herzinsuffizienz bei, es entsteht ein circulus vitiosus (Rickenbacher 2001) (Abb. 6).

Die Frage, ob bakterielle Endotoxine (Lipopolysaccharide) eine Rolle bei der Pathogenese und Progression der Herzinsuffizienz spielen, ist bis heute noch nicht abschließend geklärt. Verschiedene Untersuchungen konnten einen erhöhten TNF- $\alpha$ Plasmaspiegel bei Patienten mit chronischer Herzinsuffizienz ermitteln (Seta et al. 1996; Anker et al. 1997; Mann 2002; Staudt et al. 2002). Es konnte außerdem gezeigt werden, dass herzinsuffiziente Patienten mit erhöhten TNF- $\alpha$-Plasmaspiegeln eine deutlich erhöhte Mortalität aufweisen (Staudt et al. 2002). Weiterhin wurde eine Korrelation von IL-6 mit dem NYHA-Stadium festgestellt (Seta et al. 1996; Staudt et al. 2002).

Die „Zytokin-Hypothese“ geht davon aus, dass Zytokine in der Lage sind, mittels hämodynamischer Störung oder eines direkt toxischen Effekts auf das Herz die Progression der Herzinsuffizienz zu beeinflussen (Seta et al. 1996).

Auch Anker et al. (1997) beschäftigten sich mit der Rolle der Zytokine bei der Herzinsuffizienz-Pathogenese und stellten verschiedene Theorien für die Herkunft der Zytokine auf: Intestinale Ödeme könnten zur bakteriellen Translokation über die Darmwand führen, wodurch Bakterien und ihre Endotoxine in die Zirkulation gelangen könnten. Eine Stimulation der Makrophagen zur Zytokinproduktion durch Verlangsamung des Blutstroms in der Peripherie könnte eine weitere Erklärung sein; außerdem wäre es möglich, dass die Kardiomyozyten selbst die Zytokine (v.a. TNF- $\alpha$ ) produzieren (Anker et al. 1997). Es konnte jedoch gezeigt werden, dass keine signifikanten Unterschiede zwischen dem TNF-a-Plasmaspiegel im Sinus coronarius und im arteriellen Blut bestehen und demnach das Herz als alleinige Quelle für die erhöhte Zytokinproduktion auszuschließen ist (Munger et al. 1996).

Jüngere Studien befassten sich mit der Wirkung der Zytokine auf das Herz, wobei der Fokus auf TNF- $\alpha$ und IL-6 gelegt wurde (Staudt et al. 2002; Mann 2002). Man geht davon aus, dass viele Aspekte der Herzinsuffizienz durch biologische Effekte der Zytokine erklärt werden können (Mann 2002). Die pathophysiologischen Mechanismen mit kardialer Wirkung, die durch die Zytokine ausgelöst werden können, sind in Tabelle 6 aufgelistet. 


\begin{tabular}{|l|l|}
\hline Zytokin & kardiale Wirkung \\
\hline TNF- $\alpha$ & $\begin{array}{l}\text { negativ inotrop } \\
\text { myokardiale Hypertrophie } \\
\text { Expression fetaler Gene } \\
\text { proapoptotisch }\end{array}$ \\
\hline IL-1 $\alpha$ & myokardiale Hypertrophie \\
\hline IL-1 $\beta$ & $\begin{array}{l}\text { negativ inotrop } \\
\text { proapoptotisch }\end{array}$ \\
\hline IL-6 & $\begin{array}{l}\text { negativ inotrop } \\
\text { antiapoptotisch } \\
\text { myokardiale Hypertrophie }\end{array}$ \\
\hline IFN- $\gamma$ & $\begin{array}{l}\text { Antiviral } \\
\text { proapoptotisch }\end{array}$ \\
\hline
\end{tabular}

Tab. 6: Zytokine und deren Eigenschaften (vgl. Staudt et al. 2002, S. 693)

Vermutlich spielen die Zytokine neben anatomischen, funktionellen und biologischen Veränderungen eine gewisse Rolle bei der komplexen Pathogenese der Herzinsuffizienz (Seta et al. 1996).

\subsection{Bekannte Assoziationen zwischen Parodontitis und Herzerkrankungen}

Bereits 1989 stellten Mattila et al. die Hypothese auf, dass eine Assoziation zwischen der parodontalen Gesundheit und dem Auftreten eines akuten Herzinfarktes besteht (Mattila et al. 1989). Mit weiteren Studien unterstützten sie die Vermutung, dass dentale Infektionen einen Risikofaktor für Herzerkrankungen darstellen (Mattila et al. 1993; Mattila et al. 1995). DeStefano et al. ermittelten für männliche Parodontitispatienten unter 50 Jahren ein zweifach erhöhtes Risiko für die Entwicklung einer Koronaren Herzerkrankung (KHK) im Vergleich zu einer entsprechenden Kontrollgruppe (DeStefano et al. 1993). Eine Korrelation zwischen Zahnverlust und Koronarer Herzerkrankung wurde untersucht, und es konnte für Patienten mit 10 oder weniger Zähnen im Vergleich zu Patienten mit 25 oder mehr Zähnen ein erhöhtes KHK-Risiko festgestellt werden (Joshipura et al. 1996). Auf Störungen im Fettstoffwechsel als wichtiger Risikofaktor bei der Entwicklung einer Arteriosklerose und daraus resultierender KHK konzentrierten sich Tang et al. und konnten nachweisen, dass die Werte für Cholesterol, Triglyceride, LDL, oxLDL, CRP, IL-6 und TNF- $\alpha$ bei Patienten mit KHK und Parodontitis signifikant höher waren als bei parodontal gesunden Patienten mit KHK (Tang et al. 2011). Außerdem wurden in der Gruppe der KHKPatienten signifikant höhere Werte für Sondierungstiefe, Attachmentverlust, SulkusBlutungs-Index und fehlende Zähne ermittelt als in der Kontrollgruppe. Nach Analyse 
der NHANES III (National Health and Nutrition Examination Survey) konnte eine vierfach erhöhte Herzinfarkt-Inzidenz für Parodontitispatienten ermittelt werden (Arbes et al. 1999). Es konnte festgestellt werden, dass Antikörper gegen Porphyromonas gingivalis mit dem Auftreten einer Koronaren Herzerkrankung assoziiert sind (Kuramitsu et al. 2001; Pussinen et al. 2003). Verschiedene Studien konnten jedoch keinen signifikanten Zusammenhang zwischen Parodontitis und Arteriosklerose bzw. KHK feststellen (Hujoel et al. 2000; Yamazaki et al. 2005).

Auch wenn eine Assoziation zwischen Parodontitis und KHK in vielen Studien vermutet wird, konnte der genaue Mechanismus noch nicht geklärt werden (Tang et al. 2011). Verschiedene Risikofaktoren für die Entstehung einer Arteriosklerose sind bekannt, diese sind jedoch für nur 50-70\% der Fälle verantwortlich (Haynes und Stanford 2003). Eine Reihe von weiteren Risikofaktoren wird diskutiert, u.a. die Parodontitis (Haynes und Stanford 2003).

Laut Haynes et al. gibt es mehrere mögliche Erklärungen für den Zusammenhang zwischen Parodontitis und KHK (Haynes und Stanford 2003). Diskutiert wird eine mögliche Korrelation zwischen Parodontitis und KHK aufgrund gemeinsamer Risikofaktoren wie Alter, Rauchen, Geschlecht, Alkohol, Bildung, Hypertonie, finanzieller Status und Stress (Beck et al. 1999), und eventuell weitere noch unbekannte gemeinsame Faktoren.

Als weitere Erklärung käme eine individuelle Neigung des Patienten zu einer überschießenden Entzündungsreaktion in Frage, die sowohl die Entstehung der Parodontitis als auch der Arteriosklerose begünstigen würde (Haynes und Stanford 2003). Eine weitere Überlegung geht dahin, dass ein Entzündungsherd in der Mundhöhle durch Stimulation der humoralen und zellvermittelten Abwehr in der Lage sein könnte, eine systemische Entzündungsreaktion auszulösen und einen Arteriosklerose-Prozess dadurch zu verstärken (Haynes und Stanford 2003).

Weiterhin wird eine mögliche Kreuzreaktivität von Antikörpern gegen Parodontopathogene und gegen Antigene von Thrombozyten und Endothelzellen diskutiert.

Als mögliche Ursache für die Assoziation zwischen Parodontitis und arteriosklerotischen Vorgängen wurde weiterhin das Eindringen von Parodontitis-Bakterien wie Porphyromonas gingivalis, Aggregatibacter actinomycetemcomitans und Bacteroides forsythensis in die arteriosklerotische Plaque betrachtet, wodurch es zu Entzündung und Instabilität der Plaque kommen könnte (Haraszthy et al. 2000). Ein Vorhandensein parodontopathogener Bakterien in der arteriosklerotischen Plaque konnte bei $18-30 \%$ der Patienten mit Arteriosklerose nachgewiesen werden (Haraszthy et al. 2000).

Dietrich et al. (2008) ermittelten einen signifikanten Zusammenhang zwischen chronischer Parodontitis und koronarer Herzerkrankung unabhängig von bekannten 
kardiovaskulären Risikofaktoren für männliche Patienten, die jünger als 60 Jahre alt waren. Sie stellten fest, dass verschiedene Studien kausale und nicht-kausale Beziehungen zwischen chronischer Parodontitis und $\mathrm{KHK}$ als Erklärung für eine mögliche Assoziation heranzogen (Dietrich et al. 2008). Es wurde die Hypothese formuliert, dass sowohl direkte Effekte (Bakteriämie) als auch indirekte Effekte (systemische Inflammation) der Parodontitis eine Rolle spielen, gleichzeitig aber auch genetische und immunologische Faktoren sowohl die Wahrscheinlichkeit einer Parodontitis als auch eines arteriosklerotischen Prozesses erhöhen. Angelehnt an Dietrich et al. (2008) sind in Abbildung 7 mögliche Einflussfaktoren und deren Wechselbeziehungen, die einen Zusammenhang zwischen Parodontitis und KHK erklären könnten, graphisch dargestellt.

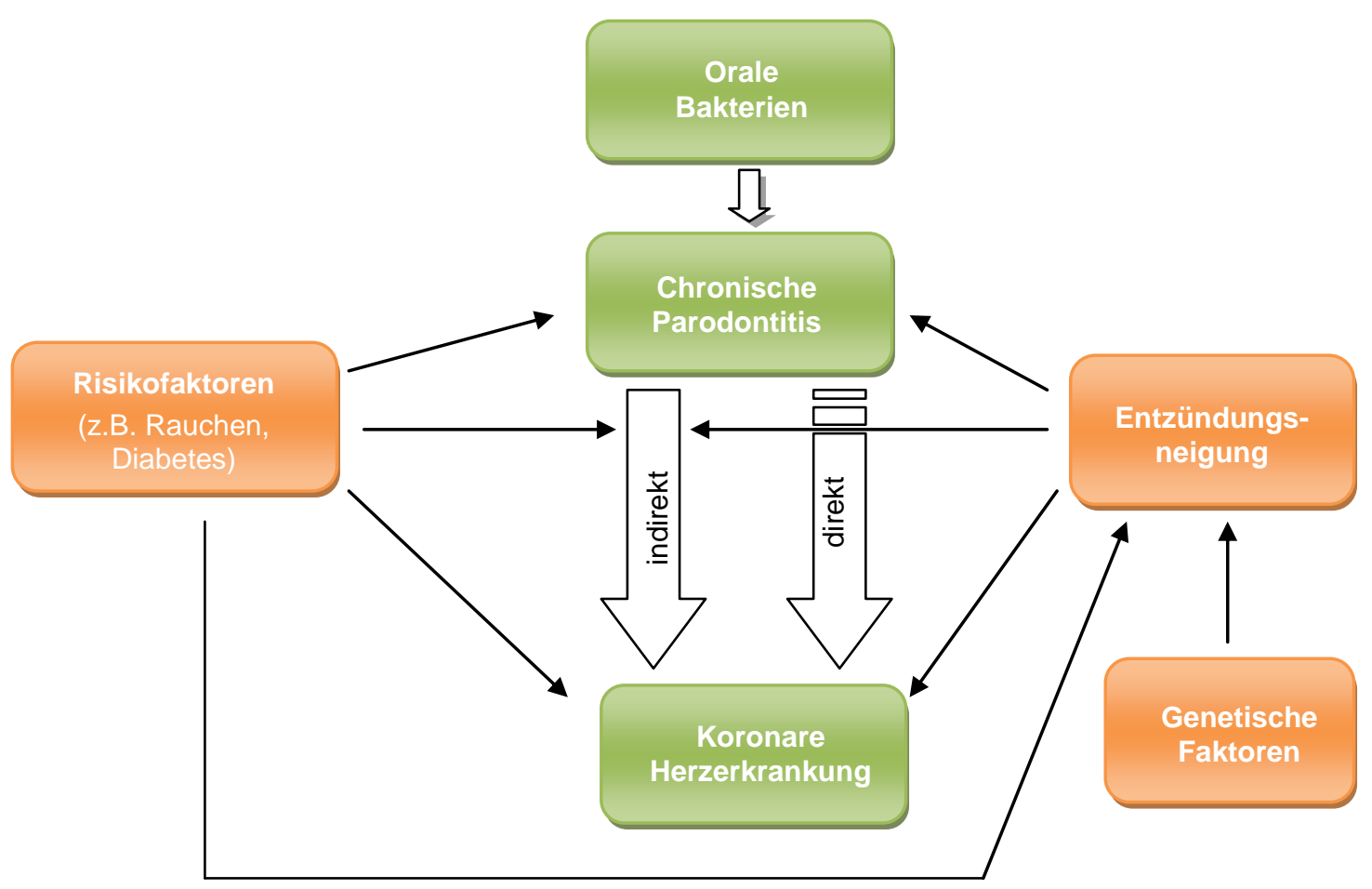

Abb. 7: Mögliche pathways der Assoziation zwischen Parodontitis und KHK (nach Dietrich et al. 2008, S. 1672)

Tang et al. gehen davon aus, dass Langzeitstudien durchgeführt werden sollten, um die Beziehung zwischen Parodontitis und Koronaren Herzerkrankungen genauer zu erforschen, und empfehlen, die parodontale Gesundheit bei der Therapie von KHKPatienten zu berücksichtigen (Tang et al. 2011).

Aufgrund der Annahme, dass die Parodontitis eine Rolle bei der Pathogenese der Koronaren Herzerkrankung spielt, wurde die Hypothese aufgestellt, dass parodonto- 
pathogene Mikroorganismen und ihre Endotoxine auch die Entstehung der Herzinsuffizienz beeinflussen könnten. Die vorliegende Arbeit untersucht in diesem Zusammenhang, ob die Endotoxine (Lipopolysaccharide) der parodontopathogenen Mikroorganismen in der Lage sind, am Myokard zu binden und dort Entzündungsreaktionen auszulösen und inwieweit die Menge an Lipopolysaccharid-bindendem Protein mit dem Schweregrad der Parodontitis assoziiert ist. 


\section{$3 \quad$ Material und Methoden}

Bei der vorliegenden Studie handelt es sich um eine klinisch-experimentelle Querschnittsstudie, bei der Patienten mit operationsbedürftiger Aortenklappenstenose oder -insuffizienz untersucht wurden. Im Rahmen eines Pilotprojektes mit verschiedenen Einzelprojekten dienten das untersuchte Patientenkollektiv und die erhobenen klinischen Befunde als Basis für die vorliegende Untersuchung sowie weitere Teilprojekte (Jahn 2012).

\subsection{Administrative Vorbereitungen}

Der Antrag zur Beurteilung des klinischen Forschungsvorhabens wurde unter dem Titel „Klinisch-experimentelle Studie zur möglichen Assoziation parodontaler Gesundheit und verschiedenen Herzerkrankungen" mit der Nummer 6/2/09 gestellt und die Durchführung der Studie von der Ethikkommission der Universität Göttingen ohne ethische oder rechtliche Bedenken genehmigt.

Da für die Untersuchung Herzgewebe von Patienten benötigt wurde, wurde im Vorfeld die Zusammenarbeit und Kommunikation mit der Abteilung Thorax-, Herz- und Gefäßchirurgie der Universitätsmedizin Göttingen unter Leitung von Prof. Dr. Schöndube geregelt.

\subsection{Probandengewinnung}

Als Probanden dienten Patienten, die sich im Zeitraum von Mai 2009 bis August 2010 in der Thorax-, Herz- und Gefäßchirurgie des Universitätsklinikums Göttingen einer Operation wegen eines Aortenklappen-Ersatzes unterzogen.

Von der Studie ausgeschlossen wurden gemäß Ethikantrag immunsupprimierte oder organtransplantierte sowie suchtkranke Patienten. Weitere Ausschlusskriterien waren das Vorliegen von Hepatitis A, B, C, Tuberkulose oder HIV sowie ein Herzinfarkt oder Apoplex innerhalb der letzten sechs Monate.

Vor Beginn der Untersuchung wurden die Patienten mündlich aufgeklärt. Eine entsprechende Patientenaufklärung sowie eine Einverständniserklärung zur Teilnahme an der Untersuchung und eine Einverständniserklärung zur wissenschaftlichen Verwendung ihres Blutes und des Restgewebes, das während der OP anfällt, wurden vom Patienten unterzeichnet. Die Einverständniserklärungen wurden vom Prüfarzt gegengezeichnet. Alle untersuchten Patienten und deren Daten wurden durchnummeriert und die entsprechenden Datenblätter pseudonymisiert.

Die medizinische Diagnostik erfolgte im Vorfeld durch Allgemeinmediziner und Kardiologen. Angaben zu Geschlecht und Alter, Größe und Gewicht, Allgemein- 
erkrankungen, kardialen Diagnosen, Medikamenten, OP-Indikation und -Lokalisation sowie bestimmten Blutwerten wurden Befund- und Behandlungsdokumentationen der jeweiligen Patientenakte entnommen.

\subsection{Kalibrierung}

Im Vorfeld der zahnärztlichen Untersuchungen erfolgte eine Kalibrierung der Untersucher, indem die jeweiligen dentalen und parodontalen Befunde von zwei Untersuchern unabhängig bei einem weiteren erhoben wurden. Hierbei mussten $80 \%$ der Messwerte übereinstimmen, wobei eine Abweichung um eine Einheit $(=1 \mathrm{~mm})$ toleriert wurde.

\subsection{Anamnese}

Mit Hilfe eines Anamnesebogens wurden Informationen zu Herzerkrankungen und Medikamenteneinnahme sowie spezielle zahnmedizinische Angaben wie Temperaturempfindlichkeit der Zähne, Zahnfleischbluten, vorangegangene Parodontalbehandlungen etc. erfragt. Zusätzlich wurde das Rauchverhalten der Patienten dokumentiert.

\subsection{Klinisch-zahnärztliche Untersuchung}

Die Patienten wurden in der Regel einen Tag präoperativ auf der entsprechenden Station der Thorax-Herz-Gefäßchirurgie untersucht. In wenigen Ausnahmefällen erfolgte die Untersuchung erst postoperativ. In diesen Fällen bestimmte der gesundheitliche Zustand bzw. der Fortschritt der Genesung der Patienten den Zeitpunkt der Untersuchung.

Um das Risiko einer Endokarditis zu minimieren, erhielten die Patienten eine Stunde vor der zahnärztlichen Untersuchung ein orales Antibiotikum im Sinne eines „single shots“. In der Regel erfolgte die Antibiose mit $1 \times 2$ g Amoxicillin (Aminopenicillin), bei Unverträglichkeit wurde auf 1 x 600 mg Clindamycin zurückgegriffen.

\subsubsection{Zahnärztlicher Befund (DMFT)}

Der DMFT ist ein von der Weltgesundheitsorganisation (WHO) empfohlener Index für die Zahngesundheit. Hierbei werden im bleibenden Gebiss maximal 28 Zähne ( $T=$ teeth) beurteilt, die Weisheitszähne werden nicht berücksichtigt. Beurteilt werden die Zähne mit D: decayed = zerstört/kariös, M: missing = fehlt/extrahiert oder F: filled = mit Füllung versorgt. Die Summe $D+M+F$ ergibt den so genannten DMFT-Wert (maximal 28). Für eine differenziertere Aussage ist eine Einteilung in D-T, M-T und F-T sinnvoll. 


\subsubsection{Papillen-Blutungs-Index (PBI)}

Der Papillen-Blutungs-Index dient der Beurteilung des Entzündungsgrades der Gingiva (Saxer und Mühlemann 1975). Der Sulkus wird im Papillenbereich mit einer Parodontalsonde stumpf ausgestrichen, wobei die Sonde im Winkel von ca. $45^{\circ}$ zur Zahnachse geführt werden sollte. Nach 20 Sekunden wird eine eventuelle Blutung beurteilt. Der PBI wird im ersten und dritten Quadranten oral und im zweiten und vierten Quadranten vestibulär erhoben.

Folgende Grade werden unterschieden (Saxer und Mühlemann 1975):

- Grad 0: keine Blutungen

- Grad 1: Auftreten eines Blutungspunktes

- Grad 2: Auftreten mehrerer Blutungspunkte oder einer Blutlinie

- Grad 3: Ausfüllen des interdentalen Dreiecks mit Blut

- Grad 4: profuse Blutung nach der Sondierung; Blut fließt über den Zahn.

Der Index wird berechnet, indem die Summe der Blutungsbefunde durch die Anzahl untersuchter Papillen dividiert wird.

\subsubsection{Parodontalstatus}

Sondierungstiefen und Attachmentlevel der Probanden wurden mit Hilfe einer millimeterskalierten Parodontalsonde (PCP15, Hu-Friedy, Rotterdam, Niederlande) aufgenommen.

Die Messung der Sondierungstiefen erfolgte in Form einer modifizierten Vier-PunktMessung, d.h. es wurde an jedem Zahn an jeweils vier Messpunkten gemessen: mesio-vestibulär, disto-vestibulär, mesio-oral und disto-oral.

Kommt es bei Sondierung der Taschen zu einer Blutung, wird ein positiver BOP (bleeding on probing) vermerkt. Bleibt eine Blutung aus, ist der BOP negativ.

Anschließend wurden die Rezessionen gemessen, um das Attachmentlevel bestimmen zu können, welches der Distanz zwischen der Schmelz-Zement-Grenze und dem klinisch sondierbaren Boden der Zahnfleischtasche entspricht.

Die Patienten wurden nach einem Vorschlag der Working Group des CDC (Center of Disease Control) und der AAP (American Academy of Periodontology) anhand der Sondierungstiefen (ST) und des Attachmentlevels (AL) in Gruppen nach Schweregrad der vorliegenden Parodontitis eingeteilt (Page und Eke 2007) (Tab. 7). 


\begin{tabular}{|c|c|c|c|}
\hline \multirow{2}{*}{ Schweregrad } & \multicolumn{3}{|l|}{ Klinische Definition") } \\
\hline & Attachmentlevel (AL) & & Sondierungstiefen (ST) \\
\hline Schwere Parodontitis & $\begin{array}{l}\geq 2 \text { Approximalräume mit } \mathrm{AL} \geq 6 \\
\mathrm{~mm} \text { (nicht am selben Zahn) }\end{array}$ & und & $\begin{array}{l}\geq 1 \text { Approximalraum mit } \mathrm{ST} \geq 5 \\
\mathrm{~mm}\end{array}$ \\
\hline Leichte Parodontitis & $\begin{array}{l}\geq 2 \text { Approximalräume mit } \mathrm{AL} \geq 4 \\
\mathrm{~mm} \text { (nicht am selben Zahn) }\end{array}$ & oder & $\begin{array}{l}\geq 2 \text { Approximalräume mit ST } \geq 5 \\
\text { mm (nicht am selben Zahn) }\end{array}$ \\
\hline $\begin{array}{l}\text { Keine oder milde } \\
\text { Parodontitis }\end{array}$ & $\begin{array}{l}\text { Weder leichte noch schwere } \\
\text { Parodontitis }\end{array}$ & & \\
\hline
\end{tabular}

Tab. 7: Schweregrade der Parodontitis (vgl. Page und Eke 2007, S. 1396)

An mehrwurzeligen Zähnen wurde mit Hilfe einer Furkationssonde (Hu-Friedy, Rotterdam, Niederlande) der Furkationsbefall untersucht. Bei Ermittlung des Furkationsbefundes können folgende Grade unterschieden werden (Hamp et al. 1975):

- Grad 0: Furkation nicht sondierbar

- Grad I: Furkation bis $3 \mathrm{~mm}$ sondierbar

- Grad II: Furkation über $3 \mathrm{~mm}$ sondierbar, aber nicht durchgängig

- Grad III: Furkation durchgängig sondierbar.

Zur Bestimmung der Zahnlockerung wird der Zahn mit zwei Instrumentengriffen sowohl horizontal als auch vertikal bewegt. Die Auslenkung wird visuell beurteilt und in folgende Grade eingeteilt (Hellwig et al. 2006):

- Grad 0: physiologische, nicht erhöhte Zahnbeweglichkeit

- Grad I: erhöhte Zahnbeweglichkeit, spürbar oder sichtbar bis $1 \mathrm{~mm}$ horizontal

- Grad II: erhöhte Zahnbeweglichkeit, sichtbar über $1 \mathrm{~mm}$ horizontal

- Grad III: erhöhte Zahnbeweglichkeit, beweglich auf Lippen- und Zungendruck und/oder in axialer Richtung.

\subsection{Gewinnung der Blut- und Herzgewebeproben}

Das Herzgewebe, welches im Rahmen der Studie im Labor untersucht wurde, wurde während der Operationen in der Thorax-Herz-Gefäßchirurgie gewonnen. Die Blutproben wurden ebenfalls im Laufe der OP entnommen. Das Gewebe wurde mit einem Skalpell zerkleinert und bis zur weiteren Verwendung bei $-80^{\circ} \mathrm{C}$ eingefroren.

\subsection{Materialien}

Alle für die Untersuchung der Blut- und Gewebeproben verwendeten Chemikalien, Hilfsmittel, Geräte und Softwares sind den Materiallisten im Anhang zu entnehmen. 


\subsection{Aufbereitung der Herzgewebeproben durch Proteinaufreinigung mit Lysispuffer}

Um aus den Gewebezellen DNA, RNA oder Proteine zu gewinnen, ist eine Aufreinigung mit Lysispuffer notwendig. Der hier verwendete Lysispuffer (Tab. 8) wurde vorbereitet und bei $+4^{\circ} \mathrm{C}$ gelagert:

\begin{tabular}{|c|c|c|}
\hline & & Konzentration in $100 \mathrm{ml}$ \\
\hline TRIS & $0,242 \mathrm{~g}$ & $20 \mathrm{mM}$ \\
\hline $\mathrm{NaCl}$ & $0,292 \mathrm{~g}$ & $50 \mathrm{mM}$ \\
\hline $\mathrm{NaF}$ & $0,209 \mathrm{~g}$ & $50 \mathrm{mM}$ \\
\hline Na-Pyrophosphat & $0,223 \mathrm{~g}$ & $5 \mathrm{mM}$ \\
\hline Sucrose & $8,557 \mathrm{~g}$ & $0,25 \mathrm{mM}$ \\
\hline
\end{tabular}

Tab. 8: Mengen für $100 \mathrm{ml}$ Lysispuffer

Anschließend wurden Triton X-100, DTT und Protease Inhibitor Cocktail hinzugegeben (Tab. 9).

\begin{tabular}{|l|l|l|}
\hline & & Konzentration in 1 ml \\
\hline Triton X-100 & $10 \mu \mathrm{l}$ & $1 \%$ \\
\hline DTT (100mM) & $10 \mu \mathrm{l}$ & $1 \mathrm{mM}$ \\
\hline Protease Inhibitor Cocktail & $1 \mu \mathrm{l}$ & $1: 1000$ \\
\hline
\end{tabular}

Tab. 9: Zugabe zu vorbereitetem Lysispuffer

Die Gewebeproben wurden nach Entnahme aus dem $-80^{\circ} \mathrm{C}$-Gefrierschrank in FlüssigStickstoff $\left(\mathrm{N}_{2}\right)$ gelagert und in einer Reibeschale mit Flüssig-Stickstoff mit Hilfe eines Stößels homogenisiert. Das Homogenat wurde in ein Eppendorf-Cup (E-Cup) mit 500 bis $1000 \mu \mathrm{l}$ Lysispuffer (je nach Gewebemenge) gegeben und anschließend 10 Minuten bei $+4^{\circ} \mathrm{C}$ zentrifugiert (3000 rpm). Der Überstand wurde abpipettiert und in ein neues E-Cup überführt. Die Proben wurden bis zum nächsten Arbeitsschritt bei $-18^{\circ} \mathrm{C}$ eingefroren.

\subsection{Analyse der Herzgewebeproben im Labor}

\subsubsection{Bestimmung der Proteinkonzentration}

Die Konzentrationsbestimmung der Proteinproben erfolgte mit Hilfe des BCAProteinassay Kit (Thermo Fisher Scientific, Waltham, USA). Zunächst wurde die Verdünnungsreihe für den Standardtestbereich von 20 bis $2000 \mu \mathrm{g} / \mathrm{ml}$ erstellt. 
Dafür wurde der mitgelieferte Albumin-Standard $(2,0 \mathrm{mg} / \mathrm{ml})$ in unterschiedlichem Maße mit zuvor verdünntem Lysispuffer (1:10 mit doppelt destilliertem Wasser (aqua bidest)) verdünnt (Tab. 10).

\begin{tabular}{|c|l|l|l|}
\hline Tube & $\begin{array}{l}\text { Verdünnungsmedium } \\
\text { (verdünnter Lysispuffer) }\end{array}$ & $\begin{array}{l}\mathbf{2 , 0} \mathbf{~ m g} / \mathbf{m l} \\
\text { Albumin-Standard }\end{array}$ & Endkonzentration \\
\hline A & $0 \mu \mathrm{l}$ & $300 \mu \mathrm{l}$ & $2000 \mu \mathrm{g} / \mathrm{ml}$ \\
\hline $\mathrm{B}$ & $125 \mu \mathrm{l}$ & $375 \mu \mathrm{l}$ & $1500 \mu \mathrm{g} / \mathrm{ml}$ \\
\hline $\mathrm{C}$ & $325 \mu \mathrm{l}$ & $325 \mu \mathrm{l}$ & $1000 \mu \mathrm{g} / \mathrm{ml}$ \\
\hline $\mathrm{D}$ & $175 \mu \mathrm{l}$ & $175 \mu \mathrm{l}$ aus Tube B & $750 \mu \mathrm{g} / \mathrm{ml}$ \\
\hline $\mathrm{E}$ & $325 \mu \mathrm{l}$ & $325 \mu \mathrm{l}$ aus Tube C & $500 \mu \mathrm{g} / \mathrm{ml}$ \\
\hline $\mathrm{F}$ & $325 \mu \mathrm{l}$ & $325 \mu \mathrm{l}$ aus Tube E & $250 \mu \mathrm{g} / \mathrm{ml}$ \\
\hline $\mathrm{G}$ & $325 \mu \mathrm{l}$ & $325 \mu \mathrm{l}$ aus Tube F & $125 \mu \mathrm{g} / \mathrm{ml}$ \\
\hline $\mathrm{H}$ & $400 \mu \mathrm{l}$ & $100 \mu \mathrm{l}$ aus Tube G & $25 \mu \mathrm{g} / \mathrm{ml}$ \\
\hline $\mathrm{I}$ & $400 \mu \mathrm{l}$ & - & $\begin{array}{l}0 \mu \mathrm{g} / \mathrm{ml} \\
=B \text { lindwert (Blank) }\end{array}$ \\
\hline
\end{tabular}

Tab. 10: Herstellung der Standardreihe zur Bestimmung der Proteinkonzentration

Die Bestimmung der Proteinkonzentration wurde in einer Doppelbestimmung vorgenommen. Zur Testdurchführung wurden $25 \mu \mathrm{l}$ jeder Probe (in E-Cups 1:10 vorverdünnt) sowie je $25 \mu \mathrm{l}$ der Standardreihe (Tubes A-I) mit jeweils $500 \mu \mathrm{l}$ des vorbereiteten BCA-Reagenz (Mischen der Komponenten A und B im Verhältnis 50:1) gemischt. Anschließend wurden alle E-Cups für 30 Minuten bei $37^{\circ} \mathrm{C}$ im Thermostat inkubiert.

Im Anschluss erfolgte die Messung der Proteinkonzentration in einem Spektralphotometer (BioMate 5) bei $562 \mathrm{~nm}$. Als Ergebnis erhielt man die Konzentration an Proteinen in $\mu \mathrm{g} / \mathrm{ml}$, die für weitere Untersuchungen in $\mu \mathrm{g} / \mu \mathrm{l}$ umgerechnet wurde. Anhand dieser Daten wurde die Menge an aqua bidest berechnet, die benötigt wird, um einheitlich konzentrierte Proben zu gewinnen.

\subsubsection{SDS-Polyacrylamid-Gelelektrophorese (SDS-Page)}

Die Polyacrylamid-Gelelektrophorese dient zur Auftrennung der Proteine nach ihrer Größe. Die Proteine binden an SDS (sodium dodecyl sulfate $=$ Natriumdodecylsulfat) und erhalten dadurch eine negative Ladung, die proportional zum Molekulargewicht des Proteins ist. Dadurch werden sie im Laufe der Elektrophorese entsprechend ihrer Ladung und demnach entsprechend ihrem Molekulargewicht aufgetrennt.

Gemäß dem diskontinuierlichen System nach Laemmli (1970) wurden ein 4\%iges Sammelgel und ein 12\%iges Trenngel verwendet. 
Mengenangaben für Trenngel (12\%):

$\begin{array}{ll}40 \% \text { Acryl } & 3,0 \mathrm{ml} \\ 1,5 \mathrm{M} \text { TRIS }(\mathrm{pH} 8,8) & 3,7 \mathrm{ml} \\ \mathrm{ddH}_{2} \mathrm{O} & 3,25 \mathrm{ml} \\ 20 \% \text { SDS } & 50 \mu \mathrm{l} \\ 10 \% \text { APS } & 50 \mu \mathrm{l} \\ \text { TEMED } & 5 \mu \mathrm{l} .\end{array}$

Mengenangaben für Sammelgel (4\%):

$\begin{array}{ll}40 \% \text { Acryl } & 300 \mu \mathrm{l} \\ 0,5 \mathrm{M} \text { TRIS }(\mathrm{pH} 6,8) & 380 \mu \mathrm{l} \\ \mathrm{ddH}_{2} \mathrm{O} & 2,3 \mathrm{ml} \\ 20 \% \text { SDS } & 15 \mu \mathrm{l} \\ 10 \% \text { APS } & 15 \mu \mathrm{l} \\ \text { TEMED } & 3 \mu \mathrm{l} .\end{array}$

Das Auftragsvolumen pro Geltasche betrug $30 \mu \mathrm{l}$. Es setzte sich zusammen aus $10 \mu \mathrm{l}$ Auftragspuffer (380 $\mu$ I SDS Reducing Buffer $+20 \mu$ l Mercaptoethanol), der anhand der Messergebnisse der photometrischen Analyse errechneten Menge der Probe in $\mu \mathrm{l}$ und der entsprechenden Menge aqua bidest in $\mu \mathrm{l}$.

Zusammensetzung des SDS Reducing Buffer:

$0,5 \mathrm{M}$ TRIS $(\mathrm{pH} 6,8) \quad 2,5 \mathrm{ml}$

$20 \%$ SDS $\quad 2 \mathrm{ml}$

$1 \%$ Bromphenolblau $0,2 \mathrm{ml}$

Glycerol $\quad 5 \mathrm{ml}$.

Die mit aqua bidest verdünnten Proben wurden mit dem Auftragspuffer vermischt und für 7 Minuten bei $+97^{\circ} \mathrm{C}$ inkubiert. Anschließend wurden die Proben kurz anzentrifugiert und auf Eis gestellt. Mit Hilfe von Gelloadertips wurden zunächst $5 \mu \mathrm{l}$ Proteingrößenmarker (Kaleidoscope ${ }^{\mathrm{TM}}$, Bio-Rad, München, Deutschland) in die randständigen Geltaschen pipettiert und anschließend je $30 \mu \mathrm{l}$ der Proben in die übrigen Taschen.

Die Elektrophorese erfolgte zunächst über ca. 15 Minuten bei 100 Volt, bis die Banden das Trenngel erreicht hatten. Anschließend folgten zwei Stunden bei 160 Volt. 


\subsubsection{Proteintransfer durch Western Blot}

Der Proteintransfer von den Polyacrylamidgelen auf eine Nitrocellulosemembran erfolgte in einer Mini Trans-Blot Cell (Bio-Rad, München, Deutschland).

Zur Vorbereitung wurden die Nitrocellulosemembran, Filterpapier und Fiberpads ca. 30 Minuten bei $+4^{\circ} \mathrm{C}$ in Blotpuffer eingeweicht.

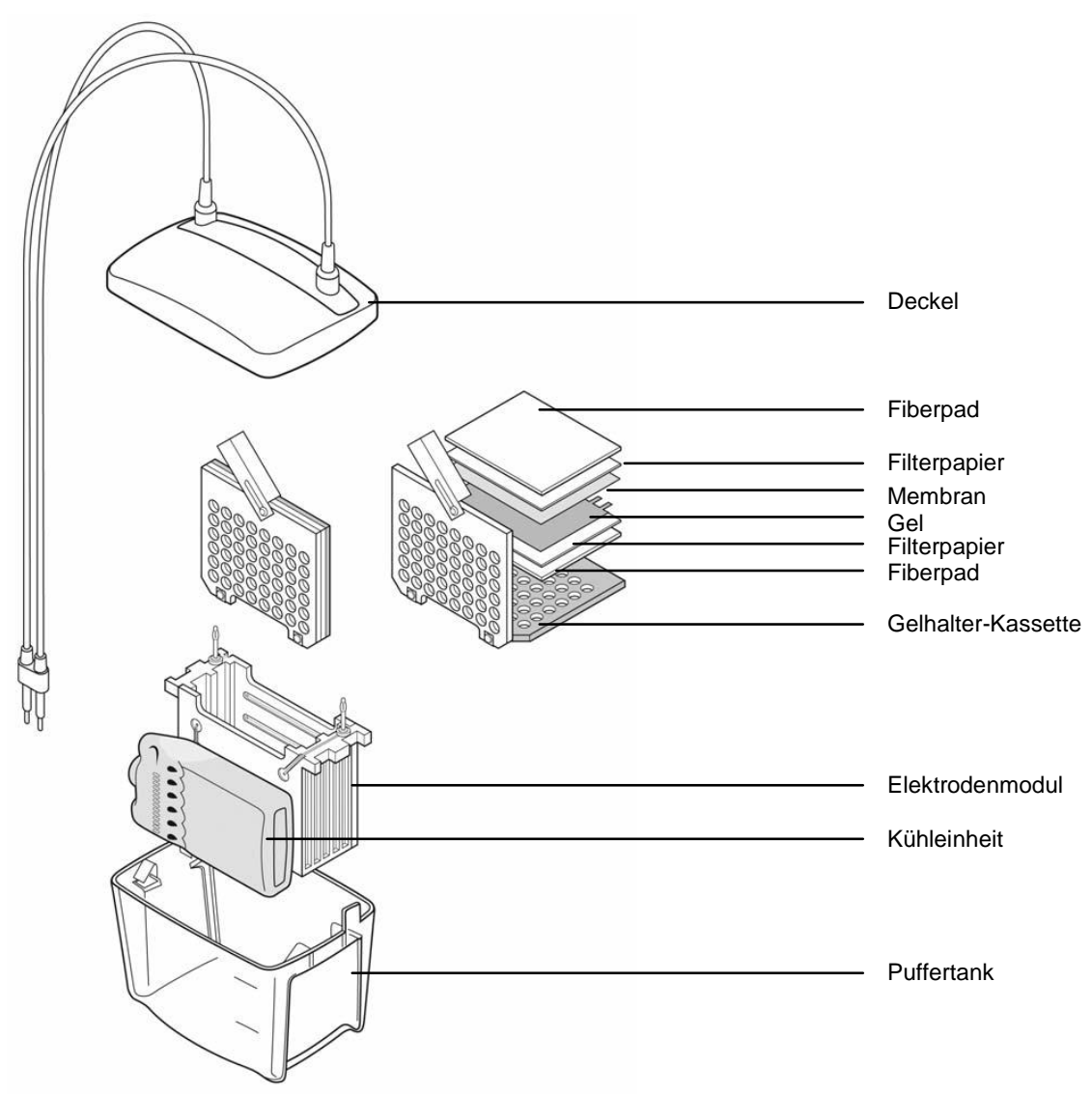

Abb. 8: Vorbereitung des Proteintransfers in der Mini Trans-Blot Cell (vgl. www3.bio-rad.com/cmc_upload/Literature/13280/M1703930.pdf)

Das Elektrodenmodul wurde beladen (Abb. 8), zusammen mit einer Kühleinheit in den Puffertank gestellt, und der Tank mit Blotpuffer aufgefüllt und in eine Styroporbox mit Eis gestellt.

Der Proteintransfer erfolgte bei $300 \mathrm{~mA}$ für drei Stunden. Nach Abschluss des Blotverfahrens konnte der Erfolg des Transfers anhand der gefärbten Größenmarker beurteilt werden.

\subsubsection{Unspezifischer Proteinnachweis (Ponceau-Rot-Färbung)}

Um nach Abschluss des Proteintransfers den Erfolg des Verfahrens zu kontrollieren, wurde die Nitrocellulose-Membran für ca. 5 Minuten bei Raumtemperatur mit PonceauRot gefärbt und anschließend so oft mit aqua bidest gespült, bis sich keine Farbe mehr 
löste. Zur Dokumentation wurde eine Farbkopie der gefärbten Membran hergestellt (Abb. 9).

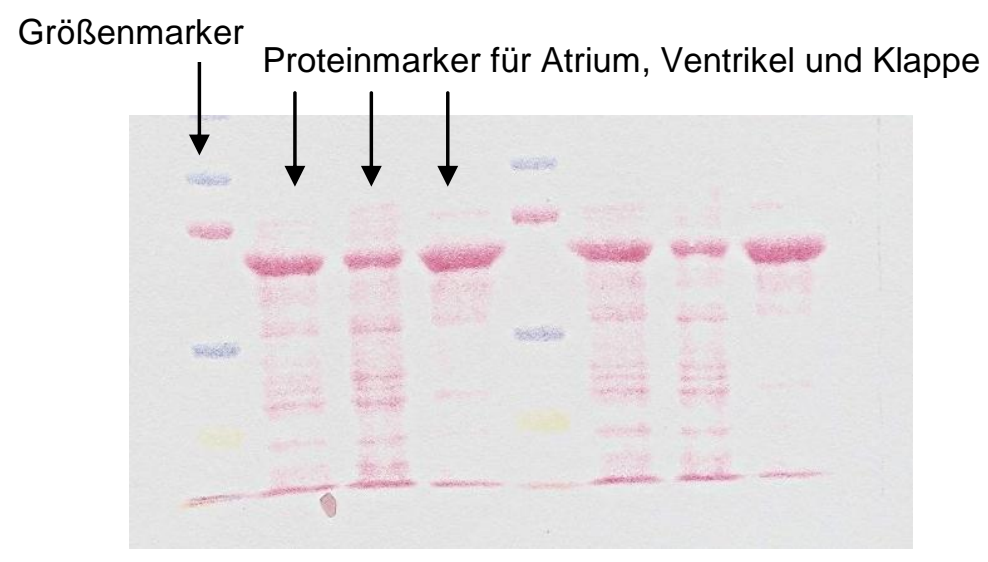

Abb. 9: Farbkopie der gefärbten Nitrocellulosemembran

Für die weitere Bearbeitung wurde die Membran zwischen der blauen (50 kDa) und der grünen Bande (37 kDa) durchtrennt, sodass sich auf einer Membran die Glycerinaldehyd-3-phosphat-Dehydrogenase (GAPDH) mit einer Molekülmasse von 34 kDa und auf der anderen das Lipopolysaccharid-bindende Protein (LBP) mit 58 kDa befand. Die Membranen wurden dann dreimal für zwei Minuten mit 1xTBS auf dem Schüttler gewaschen. Alle nachfolgenden hier beschriebenen Wasch- und Inkubationsschritte wurden ebenfalls auf dem Schüttler durchgeführt.

Herstellung von 10xTBS-Puffer:

TRIS $\quad 60,57 \mathrm{~g}$

$\mathrm{NaCl} \quad 87,66 \mathrm{~g}$

$\mathrm{pH} 7,6$

ad $1000 \mathrm{ml}$ aqua bidest.

Um 1xTBS-Puffer herzustellen, wurden $200 \mathrm{ml}$ des 10xTBS-Puffers mit $1800 \mathrm{ml}$ aqua bidest verdünnt.

\subsubsection{Blocken}

Um die freien Bindungsstellen zu blockieren, wurde die Membran für 15 Minuten bei Raumtemperatur in $10 \mathrm{ml}$ Starting Block (TBS) Blocking Buffer (Thermo Scientific, Bonn, Deutschland) inkubiert. Es folgten fünf Waschschritte für je fünf Minuten mit 1xTTBS. Zur Herstellung von 1xTTBS Puffer wurden $200 \mathrm{ml}$ des 10xTBS mit $1800 \mathrm{ml}$ aqua bidest verdünnt und $2 \mathrm{ml}$ Tween20 hinzu gegeben. 


\subsubsection{Immundetektion}

\subsubsection{Primärer Antikörper: big42-LBP}

Der erste Antikörper (big42 antibody to human LBP, Biometec GmbH, Greifswald, Deutschland) wurde 1:1000 mit Verdünnungslösung (5 ml Starting Block Solution, 0,05 $\mathrm{ml}$ Tween 20 und 94,95 $\mathrm{ml}$ 1xTBS) verdünnt.

Die Inkubation der Membran mit dem ersten Antikörper erfolgte über Nacht bei $+4^{\circ} \mathrm{C}$. Nach Entfernung der Antikörperlösung am darauf folgenden Tag wurde die Membran zunächst 15 Minuten und anschließend vier Mal 10 Minuten mit 1xTTBS gewaschen, um ungebundene oder nur schwach gebundene Antikörper zu entfernen.

\subsubsection{Glycerinaldehyd-3-phosphat-Dehydrogenase (GAPDH)}

Die GAPDH (Hy-Test Ltd., Turku, Finnland) dient als Haushaltsgen, welches unabhängig von Zelltyp, Zellstadium und äußeren Einflüssen exprimiert wird (Koolman und Röhm 2009).

Die GAPDH wurde mit der oben genannten Verdünnungslösung im Verhältnis 1:300.000 verdünnt. Die entsprechende Membran wurde auch hier über Nacht bei $+4^{\circ} \mathrm{C}$ inkubiert und am darauf folgenden Tag entsprechend gewaschen.

\subsubsection{Sekundärantikörper: goat anti-mouse HRP}

Der zweite Antikörper (goat anti mouse HRP, Thermo Fisher Scientific, Waltham, USA) bindet spezifisch an den ersten Antikörper. Er wurde 1:25.000 mit der Verdünnungslösung verdünnt und die Membranen darin zwei Stunden bei Raumtemperatur bei 30 rpm inkubiert. Anschließend wurden die Membranen ein Mal 15 Minuten und dann vier Mal für jeweils 10 Minuten mit 1xTTBS gewaschen.

\subsubsection{Chemilumineszenz}

An den zweiten Antikörper ist das Enzym HRP (horseradish peroxidase) gekoppelt, das die Oxidation von Luminol katalysiert, wodurch eine Lumineszenz erreicht wird. Als Chemilumineszenz-Präparat wurde das SuperSignal West Pico Chemiluminescent Substrate (Thermo Scientific, Bonn, Deutschland) verwendet.

Die Membranen wurden 5 Minuten in einer lichtundurchlässigen Box in der Lösung inkubiert und anschließend in die Filmkassette gelegt.

Nach 30 Minuten wurden Röntgenfilme (SuperRX Fuji Medical X-Ray Film) jeweils 30 Sekunden, 1 Minute und 3 Minuten belichtet und entwickelt (Abb. 10). 


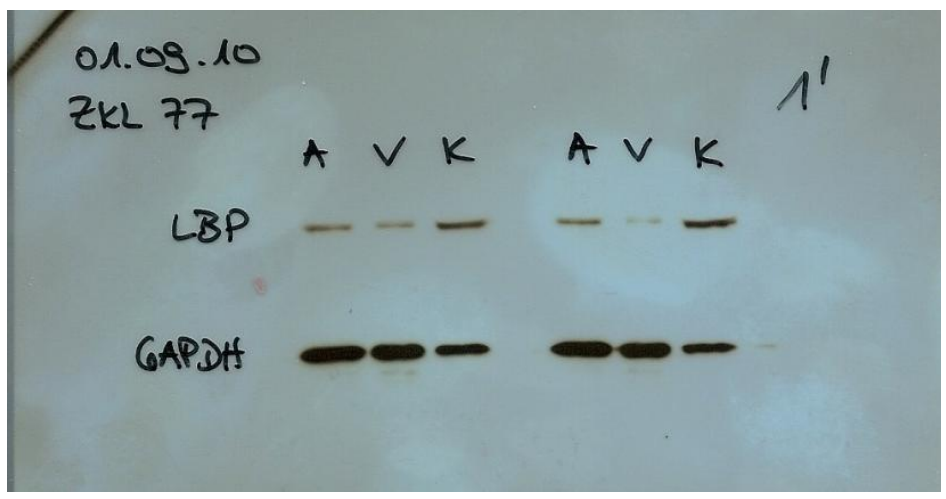

Abb. 10: Entwickelter Röntgenfilm nach 1 min. Belichtung

\subsubsection{Auswertung der Banden für big42-LBP und GAPDH}

Zur Digitalisierung der exponierten Filme wurden diese mit Hilfe des BioDocAnalyzeGerätes eingescannt. Die densitometrische Auswertung der Banden für big42-LBP und für GAPDH erfolgte dann mittels der entsprechenden Software (Abb. 11).

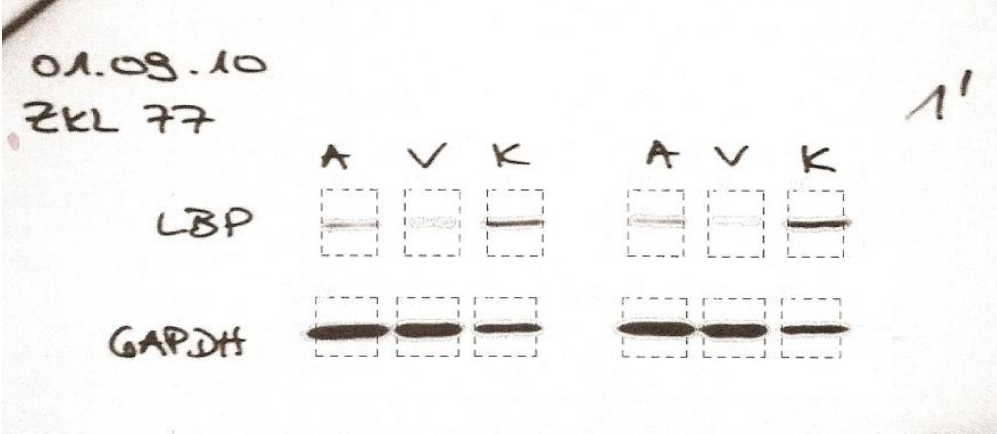

Abb. 11: Screenshot der Auswertung

Nachdem so die Ausprägung des Lipopolysaccharid-Binding-Protein-spezifischen Antikörpers big42 sowie der Glycerinaldehyd-3-phosphat-Dehydrogenase (GAPDH) für Atrium, Ventrikel und Klappe quantitativ erfasst war, wurden die Werte dokumentiert und anschließend das Verhältnis der absoluten big42-Werte zu denen der GAPDH errechnet. 


\subsection{Aufbereitung der Blutproben im Labor}

\subsubsection{Isolierung und Aufreinigung der Leukozytenfraktion (Buffy Coat)}

Um die Leukozyten und Thrombozyten (sog. Buffy Coat) zu isolieren, wurden je $5 \mathrm{ml}$ EDTA-Blut in Zentrifugenröhrchen mit $4 \mathrm{ml}$ Ficoll-Lösung gegeben und 20 Minuten bei $+4^{\circ} \mathrm{C}$ zentrifugiert (2200 rpm). Als Ergebnis erhielt man vier Phasen (Tab. 11).

\begin{tabular}{|l|l|}
\hline Phase & Inhalt \\
\hline obere Phase & Plasma \\
\hline Zwischenschicht (trüb) & Buffy Coat \\
\hline mittlere klare Phase & Ficoll-Lösung \\
\hline untere Schicht (rot) & Erythrozyten \\
\hline
\end{tabular}

Tab. 11: Vier Phasen der Buffy-Coat-Aufreinigung

Das Plasma wurde für eventuelle spätere Untersuchungen bei $-85^{\circ} \mathrm{C}$ eingefroren. Der Buffy Coat wurde in ein neues Zentrifugenröhrchen überführt und zwei Waschschritten unterzogen. Diese erfolgten durch Mischen mit je $5 \mathrm{ml}$ 1xPBS-Puffer und Zentrifugieren für 10 Minuten bei $+4^{\circ} \mathrm{C}$ und $1000 \mathrm{rpm}$. Zwischen den Waschschritten und danach wurde der Überstand abpipettiert und verworfen. Der Buffy Coat wurde anschließend in ein 1,5 ml-Eppendorf-Cup mit $200 \mu \mathrm{l}$ 1xPBS gegeben.

\subsubsection{DNA-Isolierung mit QIAamp ${ }^{\circledR}$ DNA Mini Kit}

Die DNA-Extraktion erfolgte mit Hilfe des QIAamp DNA Mini Kits (Fa. Qiagen, Hilden, Deutschland) gemäß der mitgelieferten Bedienungsanleitung. Hierbei wird die Zellmembran mit Hilfe einer Proteinase zersetzt, die DNA mittels Ethanolfällung extrahiert und durch Zentrifugieren an die Silicagel-Membran einer Spinnsäule gebunden. Anschließend erfolgen zwei Waschschritte mit unterschiedlichen Waschpuffern, um Kontaminationen zu beseitigen. Zum Schluss wird die DNA mittels eines Extraktionspuffers eluiert.

Die einzelnen Arbeitsschritte sind in Tabelle 12 und Abbildung 12 aufgeführt. 


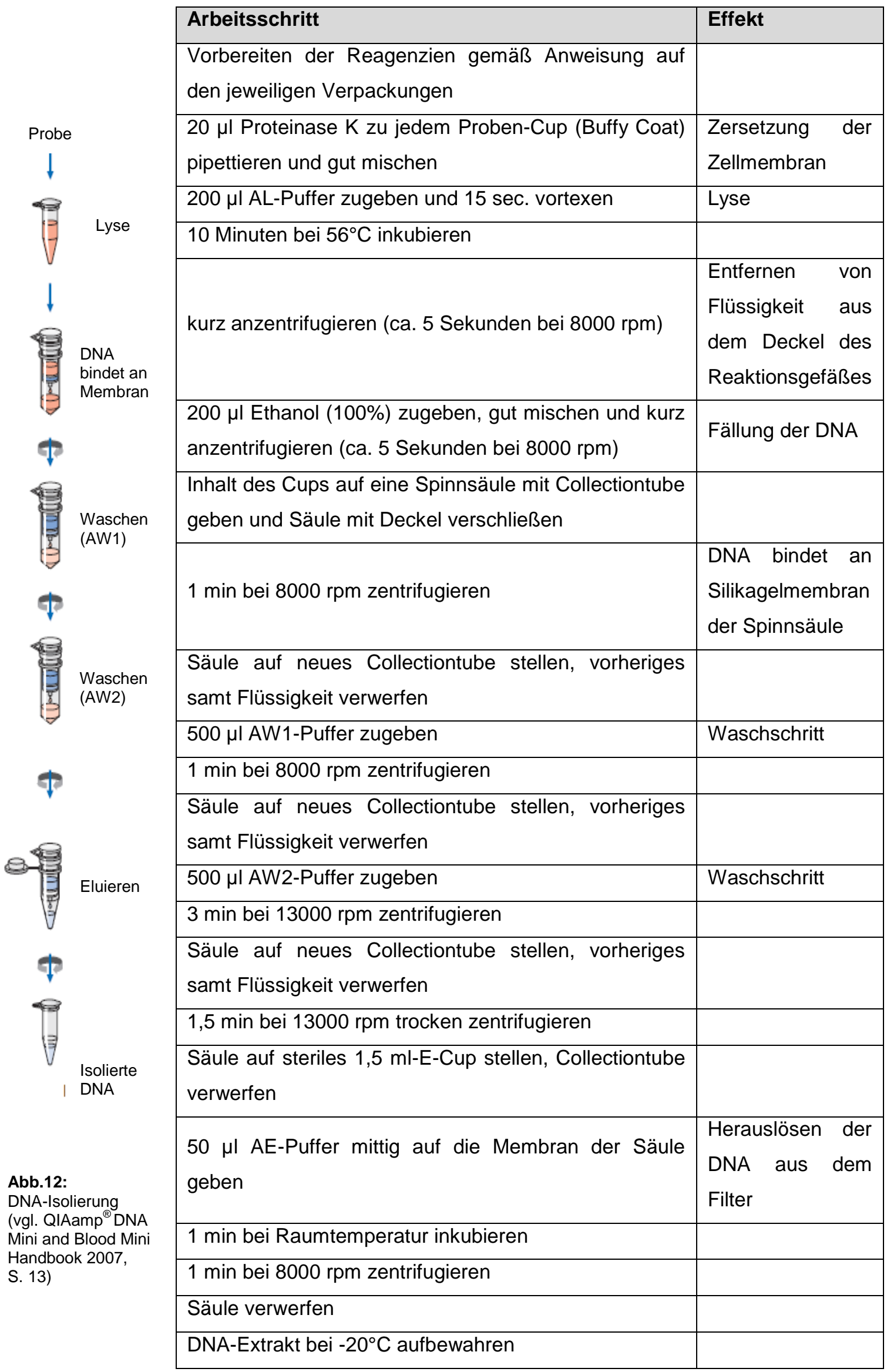

Tab. 12: Arbeitsschritte zur DNA-Isolierung und deren Effekte (QIAamp ${ }^{\circledR}$ DNA Mini and Blood Mini Handbook 2007) 


\subsection{Analyse der DNA}

\subsubsection{Amplifikation mit Biotin-markierten Primern}

Die Amplifikation der DNA erfolgte mit Hilfe des GenoType ${ }^{\circledR} \mathrm{IL}-1-T e s t s$ (HainLifescience, Nehren, Deutschland) in Form einer Polymerase-Kettenreaktion (PCR), wobei als DNA-Polymerase die HotStar Taq plus (Qiagen, Hilden, Deutschland) verwendet wurde.

Zunächst erfolgte die Herstellung des Amplifikations-Mixes.

Mengenangaben pro Ansatz:

$\begin{array}{ll}\text { Primer-/Nukleotid-Mix } & 35 \mu \mathrm{l} \\ \text { 10fach Polymerase-Puffer } & 5 \mu \mathrm{l} \\ \text { MgCl}_{2} \text {-Lösung } & 2 \mu \mathrm{l} \\ \text { DNA-Polymerase } & 0,5 \mu \mathrm{l} \\ \text { Wasser } & 3 \mu \mathrm{l} \\ \text { DNA-Lösung } & 5 \mu \mathrm{l} .\end{array}$

Sinnvoll ist die Herstellung eines Master-Mixes, der alle oben aufgeführten Reagenzien bis auf die DNA-Lösung enthält. Die Gesamtmenge errechnet man anhand der Anzahl der zu untersuchenden Proben zuzüglich der Zahl der Kontrollproben. Bei der Kontaminationskontrolle wird statt DNA-Lösung Wasser hinzugefügt, der PositivKontrolle wird die mitgelieferte Kontroll-DNA-Lösung zugegeben. Es wurden je $45 \mu \mathrm{l}$ des Master-Mixes in vorbereitete PCR-Reaktionsgefäße pipettiert. Nach Zugabe der jeweiligen DNA-Lösung erfolgte die Polymerase-Kettenreaktion nach folgendem Protokoll (Tab. 13):

\begin{tabular}{|c|c|c|}
\hline $5 \min$ & $95^{\circ} \mathrm{C}$ & 1 Zyklus \\
\hline $30 \mathrm{sec}$ & $95^{\circ} \mathrm{C}$ & \multirow{2}{*}{10 Zyklen } \\
\hline $2 \min$ & $58^{\circ} \mathrm{C}$ & \\
\hline $25 \mathrm{sec}$ & $95^{\circ} \mathrm{C}$ & \multirow{3}{*}{20 Zyklen } \\
\hline $40 \mathrm{sec}$ & $53^{\circ} \mathrm{C}$ & \\
\hline $40 \mathrm{sec}$ & $70^{\circ} \mathrm{C}$ & \\
\hline $8 \min$ & $70^{\circ} \mathrm{C}$ & 1 Zyklus \\
\hline
\end{tabular}

Tab. 13: Protokoll für die Polymerase-Kettenreaktion

Die Amplifikationsprodukte wurden bis zur weiteren Verwendung bei $-20^{\circ} \mathrm{C}$ eingefroren. 


\subsubsection{Hybridisierung}

Die Hybridisierung erfolgte ebenfalls mit Hilfe des GenoType ${ }^{\circledR} \mathrm{IL}-1-$ Tests. Die Substrate wurden entsprechend der Gebrauchsanweisung vorbereitet.

\subsubsection{Denaturierung der Amplifikationsprodukte}

Zur Denaturierung wurden für jede zu untersuchende Probe jeweils $20 \mu \mathrm{l}$ des Denaturierungsreagenz mit je $20 \mu \mathrm{l}$ des entsprechenden Amplifikats in einer Wannenkavität der mitgelieferten Inkubationswanne gut gemischt und fünf Minuten bei Raumtemperatur inkubiert.

\subsubsection{Hybridisierung an membrangebundene Sonden}

Je $1 \mathrm{ml}$ des vorgewärmten Hybridisierungspuffers wurde zugegeben und in jede Kavität ein zuvor beschrifteter Membranstreifen gelegt. Nach einer 30minütigen Inkubation bei $45^{\circ} \mathrm{C}$ im Schüttelwasserbad (TwinCubator ${ }^{\circledR}$, Hain Lifescience, Nehren, Deutschland) wurde der Hybridisierungspuffer vollständig entfernt.

\subsubsection{Entfernen aller unspezifisch gebundenen Amplifikate}

Je $1 \mathrm{ml}$ vorgewärmte Stringent-Waschlösung wurde in die Kavitäten gegeben und 15 Minuten bei $45^{\circ} \mathrm{C}$ im TwinCubator inkubiert. Die Waschlösung wurde anschließend vollständig entfernt. Alle weiteren Schritte erfolgten bei Raumtemperatur.

Die Membranstreifen wurden dann mit je $1 \mathrm{ml}$ Rinse-Lösung für 1 Minute unter leichtem Schütteln auf dem Twincubator gewaschen und die Rinse-Lösung anschließend vollständig entfernt.

\subsubsection{Zugabe eines Streptavidin/Alkalische Phosphatase-Komplexes}

Daraufhin erfolgte die Zugabe von je $1 \mathrm{ml}$ des verdünnten Konjugates (Streptavidinkonjugierte Alkalische Phosphatase) und eine 30minütige Inkubation. Nach Abschütten des Konjugats folgten drei einminütige Waschschritte, die ersten beiden mit je $1 \mathrm{ml}$ Rinse-Lösung und der letzte mit je $1 \mathrm{ml}$ destilliertem Wasser.

\subsubsection{AP-vermittelte Farbreaktion}

Nach Entfernen des Wassers wurde je $1 \mathrm{ml}$ verdünntes Substrat zu den Membranstreifen gegeben und lichtgeschützt ohne Schütteln inkubiert. Die Inkubationszeit variiert und wird anhand der Farbreaktion individuell bestimmt. Um die Substratreaktion zu stoppen, wurden die Membranstreifen zweimal kurz mit destilliertem Wasser gewaschen und anschließend zum Trocknen auf saugfähiges Papier gelegt. 


\subsubsection{Auswertung}

Die Auswertung der Membranstreifen erfolgte durch Anlegen der mitgelieferten Schablone, die an der Konjugatkontrollbande ausgerichtet wurde (Abb. 13).

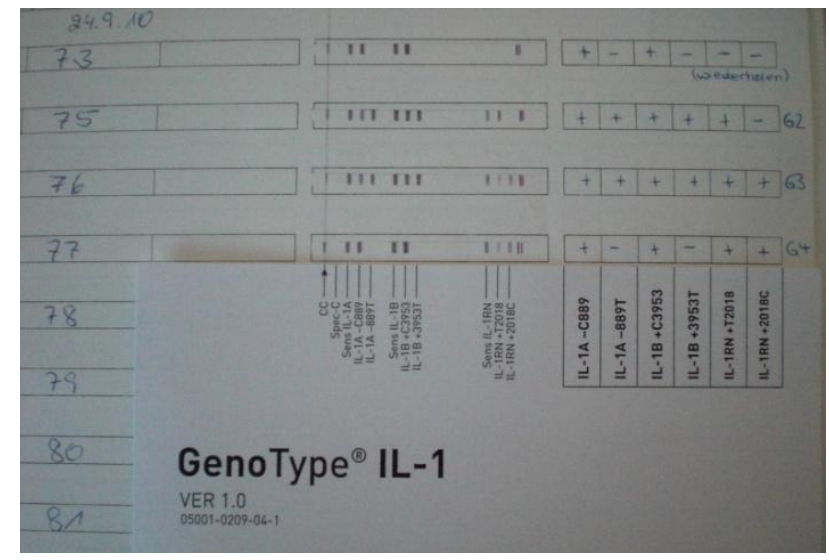

Abb. 13: Auswertung mit Schablone und Auswertungsbogen

Die Ergebnisse wurden in mitgelieferte Auswertungsbögen eingetragen und die Bandenmuster mit Hilfe einer Übersicht interpretiert. Zu beachten ist, dass die Konjugatkontrollbande (CC) sowie die drei Sensitivitätskontrollbanden (Sens IL-1A, Sens IL-1B und Sens IL-1RN) immer entwickelt sein müssen. Die Spezifitätskontrollbande (Spec-C) sollte sich hingegen nicht entwickeln, da dies ein Zeichen für suboptimale unspezifische Reaktionsbedingungen wäre.

Durch verschiedene Kombinationen von Polymorphismen der Gene IL-1A, IL-1B und IL-1RN ermöglicht der GenoType ${ }^{\circledR} \mathrm{IL}-1$-Test so eine Zuordnung des Patienten zu einem der vier vom Hersteller angegebenen Genotypmuster mit entsprechendem Risiko für die Entstehung einer progressiven Parodontitis.

Zusätzlich wurde ermittelt, ob der Patient hetero- oder homozygoter Merkmalsträger des IL-1A-, IL-1B- und IL-1RN-Gens ist.

\subsection{Statistische Auswertung}

Sämtliche Daten und Untersuchungsergebnisse der Patienten wurden anonymisiert in dem Tabellenkalkulationsprogramm Excel 2007 (Microsoft) archiviert. Die statistische Analyse erfolgte mit Hilfe des Programms Statistica 9.0 (StatSoft) in Abstimmung mit der Abteilung Medizinische Statistik der Universitätsmedizin Göttingen.

Der statistische Vergleich zwischen big42-LBP und dem Schweregrad der Parodontitis, zwischen big42-LBP und dem PBI sowie die Einflüsse von Alter und BMI auf big42LBP bzw. auf den PBI wurden mit einem t-Test für zwei unabhängige Gruppen mit getrennter Varianz durchgeführt. Die Assoziationen zwischen Genotyp und PBI und 
zwischen Genotyp und Schweregrad der Parodontitis wurden mit einem MannWhitney-U-Test untersucht. Um eine mögliche Korrelation zwischen big42-LBP und dem Genotyp festzustellen, wurde ein Kruskal-Wallis-Test angewandt. Die Einflüsse von Geschlecht und Rauchverhalten auf den Schweregrad der Parodontitis bzw. den PBI wurden anhand eines Chi-Quadrat-Tests untersucht. Alle Tests wurden mit einem Signifikanzniveau von $p<0,05$ durchgeführt. Da es sich bei der vorliegenden Studie um eine Pilotstudie handelt, wurde keine Adjustierung für multiples Testen vorgenommen. Die Ergebnisse sind entsprechend zu interpretieren: Signifikante Zusammenhänge müssen im Rahmen von Folgestudien noch umfassend analysiert und statistisch validiert werden.

Da nur wenige Patienten des Kollektivs unter die Kategorien keine oder milde bzw. leichte Parodontitis fielen, wurden diese beiden zu Paro-Gruppe 1 zusammengefasst, da eine statistische Auswertung sonst nicht möglich gewesen wäre. Die Patienten mit schwerer Parodontitis bilden die Paro-Gruppe 2. Ähnliches gilt für den PBI und den Genotyp. Bei dem PBI wurden Grad 0 und 1 zu PBI-Gruppe 1 zusammengefasst und Grad 2 und 3 zu PBI-Gruppe 2. Für die Genotypmuster gilt: Genotypmuster 0 entspricht Genotyp-Gruppe 0, Genotypmuster 1 entspricht Genotyp-Gruppe 1 und Genotypmuster 2 und 3 bilden gemeinsam Genotyp-Gruppe 2. 


\section{$4 \quad$ Ergebnisse}

\subsection{Beschreibung des Patientenkollektivs}

Im Zeitraum der durchgeführten Untersuchungen kamen 79 Patienten als potentielle Probanden in Betracht. 49 Patienten konnten entsprechend der Ausschlusskriterien nicht an der Studie teilnehmen und wurden nach Durchsicht der Patientenakten nicht untersucht. Von den insgesamt 30 untersuchten Patienten waren $33 \%$ weiblich $(n=10)$ und 67\% männlich ( $n=20$ ). Der jüngste Patient war zum Zeitpunkt der Untersuchung 38 Jahre alt, der älteste 80 Jahre. Das Durchschnittsalter aller Patienten betrug 67,7 $\pm 9,3$ Jahre. Einen Überblick über die Alters- und Geschlechtsverteilung gibt Abbildung 14.

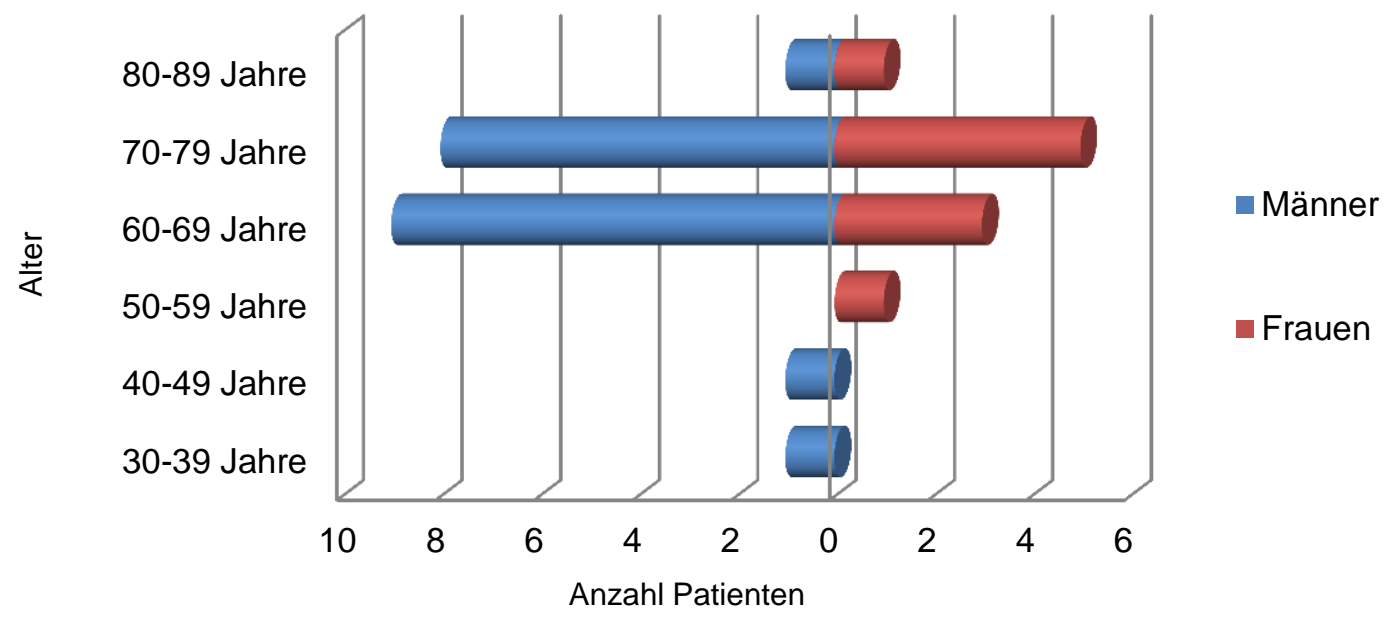

Abb. 14: Alters- und Geschlechtsstruktur des Patientenkollektivs

Unter den Patienten befanden sich 22 Nichtraucher (73\%) und 8 Raucher (27\%). Anhand der Angaben zu Dauer des Nikotinkonsums und Anzahl der täglich gerauchten Zigaretten konnte für die Raucher ein durchschnittlicher Wert an Pack years von 27,2 $\pm 21,8$ ermittelt werden. Abbildung 15 zeigt das Rauchverhalten der Probanden nach Geschlecht differenziert.

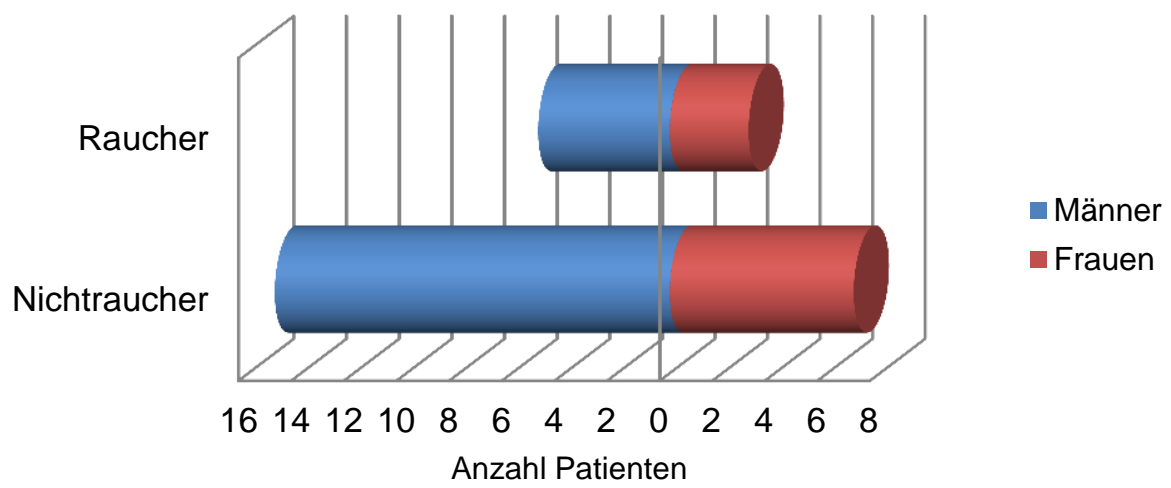

Abb. 15: Rauchverhalten nach Geschlecht differenziert 
Der durchschnittliche Body-Mass-Index der Patienten lag bei $29,1 \pm 4,6$. Lediglich 8 Patienten wiesen laut Gewichtsklassifikation der WHO von 2006 anhand des BMI Normalgewicht auf. Weitere 8 Patienten litten unter Übergewicht und 14 Patienten waren als adipös einzustufen (Abb. 16).

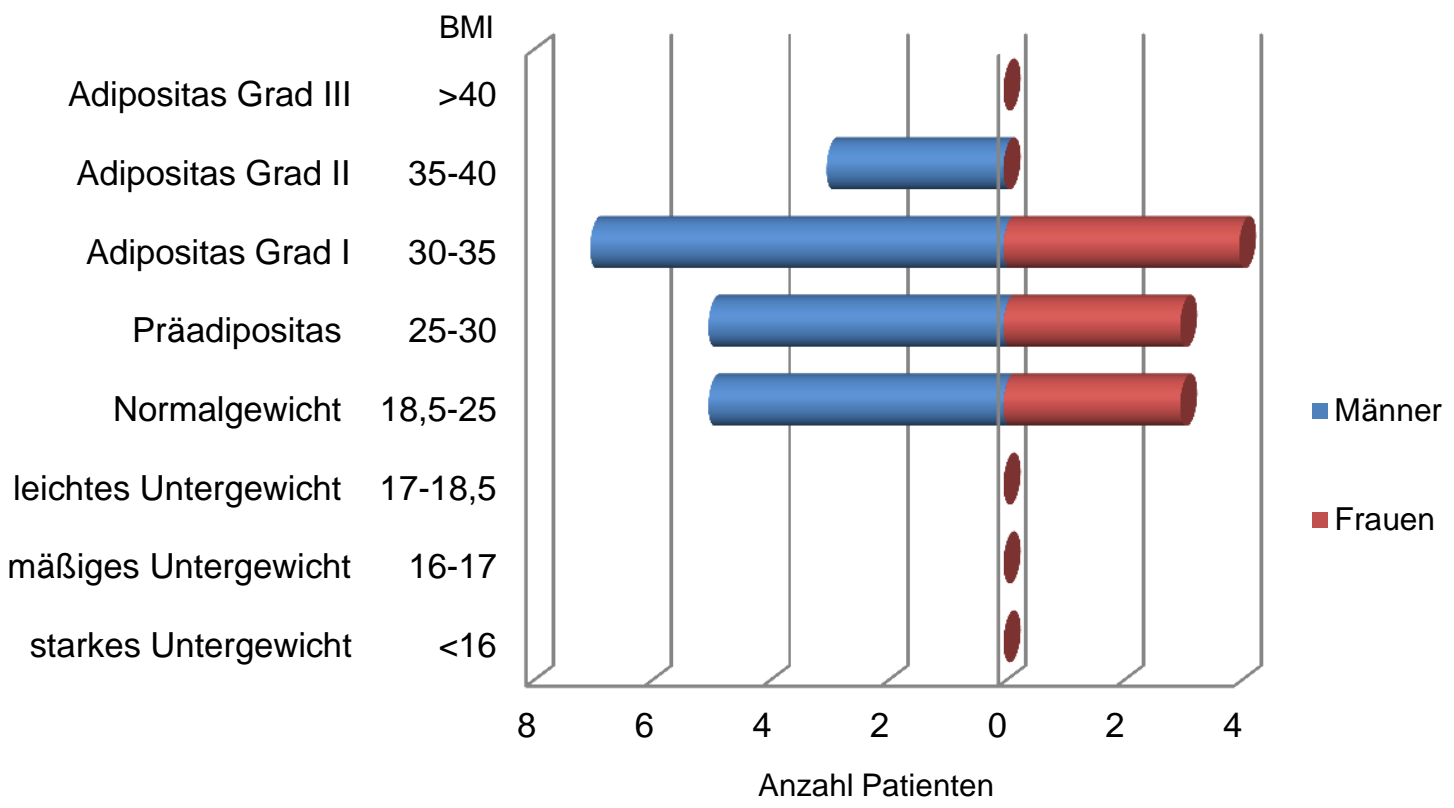

Abb. 16: Body-Mass-Index (Einteilung nach WHO 2006)

Die Blutwerte für Leukozyten, Thrombozyten und C-reaktives Protein (CRP) stellten sich wie in Tabelle 14 zu sehen dar.

\begin{tabular}{|l|l|l|l|l|}
\hline Blutparameter & Mittelwert \pm SD & Minimum & Maximum & Normbereich \\
\hline Leukozyten & $8,5 \pm 3,2 \times 10^{3} / \mu \mathrm{l}$ & $3,8 \times 10^{3} / \mu \mathrm{l}$ & $15,8 \times 10^{3} / \mu \mathrm{l}$ & $4,0-11,0 \times 10^{3} / \mu \mathrm{l}$ \\
\hline Thrombozyten & $183,4 \pm 63,5 \times 10^{3} / \mu \mathrm{l}$ & $76, \times 10^{3} / \mu \mathrm{l}$ & $313,0 \times 10^{3} / \mu \mathrm{l}$ & $150-350 \times 10^{3} / \mu \mathrm{l}$ \\
\hline P-CRP & $58,7 \pm 76,4 \mathrm{mg} / \mathrm{l}$ & $2,0 \mathrm{mg} / \mathrm{l}$ & $247,6 \mathrm{mg} / \mathrm{l}$ & $\leq 8,0 \mathrm{mg} / \mathrm{l}$ \\
\hline
\end{tabular}

${ }^{1)}$ Normwerte des Zentrallabors, Abteilung Klinische Chemie, Universitätsmedizin Göttingen

Tab. 14: Durchschnittswerte der Blutparameter

Die Leukozyten und Thrombozyten bewegten sich überwiegend im Bereich der Normwerte. Der Wert des C-reaktiven Proteins lag bei 16 Patienten (53\%) im Normbereich ( $\leq 8 \mathrm{mg} / \mathrm{l})$, bei 3 Patienten (10\%) war der Wert nur geringfügig erhöht und bei 11 Patienten (37\%) lag ein deutlich erhöhter P-CRP-Wert $>100 \mathrm{mg} / \mathrm{l}$ vor.

Bei den kardialen Diagnosen überwogen die Aortenklappenstenosen $(n=25)$ und -insuffizienzen ( $n=7)$. Außerdem litt ein Großteil der Patienten $(n=20)$ unter arterieller Hypertonie. Abbildung 17 zeigt alle gestellten kardialen Diagnosen. Jeweils $3 \%$ der Patienten litten unter Herzrhythmusstörung, Mitralvitium, ACS (Akutes Koronar- 
syndrom), NSTEMI (Nicht-ST-Strecken-Elevations-Myokardinfarkt), linksventrikulärer Funktionseinschränkung, hypertensiver Herzerkrankung, Septumhypertrophie oder Z.n. Infarkt. 7\% der Patienten waren an Trikuspidalklappeninsuffizienz, Angina Pectoris (AP), instabiler AP-Symptomatik, diastolischer Dysfunktion oder STEMI (ST-StreckenElevations-Myokardinfarkt) der Hinterwand erkrankt. Bei je 10\% wurden ein Aortenvitium, eine Koronarsklerose ohne signifikante Stenose, 2-Gefäß-KHK oder Z.n. perkutaner transluminaler koronarer Angioplastie (PTCA) diagnostiziert. In jeweils 17\% der Fälle konnte Vorhofflimmern, 3- bzw. 1-Gefäß-KHK, Mitralklappeninsuffizienz oder ein Aneurysma festgestellt werden. $23 \%$ der Patienten litten unter einer Aortenklappeninsuffizienz, 67\% an arterieller Hypertonie und bei $83 \%$ der Patienten wurde eine Aortenklappenstenose diagnostiziert.

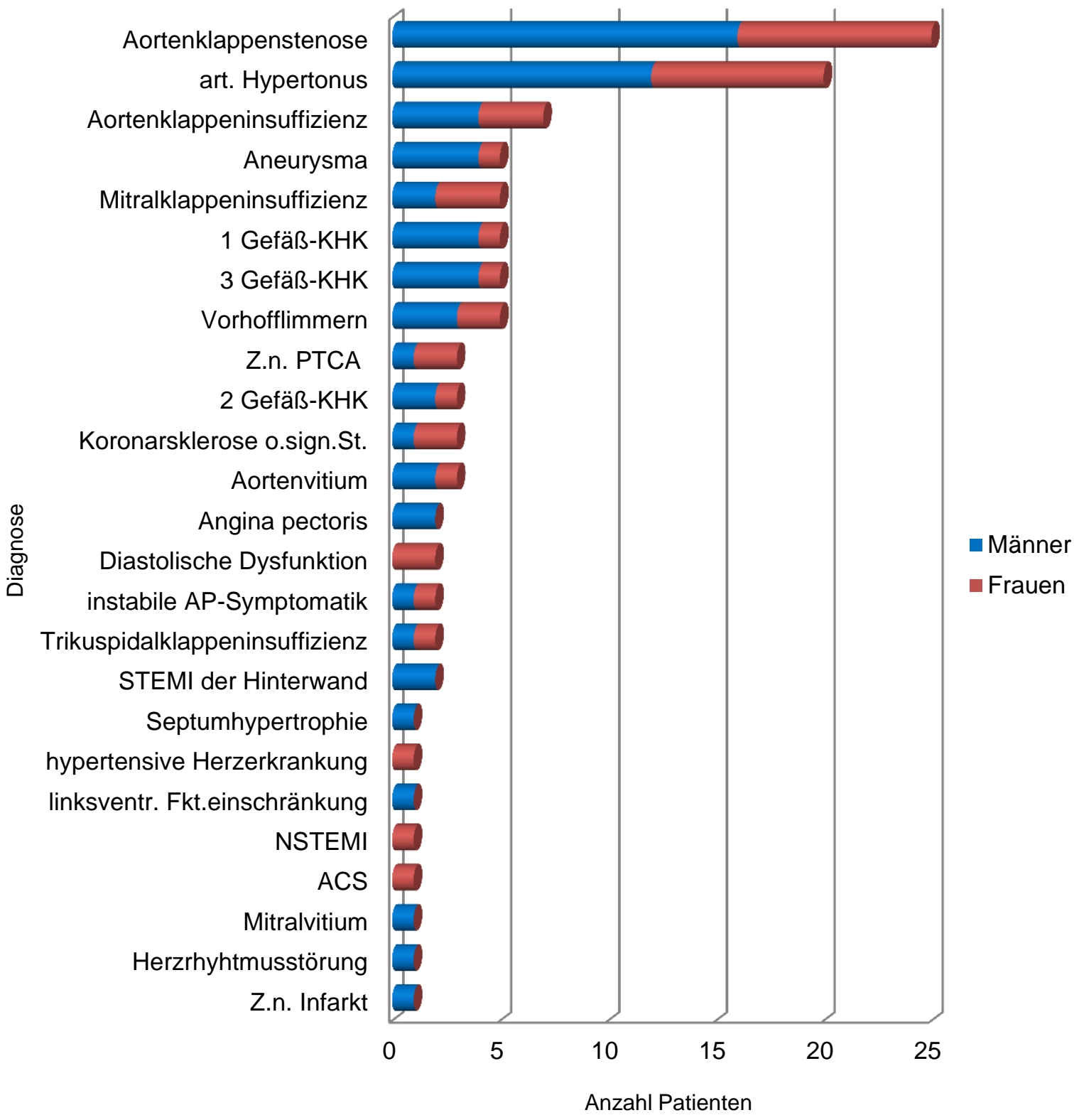

Abb. 17: Kardiale Diagnosen 
Neben den kardialen Erkrankungen lagen bei 29 von 30 Probanden weitere Allgemeinerkrankungen bzw. Risikofaktoren vor (Abb. 18). Bei jeweils $3 \%$ der Patienten konnten eine Polyneuropathie, Neurodermitis, Z.n. Colon-Karzinom, Z.n. Alkoholabusus, Z.n. Thyreoidektomie, Z.n. Cholecystektomie, Z.n. Appendektomie, Bandscheibenvorfall, Z.n. Splenektomie, Epilepsie, Magenulcus, Gastritis, kompensierte Niereninsuffizienz oder Z.n. Apoplex diagnostiziert werden. 7\% litten unter Osteoporose oder Z.n. Leistenbruch, 10\% an Hyperthyreose und 17\% an Niereninsuffizienz oder rheumatischer Arthritis. Bei jeweils 27\% der Patienten wurden Adipositas oder Diabetes mellitus Typ II festgestellt. 37\% waren an Hyperlipoproteinämie und $60 \%$ an Hypertonie erkrankt.

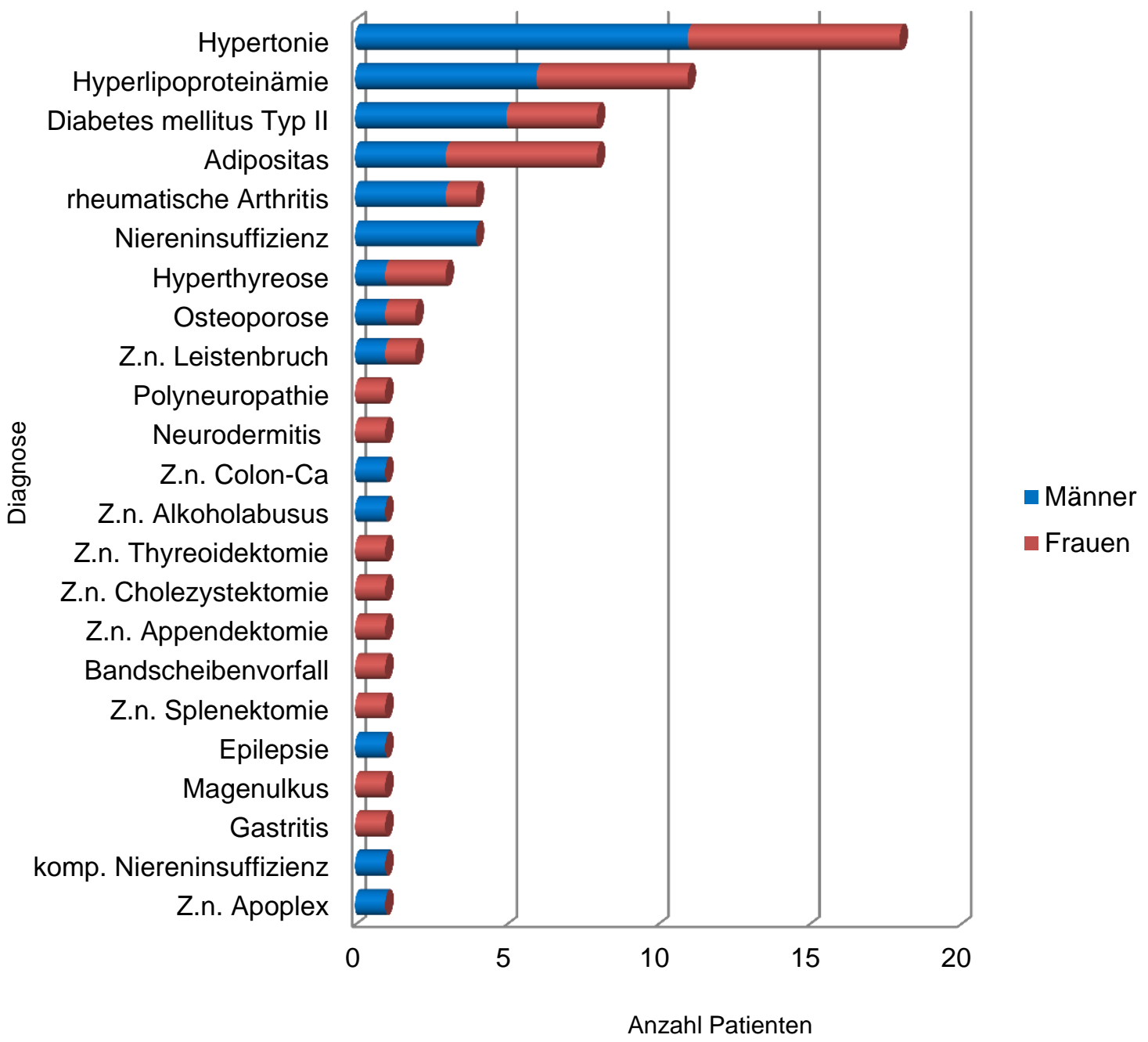

Abb. 18: Sonstige Diagnosen

Entsprechend den vorliegenden Erkrankungen stellte sich die medikamentöse Therapie der Patienten dar. Jeweils 3\% der Patienten nahmen keine Medikamente, Atemwegstherapeutika, Immunmodulatoren oder Antirheumatika ein. 
$7 \%$ bekamen Kortikosteroide und je 13\% Schilddrüsenmedikamente oder Allopurinol verabreicht. $20 \%$ nahmen Analgetika und $23 \%$ orale Antidiabetika oder Vitaminpräparate ein. Gemäß der kardialen Erkrankungen der Patienten wurden 7\% mit einem Vasodilator, 17\% mit Calciumantagonisten, 27\% mit Protonenpumpen-blockern oder Angiotensin-II-Antagonisten, 37\% mit ACE-Hemmern, 40\% mit Antikoagulantien, 43\% mit Thrombozytenaggregationshemmern, 57\% mit Diuretika und 60\% mit Betablockern behandelt. Außerdem bekamen 60\% Cholesterin-Synthese-Hemmer verabreicht. Eine Übersicht zeigt Abbildung 19.

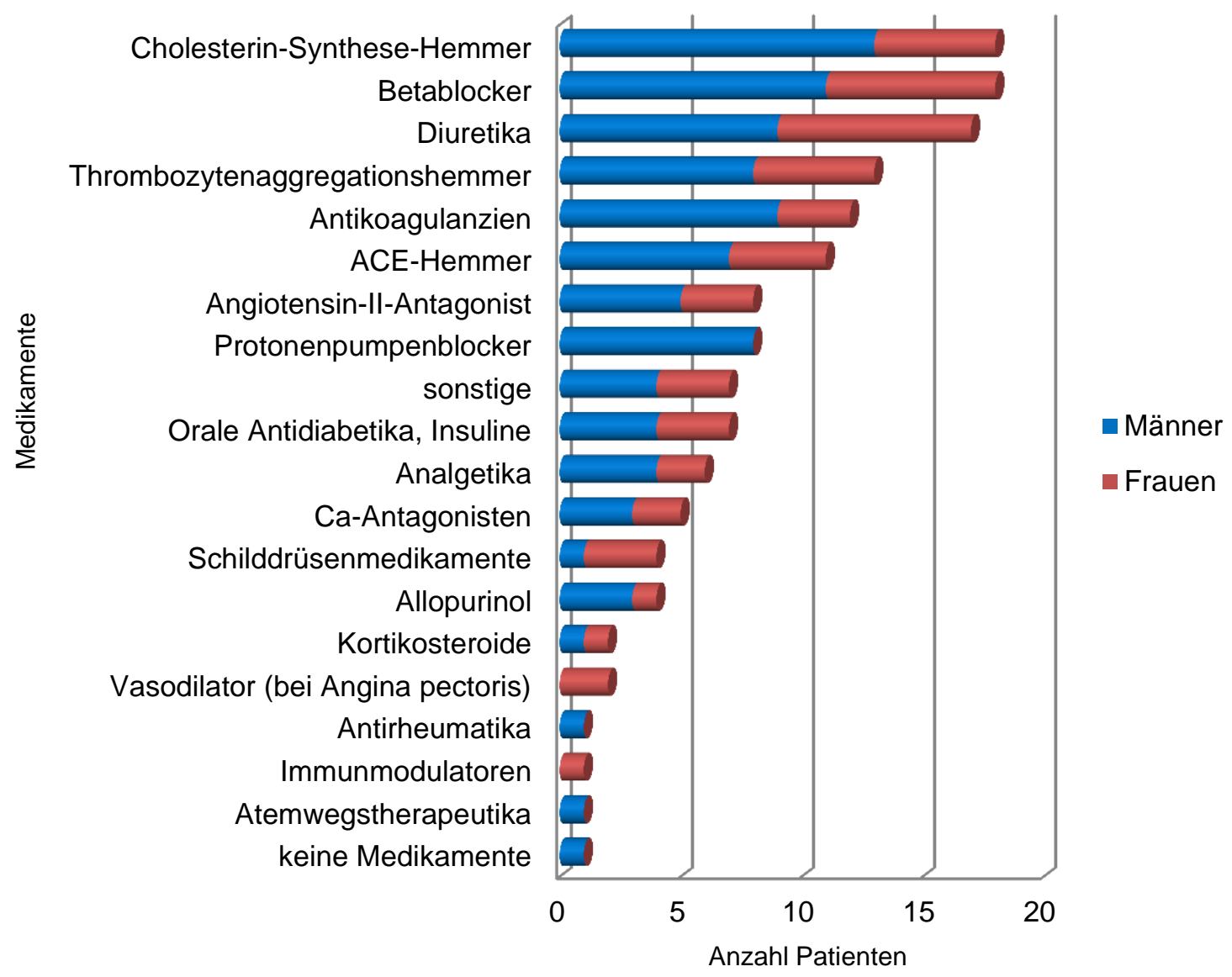

Abb. 19: Übersicht über Medikamente

Im Anamnesegespräch am Tag der Untersuchung gaben 10 Patienten (33\%) an, in den letzten drei Monaten zahnärztlich untersucht worden zu sein. 13 Patienten (43\%) hatten sich innerhalb der letzten 4-12 Monate einer zahnärztlichen Untersuchung unterzogen und 6 Patienten (20\%) innerhalb der letzten 12-24 Monate. Nur ein Patient (3\%) gab an, vor mehr als zwei Jahren das letzte Mal beim Zahnarzt gewesen zu sein. Des Weiteren gaben 13 Probanden (43\%) an, dass bei innen bereits eine Parodontalbehandlung durchgeführt worden war. 


\subsection{Zahnärztlicher Befund (DMFT) und Papillen-Blutungs-Index}

Der mittlere DMFT-Wert betrug 21,6 $\pm 4,9$. Der niedrigste ermittelte Wert war 11, der höchste 28. Durchschnittlich waren 0,9 22,1 Zähne kariös bzw. zerstört (DT =decayed), 10,9 \pm 7,4 Zähne haben gefehlt (MT =missing) und 9,8 $\pm 6,0$ waren konservierend oder prothetisch versorgt ( $F T=$ filled). Abbildung 20 zeigt die prozentualen Anteile der Einzelkomponenten DT, MT und FT am mittleren DMFT-Wert.

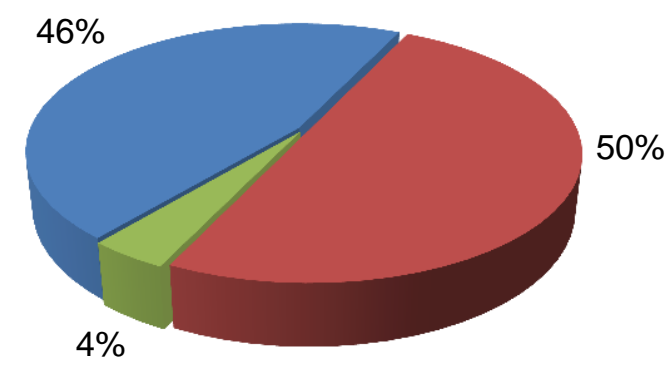

$\square$ FT (filled)

- MT (missing)

- DT (decayed)

Abb. 20: Anteil der Einzelkomponenten des DMFT-Indexes (DT, MT und FT) am mittleren DMFT-Wert

Für den Papillen-Blutung-Index (PBI) ergab sich folgende Einteilung nach Schweregrad (Abb. 21): 11 Probanden (37\%) wiesen einen PBI Grad 0 auf, weitere 11 Probanden (37\%) einen PBI Grad 1. Bei 6 Probanden (20\%) wurde ein PBI Grad 2 ermittelt und bei 2 Probanden (7\%) ein PBI Grad 3.

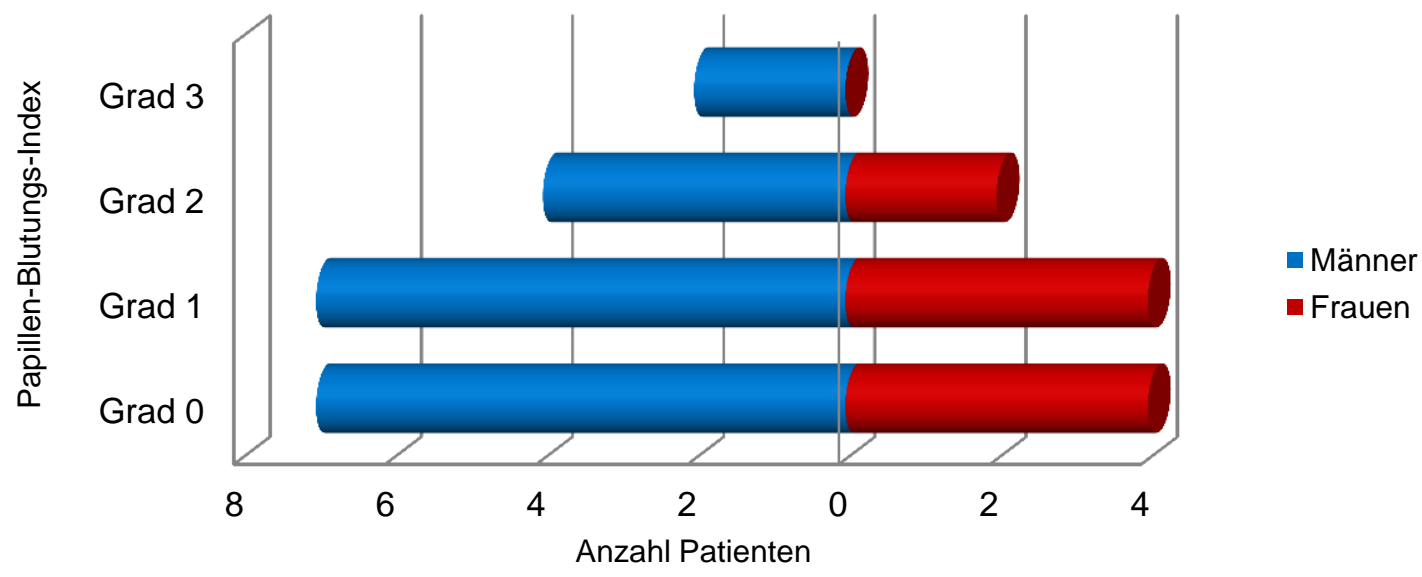

Abb. 21: Papillen-Blutungs-Index differenziert nach Geschlecht

Die Raucher verteilten sich relativ gleichmäßig auf die verschiedenen PBI-Gruppen (Abb. 22). 


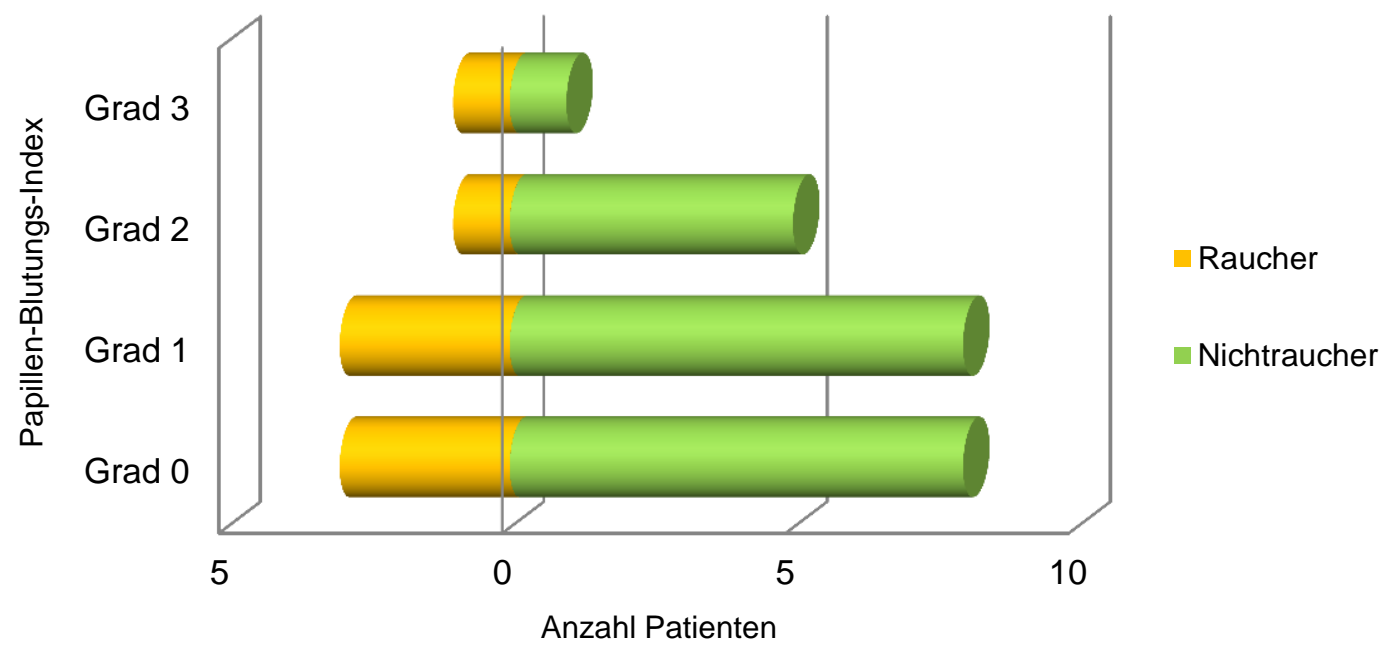

Abb. 22: Papillen-Blutungs-Index differenziert nach Rauchverhalten

\subsection{Parodontaler Befund}

Die durchschnittliche Sondierungstiefe, ermittelt anhand der jeweils höchsten Sondierungstiefe jedes Patienten, betrug 6,1 $\pm 1,9 \mathrm{~mm}$. Der niedrigste gemessene Wert lag bei $3 \mathrm{~mm}$, die größte gemessene Taschentiefe betrug $10 \mathrm{~mm}$.

Durch Addition mit den gemessenen Rezessionen ergab sich für das Attachmentlevel ein Mittelwert von $8,5 \pm 2,9 \mathrm{~mm}$, wobei das Minimum bei $4 \mathrm{~mm}$ und das Maximum bei $13 \mathrm{~mm}$ lagen.

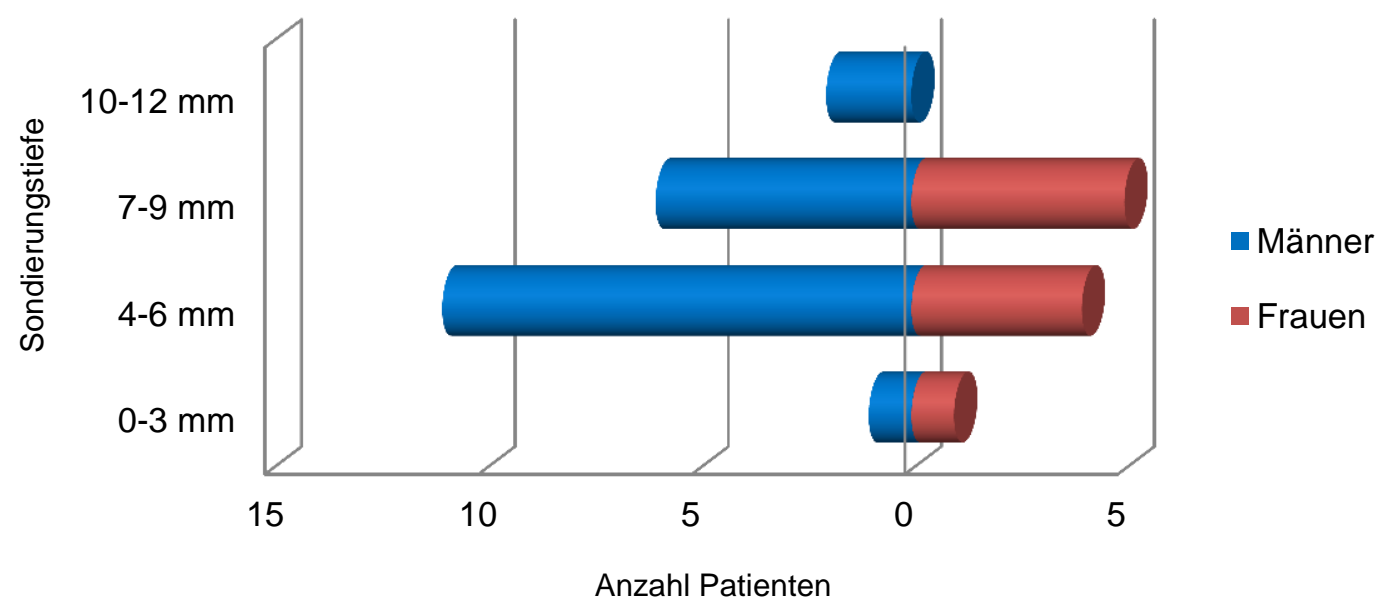

Abb. 23: Mittlere Sondierungstiefen differenziert nach Geschlecht

$7 \%(n=2)$ der Patienten wiesen eine maximale Sondierungstiefe von 0-3 mm auf (Abb. 23). Bei $50 \%(n=15)$ der Patienten konnten Taschentiefen von 4-6 mm gemessen werden, bei 37\% $(n=11)$ Taschentiefen von 7-9 mm und bei 7\% $(n=2)$ Taschentiefen von 10-12 mm (Abb. 23). Insgesamt wiesen somit 93\% $(\mathrm{n}=28)$ der Patienten Sondierungstiefen von mehr als $4 \mathrm{~mm}$ auf. 
Die Verteilung der Raucher auf die mittleren Sondierungstiefen ist in Abbildung 24 dargestellt.

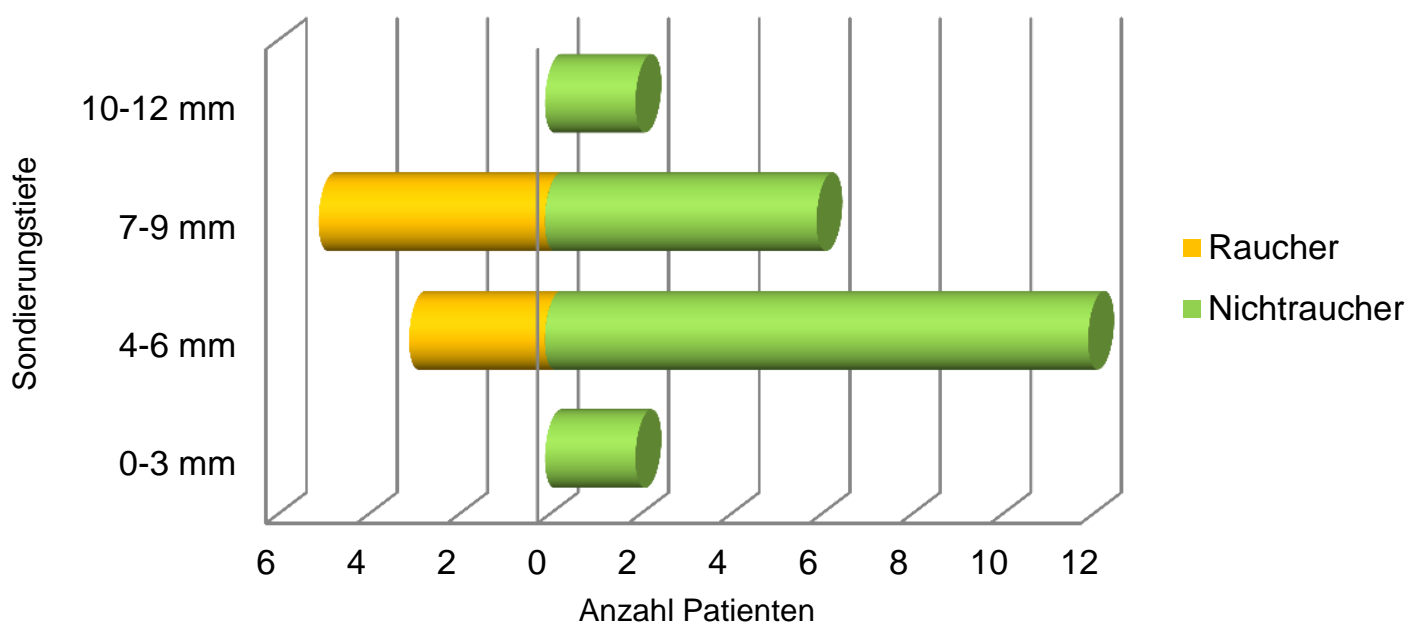

Abb. 24: Mittlere Sondierungstiefen differenziert nach Rauchverhalten

Nach dem Sondieren der Zahnfleischtaschen wurde der BOP (bleeding on probing) dokumentiert. Tabelle 15 zeigt die Ergebnisse in Form von prozentualen Anteilen der positiven BOP-Befunde an der Anzahl der noch vorhandenen Zähne.

\begin{tabular}{|c|c|}
\hline $\begin{array}{c}\text { Anteil der positiven } \\
\text { BOP-Befunde }\end{array}$ & $\begin{array}{c}\text { Anzahl } \\
\text { der Patienten }\end{array}$ \\
\hline $0-10 \%$ & $\mathrm{n}=8$ \\
\hline $11-20 \%$ & $\mathrm{n}=3$ \\
\hline $21-30 \%$ & $\mathrm{n}=0$ \\
\hline $31-40 \%$ & $\mathrm{n}=7$ \\
\hline $41-50 \%$ & $\mathrm{n}=2$ \\
\hline $51-60 \%$ & $\mathrm{n}=2$ \\
\hline $61-70 \%$ & $\mathrm{n}=2$ \\
\hline $71-80 \%$ & $\mathrm{n}=1$ \\
\hline $81-90 \%$ & $\mathrm{n}=3$ \\
\hline $91-100 \%$ & $\mathrm{n}=2$ \\
\hline
\end{tabular}

Tab. 15: Prozentuale Anteile positiver BOP-Befunde im Patientenkollektiv

Nach der Einteilung von Page und Eke (2007) anhand der Sondierungstiefen und des Attachmentlevels wiesen 2 Patienten (7\%) keine oder eine milde Parodontitis auf, 5 Patienten (17\%) eine leichte Parodontitis und bei 23 Patienten (77\%) wurde anhand der oben genannten Klassifikation eine schwere Parodontitis diagnostiziert (Abb. 25). 


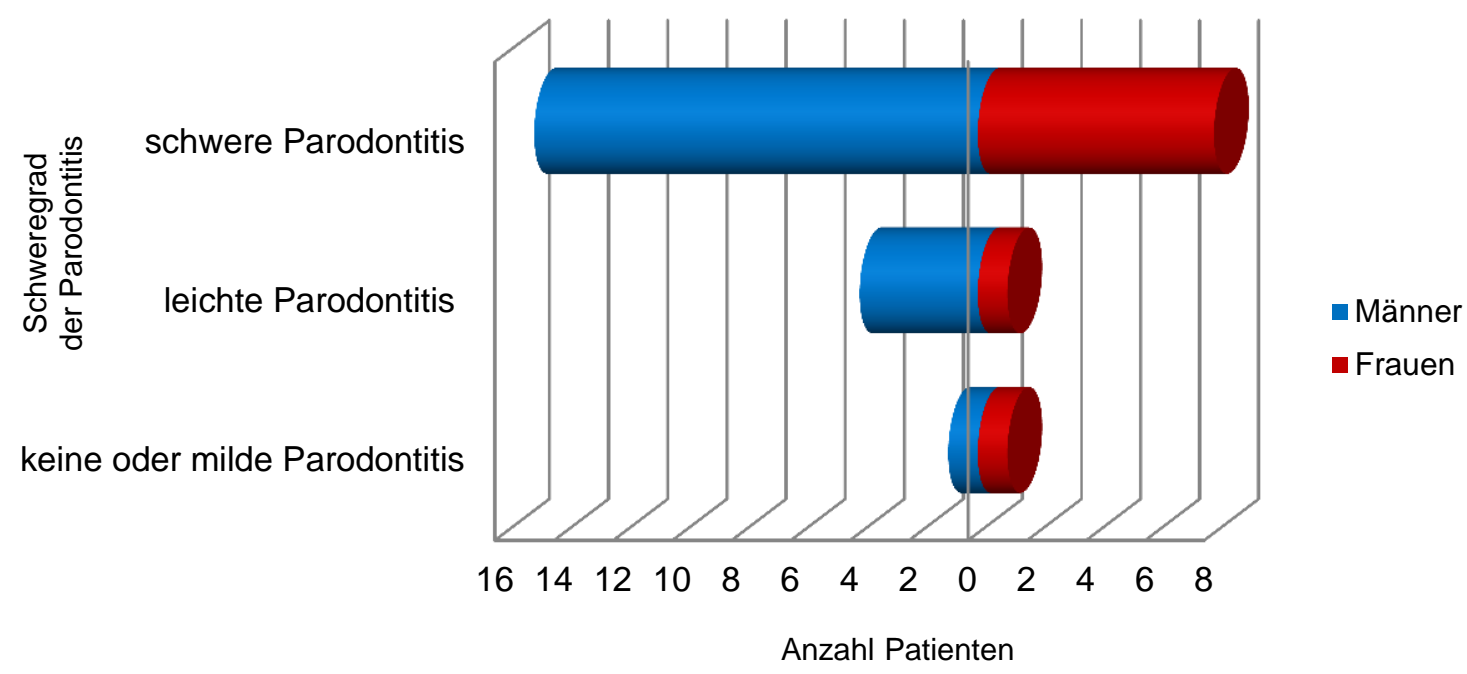

Abb. 25: Schweregrad der Parodontitis differenziert nach Geschlecht

Alle acht Raucher des Patientenkollektivs wiesen eine schwere Parodontitis auf (Abb. 26).

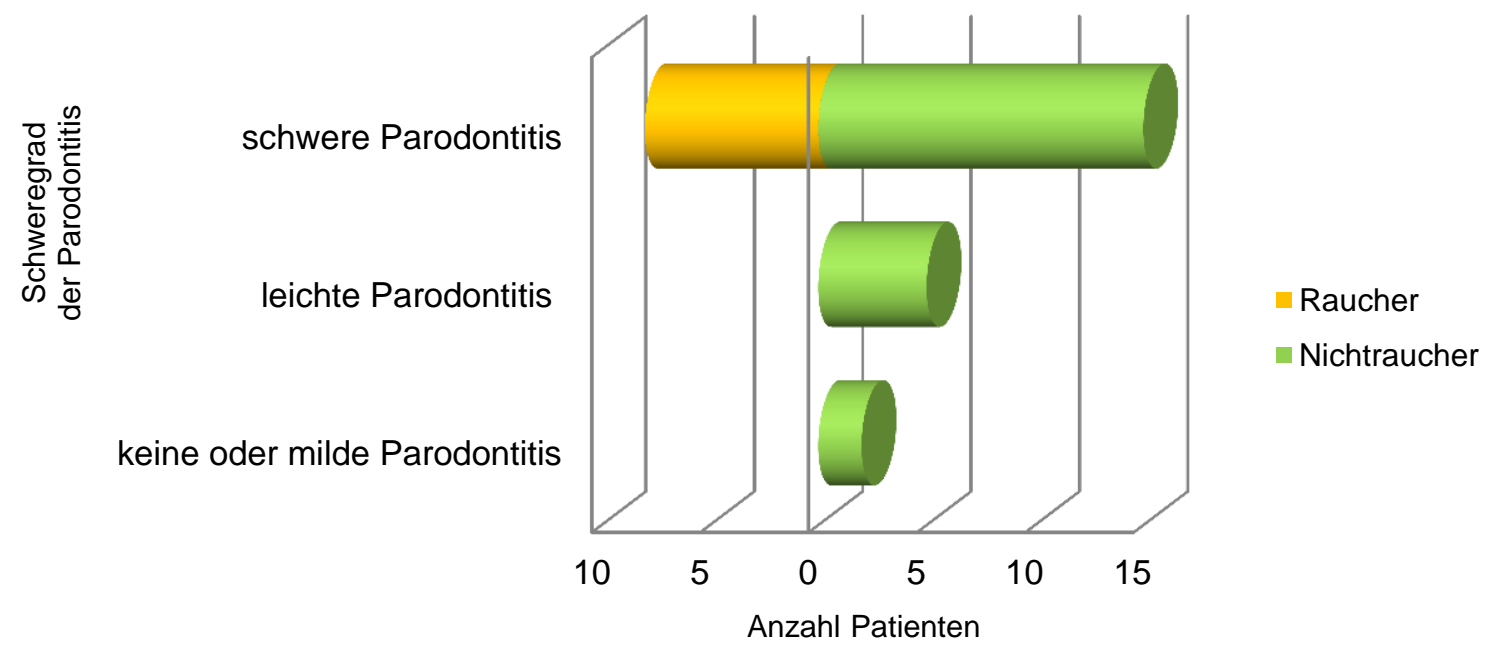

Abb. 26: Schweregrad der Parodontitis differenziert nach Rauchverhalten

\subsection{Laborergebnisse für Lipopolysaccharid-bindendes Protein bzw. big42-LBP}

Mit Hilfe der densitometrischen Auswertung konnten die in Tabelle 16 aufgeführten Werte für big42-LPB an Atrium, Ventrikel und Klappe ermittelt werden.

Die höchsten Werte wurden mit einem Mittelwert von 49490,4 (big42 absolut) bzw. 1,4 (big42 normiert auf das Expressionsniveau von GAPDH) für die Herzklappe ermittelt. 
Für das Atrium ergaben sich durchschnittliche Werte von 21708,8 (big42 absolut) bzw. 0,2 (big42 normiert auf das Expressionsniveau von GAPDH) und für den Ventrikel 12287,3 (big42 absolut) bzw. 0,1 (big42 normiert auf das Expressionsniveau von GAPDH).

\begin{tabular}{|l|c|c|c|l|l|l|c|}
\hline $\begin{array}{l}\text { Lokalisation } \\
\text { am Herzen }\end{array}$ & $\begin{array}{c}\text { Mittelwert } \\
\mathbf{\pm S D}\end{array}$ & Min. & Max. & $\begin{array}{l}\text { Lokalisation am } \\
\text { Herzen }\end{array}$ & $\begin{array}{l}\text { Mittelwert } \\
\mathbf{\pm S D}\end{array}$ & Min. & Max. \\
\hline $\begin{array}{l}\text { Atrium: } \\
\text { big42 absolut }\end{array}$ & $\begin{array}{l}21708,8 \\
\pm 19104,5\end{array}$ & 0,00 & 65080 & $\begin{array}{l}\text { Atrium: } \\
\text { big42 - GAPDH }\end{array}$ & $0,2 \pm 0,2$ & 0,00 & 0,61 \\
\hline $\begin{array}{l}\text { Ventrikel: } \\
\text { big42 absolut }\end{array}$ & $\begin{array}{l}12287,3 \\
\pm 16018,3\end{array}$ & 0,00 & 73638 & $\begin{array}{l}\text { Ventrikel: } \\
\text { big42 - GAPDH }\end{array}$ & $0,1 \pm 0,1$ & 0,00 & 0,57 \\
\hline $\begin{array}{l}\text { Klappe: } \\
\text { big42 absolut }\end{array}$ & $\begin{array}{l}49490,4 \\
\pm 30849,5\end{array}$ & 5739 & 138437 & $\begin{array}{l}\text { Klappe: } \\
\text { big42 - GAPDH }\end{array}$ & $1,4 \pm 0,8$ & 0,40 & 3,83 \\
\hline
\end{tabular}

1) big42 normiert auf das Expressionsniveau von GAPDH

Tab. 16: Werte für big42 (absolut und normiert auf das Expressionsniveau von GAPDH) an Atrium, Ventrikel und Klappe

\subsection{IL-1-Polymorphismus bzw. Genotyp}

Die Verteilung der IL-1-Polymorphismen IL-1A-C889, IL-1B+C3953 und IL-1RN+T2018 ist Tabelle $17 \mathrm{zu}$ entnehmen. 17\% der Probanden $(n=5)$ wurden homozygot negativ auf alle drei IL-1-Polymorphismen getestet. Die übrigen $83 \%(n=25)$ waren heterozygote oder homozygot positive Merkmalsträger der jeweiligen Genmutation.

\begin{tabular}{|c|c|c|}
\hline IL-1-Polymorphismus & Allel & Anzahl Probanden \\
\hline \multirow{3}{*}{ IL-1A-C889 } & homozygot negativ & $\begin{array}{l}\mathrm{n}=13 \\
(43 \%)\end{array}$ \\
\hline & homozygot positiv & $\begin{array}{l}n=2 \\
(7 \%)\end{array}$ \\
\hline & heterozygot & $\begin{array}{l}\mathrm{n}=15 \\
(50 \%)\end{array}$ \\
\hline \multirow{3}{*}{ IL-1B+C3953 } & homozygot negativ & $\begin{array}{l}\mathrm{n}=15 \\
(50 \%)\end{array}$ \\
\hline & homozygot positiv & $\begin{array}{l}\mathrm{n}=2 \\
(7 \%)\end{array}$ \\
\hline & heterozygot & $\begin{array}{l}n=13 \\
(43 \%)\end{array}$ \\
\hline \multirow{3}{*}{ IL-1RN+T2018 } & homozygot negativ & $\begin{array}{l}\mathrm{n}=18 \\
(60 \%)\end{array}$ \\
\hline & homozygot positiv & $\begin{array}{l}n=2 \\
(7 \%)\end{array}$ \\
\hline & heterozygot & $\begin{array}{l}\mathrm{n}=10 \\
(33 \%)\end{array}$ \\
\hline
\end{tabular}

Tab. 17: Verteilung der IL-1-Polymorphismen 
Entsprechend der Kombinationen aus den verschiedenen IL-1-Genpolymorphismen konnten wie in Kapitel 3.11.3. beschrieben die Probanden in vier Genotypmuster mit dem jeweils individuellen Risiko für die Entstehung einer progressiven Parodontitis eingeteilt werden (Abb. 27). Acht Probanden wiesen Genotypmuster 1 auf, d.h. laut Testergebnis liegt kein erhöhtes genetisches Risiko für eine progressive Parodontitis vor. Für elf Patienten wurde ein Genotypmuster 2 mit erhöhtem genetischen Risiko ermittelt. Ein stark erhöhtes genetisches Risiko für die Entwicklung einer fortschreitenden Parodontitis entsprechend dem Genotypmuster 3 ergab sich für drei Patienten. Und acht Probanden wiesen ein Genotypmuster 4 auf, das laut Testauswertung auf eine verminderte genetische Entzündungshemmung hinweist.

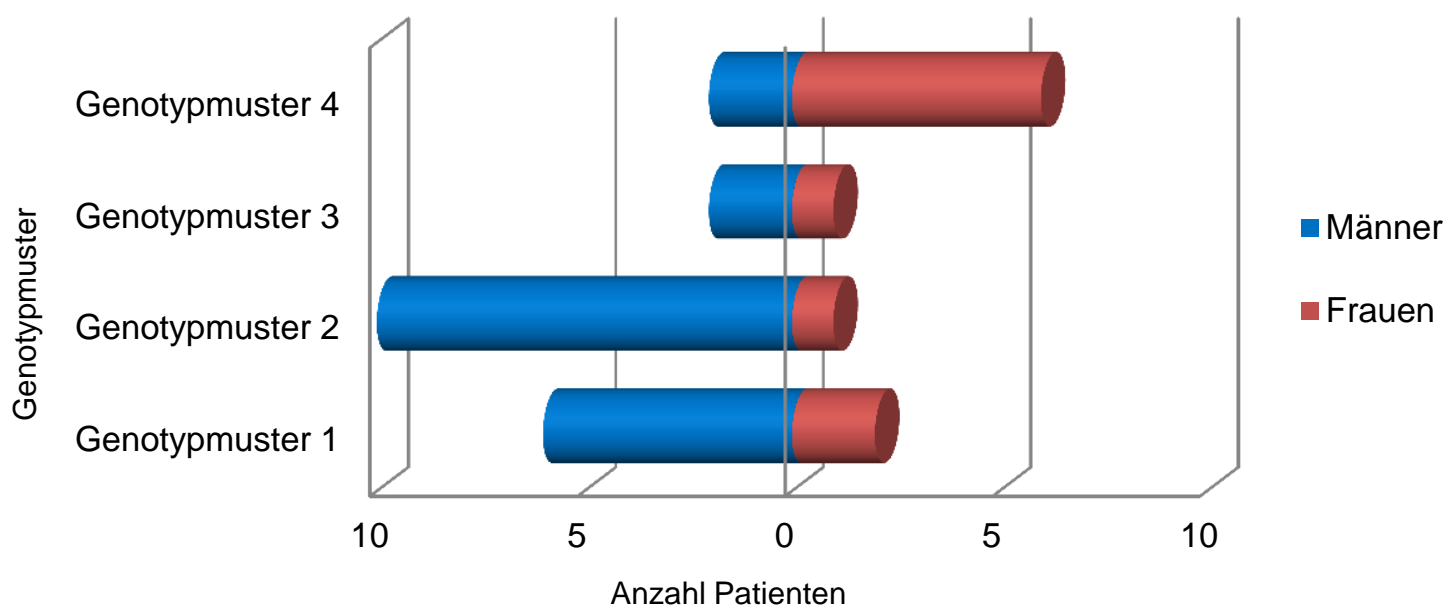

Abb. 27: Verteilung der Genotypmuster differenziert nach Geschlecht

Bei jeder der vier Genotypgruppen waren Raucher vertreten (Abb. 28).

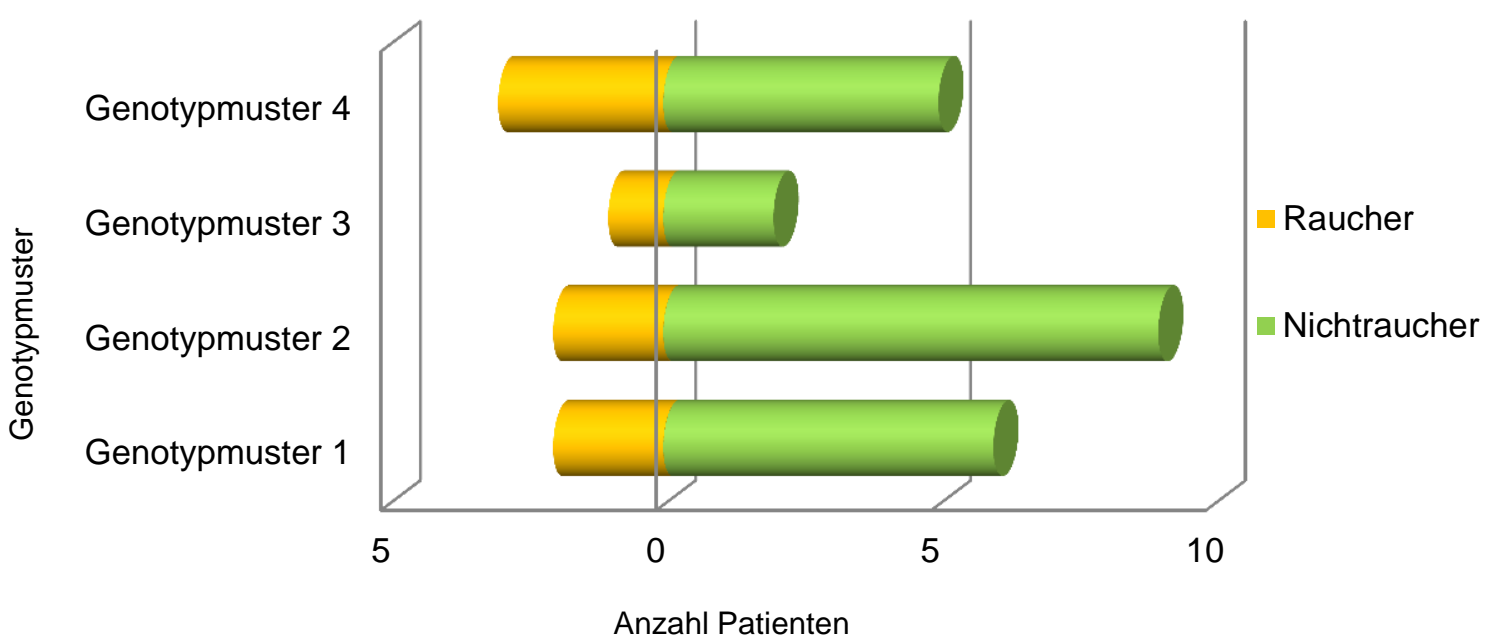

Abb. 28: Verteilung der Genotypmuster differenziert nach Rauchverhalten 


\subsection{Statistische Auswertung im Zusammenhang mit dem Papillen-Blutungs- Index (PBI)}

\subsubsection{Einfluss von Geschlecht und Rauchverhalten auf den PBI}

In Folge der statistischen Auswertung ist festzustellen, dass weder Geschlecht $(p=0,559)$ noch Rauchen $(p=0,901)$ einen signifikanten Einfluss auf den PapillenBlutungs-Index der 30 Patienten hatten. Auch das Alter stand in keinem signifikanten Zusammenhang mit dem PBI $(p=0,445)$. Lediglich zwischen dem PBI und dem BodyMass-Index konnte eine signifikante Korrelation festgestellt werden $(p=0,018)$.

\subsubsection{Assoziation zwischen Genotyp und PBI}

Es konnte weiterhin kein signifikanter Zusammenhang zwischen dem PBI und den Genotypmustern der Probanden hergestellt werden $(p=0,167)$. Abbildung 29 zeigt den Zusammenhang zwischen PBI und Genotyp in einem Boxplot.

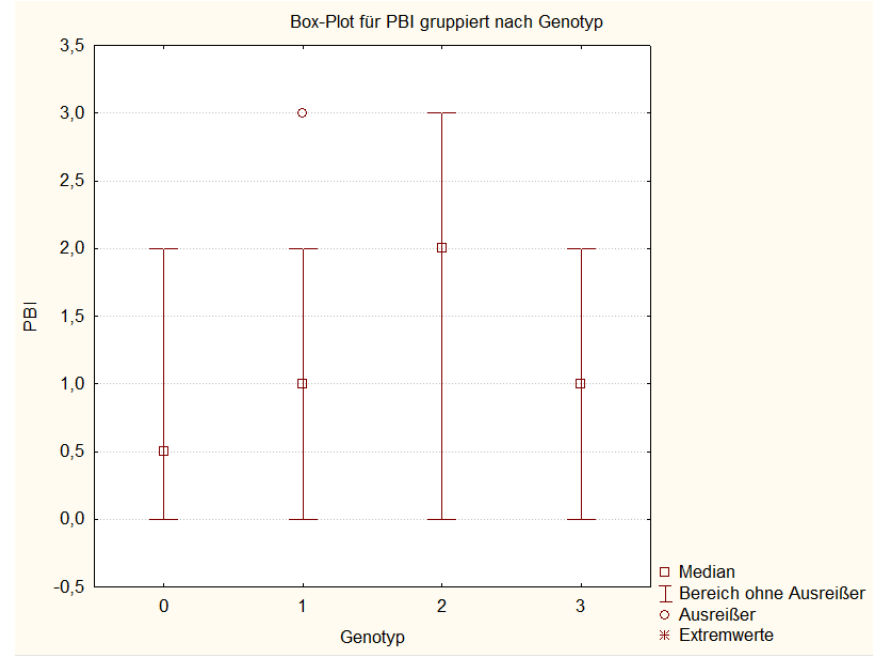

Abb. 29: Box-Plot für PBI und Genotyp

\subsection{Statistische Auswertung im Zusammenhang mit dem Schweregrad der Parodontitis}

4.7.1 Einfluss von Geschlecht und Rauchverhalten auf den Schweregrad der

\section{Parodontitis}

Bei der statistischen Auswertung wurde deutlich, dass bei dem vorliegenden Patientenkollektiv ( $n=30)$ weder das Geschlecht $(p=0,760)$ noch das Rauchverhalten $(p=0,068)$ einen signifikanten Einfluss auf den Schweregrad der Parodontitis hatten. 


\subsubsection{Assoziation zwischen Genotyp und Schweregrad der Parodontitis}

Tabelle 18 zeigt die Verteilung der Genotypmuster auf die Schweregrade der Parodontitis.

\begin{tabular}{|l|l|l|l|l|}
\hline Schweregrad der Parodontitis & $\begin{array}{l}\text { Genotyp- } \\
\text { muster 1 }\end{array}$ & $\begin{array}{l}\text { Genotyp- } \\
\text { muster 2 }\end{array}$ & $\begin{array}{l}\text { Genotyp- } \\
\text { muster 3 }\end{array}$ & $\begin{array}{l}\text { Genotyp- } \\
\text { muster 4 }\end{array}$ \\
\hline keine oder milde Parodontitis & $\mathrm{n}=0$ & $\mathrm{n}=1$ & $\mathrm{n}=1$ & $\mathrm{n}=0$ \\
\hline leichte Parodontitis & $\mathrm{n}=2$ & $\mathrm{n}=3$ & $\mathrm{n}=0$ & $\mathrm{n}=0$ \\
\hline schwere Parodontitis & $\mathrm{n}=6$ & $\mathrm{n}=7$ & $\mathrm{n}=2$ & $\mathrm{n}=8$ \\
\hline
\end{tabular}

Tab. 18: Verteilung der Genotypmuster auf die Schweregrade der Parodontitis

Es wurde eine mögliche Assoziation zwischen dem Schweregrad der Parodontitis und dem Genotyp der Patienten untersucht. Ein entsprechender Zusammenhang konnte jedoch nicht festgestellt werden $(p=0,259)$.

\subsection{Statistische Auswertung im Zusammenhang mit big42-LBP}

\subsubsection{Assoziation zwischen big42- LBP und dem Papillen-Blutungs-Index}

Die Untersuchung eines Zusammenhangs von PBI und big42-LBP ergab keine signifikanten Ergebnisse. Die p-Werte der einzelnen Lokalisationen sind in Tabelle 19 aufgeführt.

\begin{tabular}{|l|c|l|c|}
\hline Lokalisation am Herzen & $\mathbf{p}$-Wert & Lokalisation am Herzen & p-Wert \\
\hline Atrium (big42 absolut) & 0,808 & Atrium (big42 - GAPDH) ${ }^{1)}$ & 0,572 \\
\hline Ventrikel (big42 absolut) & 0,951 & Ventrikel (big42 - GAPDH) ${ }^{1)}$ & 0,957 \\
\hline Klappe (big42 absolut) & 0,497 & Klappe (big42 - GAPDH) ${ }^{1)}$ & 0,806 \\
\hline
\end{tabular}

${ }^{1)}$ big42 normiert auf das Expressionsniveau von GAPDH

Tab. 19: Ergebnisse der t-Tests für big42 und PBI für Atrium, Ventrikel und Klappe

\subsubsection{Assoziation zwischen big42-LBP und dem Schweregrad der Parodontitis}

Bei der statistischen Auswertung wurde unter anderem untersucht, ob ein Zusammenhang zwischen dem Schweregrad der Parodontitis und der Menge an big42 bzw. dem Lipopolysaccharid-bindenden Protein (LBP) an Atrium, Ventrikel und Klappe besteht. Es konnte festgestellt werden, dass im untersuchten Patientenkollektiv $(n=30)$ der Schweregrad der Parodontitis mit der Ausprägung von LBP am Ventrikel assoziiert war $(p=0,018)$ (Abb. 30). Dieser Zusammenhang sollte in Folgestudien validiert werden. 


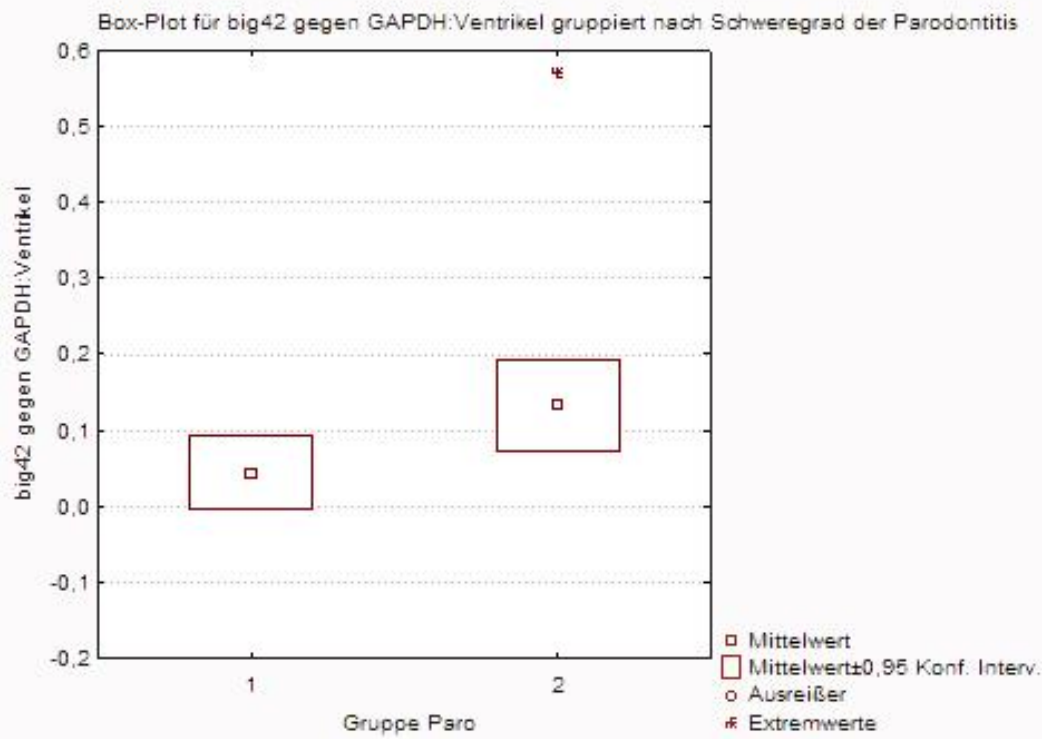

Abb. 30: Korrelation zwischen big42 (normiert auf das Expressionsniveau von GAPDH) für Ventrikel und Schweregrad der Parodontitis

(Gruppe Paro 1: keine oder milde bzw. leichte Parodontitis; Gruppe Paro 2: schwere Parodontitis)

Für Atrium konnte kein relevanter Zusammenhang zwischen der Menge an LBP und dem Schweregrad der Parodontitis nachgewiesen werden ( $p=0,577)$ (Abb. 31).

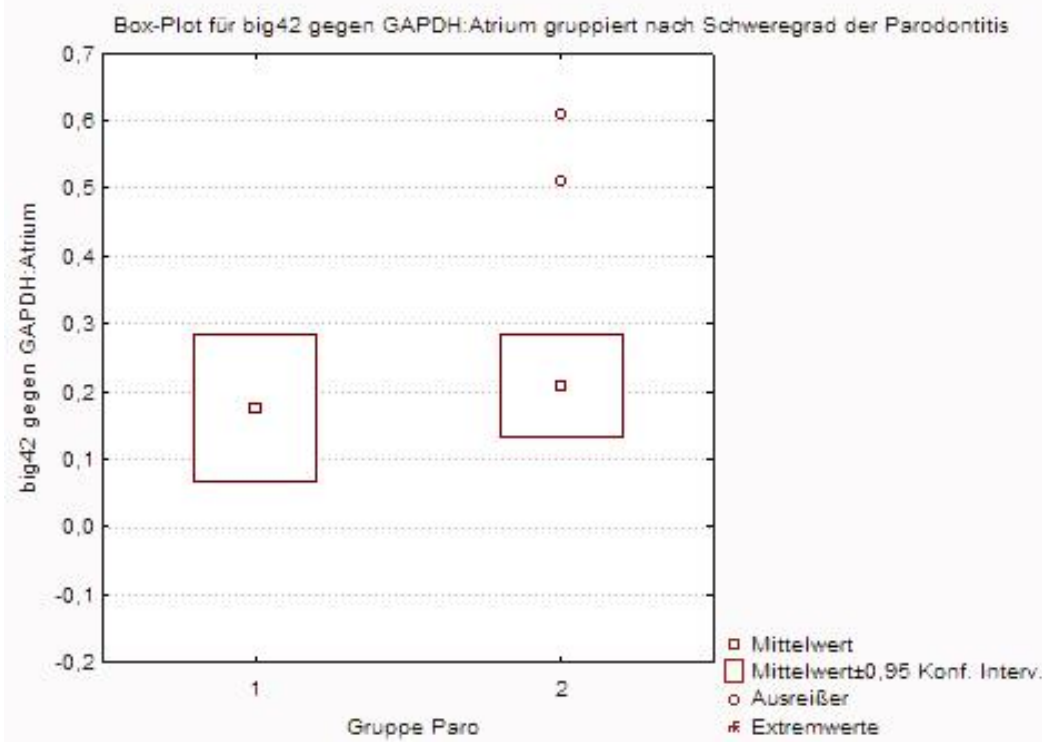

Abb. 31: Korrelation zwischen big42 (normiert auf das Expressionsniveau von GAPDH) für Atrium und Schweregrad der Parodontitis

(Gruppe Paro 1: keine oder milde bzw. leichte Parodontitis; Gruppe Paro 2: schwere Parodontitis)

Auch für die Klappe ergab die statistische Auswertung keinen signifikanten Zusammenhang zwischen den Werten für LBP und dem Schweregrad der Parodontitis $(p=0,198)($ Abb. 32). 


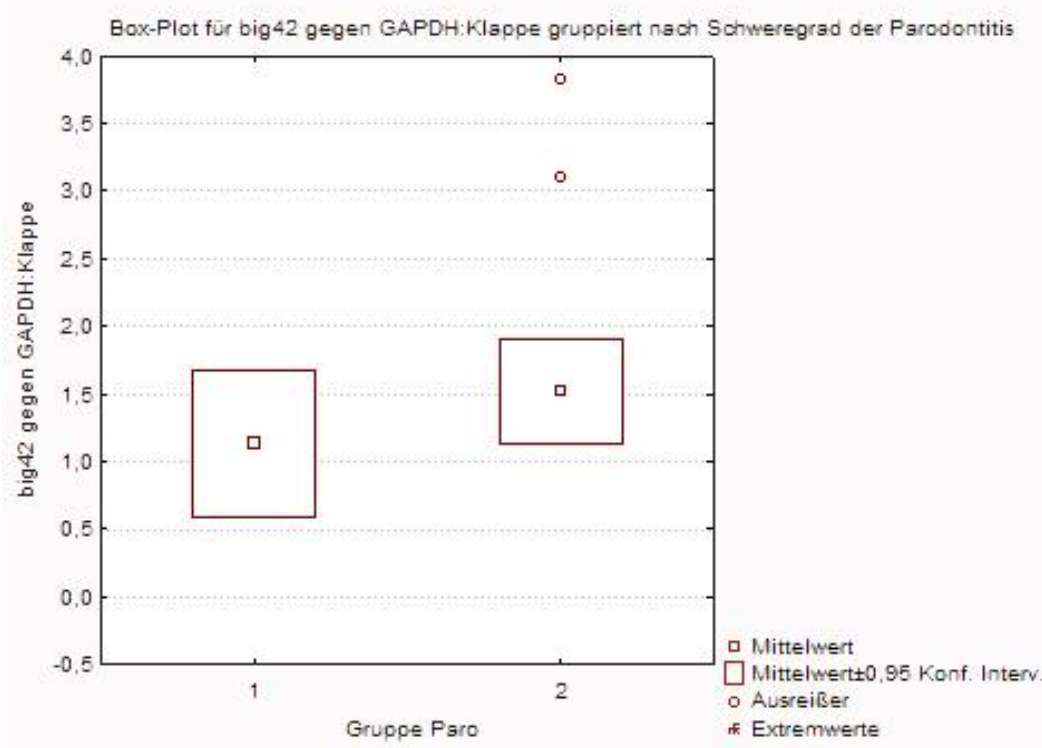

Abb. 32: Korrelation zwischen big42 (normiert auf das Expressionsniveau von GAPDH) für Klappe und Schweregrad der Parodontitis

(Gruppe Paro 1: keine oder milde bzw. leichte Parodontitis; Gruppe Paro 2: schwere Parodontitis)

Tabelle 20 zeigt die einzelnen $p$-Werte des t-Tests für big42-LBP und den Schweregrad der Parodontitis für Atrium, Ventrikel und Klappe ohne GAPDH und mit Berechnung gegen GAPDH.

\begin{tabular}{|l|c|l|c|}
\hline Lokalisation am Herzen & p-Wert & Lokalisation am Herzen & p-Wert \\
\hline Atrium (big42 absolut) & 0,519 & Atrium (big42 - GAPDH) ${ }^{1)}$ & 0,577 \\
\hline Ventrikel (big42 absolut) & 0,035 & Ventrikel (big42 - GAPDH) $)^{1)}$ & 0,018 \\
\hline Klappe (big42 absolut) & 0,519 & Klappe (big42 - GAPDH) $^{1)}$ & 0,198 \\
\hline
\end{tabular}

1) big42 normiert auf das Expressionsniveau von GAPDH

Tab. 20: Ergebnisse der t-Tests für big42-LBP und Parodontitis für Atrium, Ventrikel und Klappe

\subsection{Assoziation zwischen big42-LBP und dem Genotyp}

Bei der Untersuchung des Zusammenhangs der Werte für Genotypmuster und LBP konnte keine positive Assoziation festgestellt werden (Tab. 21).

\begin{tabular}{|l|c|l|c|}
\hline Lokalisation am Herzen & p-Wert & Lokalisation am Herzen & p-Wert \\
\hline Atrium (big42 absolut) & 0,605 & Atrium (big42 - GAPDH) ${ }^{1)}$ & 0,456 \\
\hline Ventrikel (big42 absolut) & 0,366 & Ventrikel (big42 - GAPDH) $^{1)}$ & 0,379 \\
\hline Klappe (big42 absolut) & 0,395 & Klappe (big42 - GAPDH) & 0,714 \\
\hline
\end{tabular}

${ }^{1)}$ big42 normiert auf das Expressionsniveau von GAPDH

Tab. 21: $p$-Werte für big42-LBP gegen Genotyp 


\subsection{Zusammenfassung der wichtigsten Ergebnisse}

Hervorzuheben ist, dass 28 von 30 Patienten eine Parodontitis aufwiesen (23 Patienten: schwere Parodontitis, 5 Patienten: leichte Parodontitis, 2 Patienten: keine oder milde Parodontitis).

LBP konnte bei allen Patienten am Myokard in unterschiedlicher Höhe nachgewiesen werden. Es wurde eine positive Assoziation zwischen dem Vorhandensein von LBP am Ventrikel und dem Schweregrad der Parodontitis beobachtet, die in weiterführenden Studien mit größerem Patientenkollektiv und statistischer Validierung genauer analysiert werden sollte. 


\section{Diskussion}

Aufgrund von Erkenntnissen verschiedener Studien geht man davon aus, dass ein Zusammenhang zwischen Parodontitis bzw. parodontopathogenen Bakterien und der Pathogenese der koronaren Herzerkrankung besteht (DeStefano et al. 1993, Tang et al. 2011, Kuramitsu et al. 2001, Pussinen et al. 2003, Beck et al. 1999).

Da die koronare Herzerkrankung als Hauptursache für die Entstehung einer Herzinsuffizienz gilt (Hoppe et al. 2005) und außerdem eine Beteiligung von Zytokinen an der Entstehung einer Herzinsuffizienz diskutiert wird (Seta et al. 1996; Niebauer et al. 1999), wurde die Hypothese aufgestellt, dass parodontopathogene Bakterien und ihre Endotoxine auch einen Einfluss auf die Pathogenese der Herzinsuffizienz haben könnten. Die Mikroorganismen, die für Entstehung und Progression einer Parodontitis verantwortlich sind, lösen mit Hilfe ihrer Endotoxine (Lipopolysaccharide =LPS) eine Entzündungsreaktion mit resultierender Gewebeschädigung aus (Rietschel et al. 1994; Graves und Cochran 2003). Das LPS geht eine Bindung mit dem Lipopolysaccharidbindenden Protein (LBP) ein (Tapping und Tobias 1997), dieser Komplex bindet dann über einen CD14-Rezeptor an Makrophagen, die dadurch zur Ausschüttung verschiedener Zytokine angeregt werden (Wright et al. 1990).

Diese Arbeit beschäftigt sich im Rahmen eines Pilotprojektes mit verschiedenen Einzelprojekten mit der Frage, ob Endotoxine (LPS) der parodontopathogenen Mikroorganismen in der Lage wären, am Myokardgewebe zu binden und dort Entzündungsreaktionen auszulösen. Es konnten keine entsprechenden Studien, die einen möglichen Einfluss des LPS von Parodontopathogenen im Hinblick auf Entzündungsreaktionen und Gewebeschädigung am Myokard untersucht haben, gefunden werden.

Um der genannten Fragestellung nachzugehen, untersuchte man mit Hilfe eines LBPAntikörpers (big42) das Vorhandensein von LBP am Myokard. Das Myokardgewebe fiel bei Herzklappenersatz-Operationen an und wurde für diese Studie zur Verfügung gestellt.

\subsection{Patientenkollektiv}

Das untersuchte Patientenkollektiv wies eine uneinheitliche Verteilung bezüglich Geschlecht, Nikotinkonsum, Alter und Ernährungszustand auf. Dieses Ungleichgewicht beruht auf der Tatsache, dass kein Einfluss auf die Zusammensetzung der Probandengruppe genommen werden konnte. Voraussetzung für die Studienteilnahme war die Notwendigkeit der Durchführung einer Aortenklappenersatz-Operation im Untersuchungszeitraum. 
Nachgewiesene Risikofaktoren für das Auftreten einer koronaren Herzerkrankung (KHK) sind unter anderem Rauchen, Übergewicht, Hypertonie, Diabetes mellitus, Fettstoffwechselstörungen (Lederhuber und Lange 2010) und männliches Geschlecht (Bühling 2000). Da eine KHK als Hauptursache für die Entstehung einer Herzinsuffizienz gilt (Hoppe et al. 2005), ist eine nähere Betrachtung der aufgeführten Risikofaktoren sinnvoll.

Für die 67\% Männer unter den Probanden gilt eine erhöhte Wahrscheinlichkeit für die Entstehung einer KHK (Bühling 2000).

22 der 30 Patienten des Kollektivs gaben an, Nichtraucher zu sein. Der Risikofaktor Rauchen ist demnach bei einem Großteil der Probanden zu vernachlässigen.

Begutachtet man jedoch den Ernährungszustand, wird deutlich, dass der überwiegende Anteil der Patienten nach der WHO-Klassifikation anhand des BMI als übergewichtig oder adipös einzustufen war (mittlerer BMI: 29,06). Übergewicht bzw. ein $\mathrm{BMI}>25$ gelten als prädisponierender Faktor bei der Pathogenese einer KHK (Bogers et al. 2007).

Bei Betrachtung der kardialen und allgemeinmedizinischen Diagnosen fällt auf, dass arterielle Hypertonie (60\%), Hyperlipoproteinämie (37\%) und Diabetes mellitus (27\%) am häufigsten diagnostiziert wurden. Diese Erkrankungen gehören neben Tabakrauchen zu den wichtigsten Risikofaktoren der KHK (Bühling 2000).

Zusammenfassend ist zu sagen, dass das Patientenkollektiv bei zufälliger Auswahl verschiedene bekannte Risikofaktoren aufweist.

\subsection{Zahnärztlicher Status}

Nach dem letzten Zahnarztbesuch befragt, gaben fast $80 \%$ der untersuchten Patienten an, sich innerhalb der letzten 12 Monate vor der OP einer zahnärztlichen Untersuchung unterzogen zu haben. Bei nur einem Patienten lag die letzte Untersuchung mehr als zwei Jahre zurück. Interessant wäre, ob den Patienten die zahnärztliche Untersuchung von ihrem Kardiologen empfohlen wurde. Dieser Fragestellung könnte in weiterführenden Untersuchungen nachgegangen werden.

Der ermittelte durchschnittliche DMFT-Wert der Probanden wurde mit den Ergebnissen der Vierten Deutschen Mundgesundheitsstudie (DMS IV) verglichen. Die DMS IV wurde 2005 durchgeführt, um eine repräsentative Aussage über den zahnärztlichen Befund der deutschen Bevölkerung treffen zu können. Hierzu wurden Menschen verschiedener sozialer Herkunft und Altersstruktur befragt und untersucht. Die Ergebnisse wurden für die Altersgruppen Kinder (12jährige), Jugendliche (15jährige), Erwachsene (35-44jährige) und Senioren (65-74jährige) erfasst. Da das durchschnittliche Alter der Probanden dieser Studie 67,7 Jahre betrug, ist ein Vergleich 
mit dem DMFT-Wert der Senioren sinnvoll. Der ermittelte durchschnittliche DMFT der Probanden lag bei 21,63 und entspricht annähernd dem in der DMS IV für die Senioren ermittelten Wert von 22,1 (Micheelis und Schiffner 2006).

Betrachtet man die einzelnen erhobenen Werte für $D$ (decayed =zerstört), $M$ (missing =fehlt) und F (filled =versorgt), wird deutlich, dass der hohe DMFT der Studienteilnehmer auf der großen Anzahl fehlender bzw. konservierend oder prothetisch versorgter Zähne basiert. Der mittlere D-Wert betrug 0,9, es war also nur eine geringe Anzahl von Zähnen kariös zerstört und behandlungsbedürftig, woraus man auf eine gute zahnärztliche Compliance der Probanden schließen kann. Diese Tendenz wird auch in den Ergebnissen der DMS IV widergespiegelt, bei der ein hoher Kariessanierungsgrad bei Senioren von $94,8 \%$ festgestellt werden konnte (Micheelis und Schiffner 2006).

\subsection{Papillen-Blutungs-Index}

Der Papillen-Blutungs-Index dient der Erfassung des gingivalen Entzündungszustands (Engelberger et al. 1983). Um falsch positive Messungen durch zuvoriges Sondieren zu verhindern, wurde der Papillen-Blutungs-Index vor dem Messen der Sondierungstiefen erhoben. Bei $72 \%$ der Studienteilnehmer wurde ein PBI-Grad 0 oder 1 gemessen und bei lediglich zwei Probanden (7\%) ein PBI-Grad 3.

Aus dem relativ geringen durchschnittlichen Entzündungsgrad ist zu folgern, dass bei dem überwiegenden Teil des Patientenkollektivs zum Zeitpunkt der Untersuchungen eine gute Mundhygiene vorlag. Diese Tatsache steht im Widerspruch mit der hohen Prävalenz an Parodontitispatienten unter den Probanden. Es deutet daraufhin, dass die Parodontitiden schon seit längerer Zeit bestanden und demnach als chronisch einzustufen sind.

Besonderes Augenmerk sollte in dieser Hinsicht auf die Zusammenarbeit zwischen Zahnarzt und Kardiologen gelegt werden. Wünschenswert wäre, dass gegebenenfalls vorliegende Parodontitiden vor dem operativen Eingriff zum Ersatz einer Herzklappe behandelt werden, um das Risiko möglicher postoperativer Komplikationen wie Endokarditiden zu minimieren.

\subsection{Parodontaler Status}

Bei Betrachtung der gemessenen Sondierungstiefen fällt auf, dass 93\% der Patienten Sondierungstiefen von mehr als $4 \mathrm{~mm}$ aufwiesen.

Nach der Klassifikation von Page und Eke (2007) lag bei lediglich zwei Patienten des Kollektivs keine oder eine milde Parodontitis vor, fünf Patienten litten unter einer 
leichten Parodontitis und bei 23 Patienten konnte eine schwere Parodontitis diagnostiziert werden.

Bei Beurteilung der Messergebnisse muss berücksichtigt werden, dass verschiedene Faktoren zu Fehlergebnissen bei der Messung von Sondierungstiefen führen können. Beispielsweise kann die angewandte Kraft des jeweiligen Untersuchers die Messung fehlerhaft beeinflussen (van der Velden 1979, van der Velden 1980; van der Velden und de Vries 1980). Um Messfehler durch unterschiedlich aufgewandten Druck so weit wie möglich zu reduzieren, wurden die Untersucher im Vorfeld der Studie kalibriert.

Weiterhin können der Sondendurchmesser, der Entzündungsgrad der Gingiva sowie anatomische Strukturen, subgingivaler Zahnstein, Wurzelkaries und Füllungsüberschüsse mögliche Fehlerquellen darstellen (Listgarten 1980; Larsen et al. 2009; Keagle et al. 1989; Anderson et al. 1991; Buduneli et al. 2004).

\subsection{IL-1-Genotyp}

Mit Hilfe des GenoType ${ }^{\circledR}$ IL-1-Tests VER 1.0 (Fa. Hain Lifescience, Nehren, Deutschland) wurden die Polymorphismen IL-1A-C889T, IL-1B+C3953T sowie IL1RN+T2018C mittels der DNA des Patienten, die zuvor aus den Blutproben extrahiert wurde, untersucht. Anhand der ermittelten Polymorphismen konnten die Patienten in vier IL-1-Genotyp-Gruppen eingeteilt werden. Es ergab sich eine relativ ausgeglichene Verteilung: Acht Patienten wiesen Genotypmuster 1 auf, elf Patienten Genotypmuster 2, drei Patienten Genotypmuster 3 und für acht Patienten wurde ein Genotypmuster 4 ermittelt.

IL-1 spielt nach heutigen Erkenntnissen eine entscheidende Rolle bei der Pathogenese und Progression der Parodontitis (Offenbacher 1996). Nachdem Michalowicz et al. (2000) in Zwillingsstudien zeigen konnten, dass bei der Progression der Parodontitis ein genetischer Aspekt von Bedeutung ist, befasste sich eine Vielzahl von Studien mit einer möglichen Assoziation zwischen Genpolymorphismen und der Pathogenese und Progression der Parodontitis. Der am häufigsten untersuchte Genpolymorphismus im Zusammenhang mit der chronischen Parodontitis ist der IL-1-Polymorphismus.

Kornman et al. (1997) beschrieben als erste eine positive Assoziation zwischen dem zusammengesetzten Polymorphismus (composite genotype) aus Allel 2 des IL-1A-889 und Allel 2 des IL-1B+3954 mit der Schwere einer chronischen Parodontitis. Hierzu wurden 134 nordeuropäische Nichtraucher nach Schweregrad der Parodontitis in drei Gruppen eingeteilt: milde/keine Parodontitis $(n=49)$, moderate Parodontitis $(n=42)$ und generalisierte schwere Parodontitis $(n=43)$. Die Polymorphismen wurden anhand der DNA, die aus Blutproben gewonnen wurde, bestimmt und ein Zusammenhang mit dem Parodontitisschweregrad untersucht. 
McGuire und Nunn (1999) untersuchten den von Kornman et al. (1997) beschriebenen composite genotype im Zusammenhang mit Zahnverlust, bezogen im Gegensatz zu Kornman et al. aber auch Raucher und ehemalige Raucher mit in das untersuchte Patientenkollektiv ein: Es umfasste 42 Patienten, darunter 9 Raucher und 30 ehemalige Raucher. 16 Patienten wurden positiv auf den composite genotype getestet. Die Auswertung der Ergebnisse ergab, dass Rauchen das Risiko für Zahnverlust um den Faktor 2,9 erhöhte. Ein positiver IL-1-Genotyp ließ das Parodontitisrisiko um den Faktor 2,7 ansteigen. Eine Kombination von Rauchen und positivem IL-1-Genotyp ließ das Risiko für Zahnverlust um den Faktor 7,7 ansteigen (McGuire und Nunn 1999).

Socransky et al. (2000) bestimmten die Bakterienlast mit parodontopathogenen Mikroorganismen in der subgingivalen Plaque bei Genotyp-positiven und -negativen Patienten mit Parodontitis. Untersucht wurden die Polymorphismen IL-1A+4845 und IL1B+3954. Kornman und di Giovine (1998) hatten zuvor festgestellt, dass der IL-1APolymorphismus an Position +4845 mit dem IL-1A-889-Polymorphismus übereinstimmt und technisch einfacher zu testen ist. Außerdem beschrieben Kornman und di Giovine (1998), dass der IL-1B-Polymorphismus an Position +3953 nach einer Re-Sequenzierung als +3954 zu bezeichnen ist. Der positive Genotyp setzt sich nach Kornman und die Giovine (1998) demzufolge aus Allel 2 des IL-1A+4845 und Allel 2 des IL1B+3954 zusammen.

Nach Analyse der Sulkusflüssigkeitsproben und Genotypisierung der DNA von 108 Probanden stellten Socransky et al. fest, dass bei Genotyp-positiven Patienten in den parodontalen Taschen $>6 \mathrm{~mm}$ mehr Bakterien des orangen und roten Komplexes ermittelt werden konnten als bei Genotyp-negativen (Socransky et al. 2000).

Im Gegensatz zu Kornman et al. (1997) konnten Gore et al. (1998) eine signifikante Assoziation des Allel 2 von IL-1B+3953 allein mit dem Schweregrad der Parodontitis ermitteln. Außerdem wurde eine erhöhte Produktion an IL-1 $\beta$ bei Vorhandensein des IL-1B+3953-Polymorphismus festgestellt, die jedoch nicht statistisch signifikant war. Auch der gekoppelte Genotyp mit IL-1A-889 (composite genotype) wurde von Gore et al. untersucht. Bei 6 von 12 Patienten (50\%) mit schwerer Parodontitis und bei nur 5 von 20 Patienten (25\%) mit beginnender oder moderater Parodontitis konnte der composite genotype ermittelt werden. Außerdem wurden 9 von 32 KontrollgruppenPatienten (28,1\%) Genotyp-positiv getestet. Die Ergebnisse erreichten jedoch keine Signifikanz. Differenzen zu den Ergebnissen von Kornman et al. (1997) könnten daraus resultieren, dass bei der Studie von Gore et al. Raucher mit einbezogen wurden (Gore et al. 1998).

Meisel et al. (2003) beschrieben die Ergebnisse der SHIP (Study of Health in Pomerania), der größten Langzeit-Gesundheitsstudie zur Erforschung von Volks- 
krankheiten, bezüglich der IL-1-Polymorphismen IL-1-B+3954 und IL-1A-889 im Zusammenhang mit Parodontitis. Von 1103 möglichen Probanden zwischen 40 und 60 Jahren, Raucher einbezogen, konnten 1085 erfolgreich genotypisiert werden. Entsprechend der Vorlage von Kornman et al. (1997) wurden Probanden als „Genotyppositiv" eingestuft, wenn das Allel 2 von IL-1-B+3954 und IL-1A-889 homo- oder heterozygot vorlag. Anhand der Ergebnisse konnten Meisel et al. feststellen, dass Raucher, die Genotyp-positiv sind, ein signifikant erhöhtes Risiko für Attachmentverluste $>4 \mathrm{~mm}$ aufweisen. Bei Nicht-Rauchern konnten keine entsprechenden Ergebnisse ermittelt werden (Meisel et al. 2003). Diese Aussage widerspricht denen von Kornman et al. (1997). Die beschriebenen Studien untersuchten ausschließlich kaukasische Patientenkollektive.

López et al. (2005) führten eine entsprechende Studie in Chile durch. Sie rekrutierten 330 Patienten mit Parodontitis sowie 101 gesunde Probanden als Kontrollgruppe und untersuchten den Zusammenhang zwischen IL-1A-889 und IL-1B+3954 (einzeln und als composite genotype) und dem Schweregrad der Parodontitis. Es konnte keine signifikante Assoziation zwischen dem IL-1A-Polymorphismus an Position -889 und dem Schweregrad der Parodontitis festgestellt werden. Heterozygote Träger des Allel 2 an IL-1B+3954 wiesen hingegen eine signifikant schwerere Parodontitis auf als homozygote Träger des Allel 1 dieses Gens. Der composite genotype korrelierte ebenfalls signifikant mit dem Schweregrad der Parodontitis, sowohl bei den Rauchern als auch bei den Nicht-Rauchern des Patientenkollektivs (López et al. 2005).

Ähnliche Ergebnisse erzielte eine Studie in Indien. Agrawal et al. (2006) untersuchten je 30 Patienten mit milder, moderater und schwerer Parodontitis sowie 30 gesunde Personen als Kontrollgruppe auf einen Zusammenhang zwischen IL-1A+4845 und IL1B+3954 mit dem Schweregrad der Parodontitis. Wie bei Kornman et al. (1997) wurden Raucher von der Studie ausgeschlossen. Die Auswertung der Ergebnisse ergab eine signifikante Assoziation des composite genotypes mit der schweren chronischen Parodontitis (Agrawal et al. 2006).

Somit konnten nach Kornman et al. (1997) verschiedene weitere Studien eine positive Assoziation zwischen dem IL-1-Polymorphismus und dem Schweregrad einer Parodontitis bestätigen. Die Mehrheit der Studien, die sich mit diesem Thema befasste, widerlegte jedoch die Erkenntnisse von Kornman et al. (1997) oder stellte sie zumindest in Frage:

Hodge et al. (2001) untersuchten 56 Personen mit Parodontitis und 56 gesunde Personen im Hinblick auf eine Assoziation zwischen den Polymorphismen IL-1A-889 und IL-1B+3953 mit der early onset periodontitis (heute: Aggressive Parodontitis). Es wurden keine signifikanten Zusammenhänge ermittelt. Weder die einzelnen 
Polymorphismen noch der composite genotype konnten mit der Aggressiven Parodontitis in Zusammenhang gebracht werden. Auch das Einbeziehen des Rauchverhaltens als Kovariable beeinflusste das Ergebnis nicht (Hodge et al. 2001).

Sakellari et al. (2003) untersuchten eine griechische Population im Hinblick auf den IL1-Polymorphismus. 110 gesunde Probanden mit unbekanntem Parodontalstatus und 45 Patienten mit chronischer Parodontitis wurden bezüglich IL-1A+4845 und IL1B+3954 genotypisiert. Es konnte keine signifikante Assoziation zwischen den einzelnen Polymorphismen oder dem composite genotype und dem Vorliegen einer Parodontitis ermittelt werden. In einer weiteren Studie untersuchten Sakellari et al. neben zwei weiteren Polymorphismen erneut IL-1A-+4845 und IL-1B+3954 (Sakellari et al. 2006). 192 Probanden wurden nach parodontaler Untersuchung in zwei Gruppen eingeteilt: eine gesunde Kontrollgruppe (Sondierungstiefen $<3 \mathrm{~mm}$ ) und eine Parodontitis-Gruppe. Erneut wurden keine signifikanten Zusammenhänge zwischen dem Vorliegen einer Parodontitis und den beschriebenen IL-1-Polymorphismen festgestellt (Sakellari et al. 2006).

Inzwischen wurden mehrere Reviews zu diesem Thema publiziert: Huynh-Ba et al. veröffentlichten 2007 ein Review über die Assoziation zwischen dem IL-1 composite genotype und der Progression einer Parodontitis bzw. einem Behandlungserfolg. Fünf Studien konnten keine signifikante Assoziation zwischen dem composite genotype und der Progression der Parodontitis feststellen. Zwei Studien ermittelten eine positive Assoziation mit statistischer Signifikanz und drei Studien beschrieben eine positive Assoziation des IL-1-Genotyps mit Parodontitis innerhalb einer multifaktoriellen Risikoanalyse. Eine Studie konnte keine eindeutige Aussage bezüglich einer Assoziation zwischen IL-1-Genotyp und Parodontitis machen. Zusammengefasst ist laut Huynh-Ba et al. eine Assoziation zwischen dem IL-1-Genotyp und der Progression einer Parodontitis nicht ausreichend wissenschaftlich belegt, so dass kommerziell erwerbliche IL-1-Genotyp-Tests mit Vorsicht zu betrachten sind und der Genotyp allenfalls in eine umfangreiche Risikoanalyse gemeinsam mit Rauchverhalten, mikrobiologischem Keimspektrum, Systemerkrankungen und anderen Risikofaktoren einbezogen werden sollte (Huynh-Ba et al. 2007).

Laine et al. veröffentlichten 2010 ebenfalls ein Review über Fall-Kontroll-Studien, die sich mit der Rolle von Genpolymorphismen bei der Pathogenese und Progression der Parodontitis beschäftigten. Sie stellten fest, dass von 12 Studien, die sich mit dem Polymorphismus von IL-1A-889 bzw. +4845 als alleinigen Risikofaktor für Parodontitis bei Kaukasiern befassten, lediglich eine Studie eine positive Assoziation feststellen konnte. Laine et al. berichteten weiterhin von 16 Studien, die eine mögliche Assoziation des Polymorphismus von IL-1B+3954 bzw. +3953 und Parodontitis bei Kaukasiern 
untersuchten, wovon lediglich vier Studien einen signifikanten Zusammenhang ermitteln konnten. Zehn Studien untersuchten den Zusammenhang zwischen dem composite genotype (Allel 2 an IL-1A-889 (+4845) und IL-1B+3954 (+3953)) und dem Risiko einer Parodontitiserkrankung. Drei dieser Studien stellten eine signifikante Assoziation fest (Laine et al. 2010).

Problematisch am Vergleich von Fall-Kontroll-Studien sind die potentiellen methodischen Unterschiede (Laine et al. 2010). Beispielsweise variiert die Auswahl der Kontrollgruppen. So fungieren als Kontrollgruppen u.a. gesunde Personen oder Gingivitispatienten. Auch die Klassifikation des Parodontitisschweregrads wird an unterschiedlichen Kriterien ausgemacht. Ein weiteres Problem ist die Vielfalt des ethnischen Hintergrunds der Probanden. Da Genotyp- und Allel-Varianten zwischen verschiedenen Bevölkerungsgruppen variieren können, sollten untersuchtes Patientenkollektiv und Kontrollgruppe derselben ethnischen Bevölkerungsgruppe angehören. Grund für die bisher unzureichende Evidenz ist aber vor allem die zumeist unzureichende Größe der untersuchten Patientenkollektive und die damit verbundene mangelnde statistische Aussagekraft. Es müssen ausreichend Patienten und Gesunde untersucht werden, um die Zahl falsch positiver Ergebnisse zu minimieren. MetaAnalysen wären laut Laine et al. hilfreich (Laine et al. 2010).

Eine entsprechende Meta-Analyse führten Nikolopoulos et al. (2008) durch. Es wurden 53 Studien einbezogen, die Ergebnisse von insgesamt 4178 Patienten und 4590 Kontrollgruppen-Mitgliedern lieferten. Sechs Polymorphismen wurden untersucht, darunter IL-1A-C889T und IL-1B+C3954/3T. Die Ergebnisse der Meta-Analyse lassen darauf schließen, dass der Genpolymorphismus IL-1A-889T bei Kaukasiern mit der chronischen Parodontitis assoziiert ist (Nikolopoulos et al. 2008). Ein erhöhtes Risiko einer chronischen Parodontitis für Träger des Polymorphismus IL-1B+3954/3T konnte für Patienten asiatischer Abstammung ermittelt werden. Für Träger des composite genotypes, die sowohl das T-Allel an Position IL-1A-889 als auch an IL-1B+3954/3 aufweisen, konnte verglichen mit den Effekten der einzelnen Genpolymorphismen ein noch höheres Risiko einer chronischen Parodontitis ermittelt werden (Nikolopoulos et al. 2008).

Die vorliegende Studie konnte keinen signifikanten Einfluss des IL-1-Polymorphismus auf den Schweregrad der Parodontitis nachweisen. Anzumerken ist jedoch, dass das untersuchte Patientenkollektiv $(n=30)$ dieser Pilotstudie keine ausreichende statistische Aussagekraft bietet. Außerdem sieht der für die Untersuchung verwendete GenoType ${ }^{\circledR}$ IL-1-Test VER 1.0 der Firma Hain vor, dass die DNA des Patienten aus einem Mundschleimhaut-Abstrich gewonnen werden sollte. $\mathrm{Da}$ bei den Untersuchungen für diese Arbeit die DNA aus Blutproben der Patienten gewonnen 
wurde, muss festgehalten werden, dass dies nicht der Gebrauchsanweisung des Herstellers entspricht, auch wenn fehlerhafte Ergebnisse aufgrund der Herkunft der DNA unwahrscheinlich sind.

Zusammenfassend kann nach Literaturrecherche und Auswertung der Ergebnisse der vorliegenden Studie keine endgültige Aussage bezüglich einer möglichen Assoziation zwischen den Polymorphismen an IL-1A-889(+4845) und IL-1B+3954/3 und der chronischen Parodontitis getroffen werden. Weiterführende Studien scheinen sinnvoll. Zum Einfluss des IL-1-Polymorphismus auf Herz-Kreislauf-Erkrankungen existieren verschiedene Publikationen, teilweise auch im Zusammenhang mit Parodontitis. Francis et al. (1999) genotypisierten 130 Kontrollgruppen-Patienten, 98 Patienten mit koronarer 1-Gefäßerkrankung und 328 mit koronarer Mehr-Gefäßerkrankung. Es konnten keine signifikanten Unterschiede in der Verteilung von IL-1A-889 und IL1B+3954 in den drei Gruppen festgestellt werden. Jedoch wurde eine signifikante Assoziation zwischen dem IL-1RN-Polymorphismus und der 1-Gefäßerkrankung ermittelt (Francis et al. 1999). Da IL-1-Genpolymorphismen in früheren Studien sowohl mit der Parodontitis als auch mit Herz-Kreislauf-Erkrankungen in Verbindung gebracht wurden, untersuchten Kornman et al. (1999) einen möglichen Zusammenhang. Es wurde festgestellt, dass der composite genotype aus IL-1A+4845 und IL-1B+3954 zwar mit erhöhtem Risiko einer schweren chronischen Parodontitis assoziiert ist, nicht jedoch mit dem Risiko einer Herz-Kreislauf-Erkrankung. Hingegen konnte für den Genotyp aus IL-1-RN+2018 und IL-1B-511 eine Assoziation mit der koronaren Herzerkrankung ermittelt werden, nicht aber mit der Parodontitis (Kornman et al. 1999). López et al. (2009) bestimmten bei 73 Patienten mit chronischer Parodontitis, Hyperlipidämie und anderen Risikofaktoren für eine Herz-Kreislauferkrankung den CRP-Wert vor und nach Parodontalbehandlung und Antibiotikagabe. Gleichzeitig wurden die Patienten genotypisiert (IL-1A-889 und IL-1B+3954). Nach der Parodontalbehandlung bei Patienten mit Risikofaktoren für eine Herzerkrankung konnte ein CRPAnstieg ermittelt werden, der signifikant assoziiert war mit dem IL-1-Polymorphismus und schwerer Parodontitis (López et al. 2009).

In der vorliegenden Studie wurde eine mögliche Assoziation zwischen dem IL-1Genotyp und der Menge an big42-LBP am Herzgewebe untersucht. Es konnten keine Zusammenhänge ermittelt werden.

\subsection{Untersuchung möglicher Einflussfaktoren auf den Parodontalstatus}

Verschiedene Studien ermittelten, dass Männer ein höheres Parodontitisrisiko haben als Frauen (Albandar und Kingman 1999; Shiau und Reynolds 2010). Diese Theorie 
konnte im untersuchten Patientenkollektiv nicht unterstützt werden, das Geschlecht hatte keinen Einfluss auf den Schweregrad der Parodontitis.

Bei der Untersuchung eines Einflusses des Rauchverhaltens der Probanden auf den Schweregrad der Parodontitis konnten zwar statistisch keine signifikanten Ergebnisse ermittelt werden, jedoch wiesen alle acht Raucher des Kollektivs eine schwere Parodontitis auf. Diese Tatsache entspricht den Erkenntnissen vieler Studien, die eine Assoziation zwischen Rauchen und der Pathogenese und Progression einer Parodontitis beweisen konnten (Tonetti 1998; Bergström 1989; Bergström 2004; Bergström et al. 2000).

\subsection{Lipopolysaccharide und Lipopolysaccharid-bindendes Protein}

Bei der Ermittlung der Werte für das Lipopolysaccharid-bindende Protein (LBP) an Atrium, Ventrikel und Klappe jedes Patienten konnte festgestellt werden, dass bei allen Patienten der LBP-Antikörper big42 an der Herzklappe nachgewiesen werden konnte. Am Atrium wurde big42 bei 28 Patienten und am Ventrikel bei 26 Patienten nachgewiesen.

Entsprechend stellten sich auch die ermittelten Mengen an LBP dar. So konnten die größten Mengen LBP an der Herzklappe festgestellt werden, gefolgt von Atrium und die geringsten Mengen an LBP wurden am Ventrikel ermittelt.

Anhand der Ergebnisse kann davon ausgegangen werden, dass bei den untersuchten Patienten LBP am Herzen vorhanden ist und LPS demnach dort binden kann.

Aber auch wenn LPS in der Lage scheint, über LBP am Myokard zu binden und dort Entzündungsreaktionen auszulösen, die die Entstehung einer Herzinsuffizienz begünstigen könnten, ist noch ungeklärt, woher das LPS stammt.

Einen möglichen Einfluss des LPS auf die Entstehung und Progression einer Herzinsuffizienz untersuchten bereits mehrere Studien (Rauchhaus et al. 2000; Sharma et al. 2005; Mann 2002; Seta et al. 1996; Staudt et al. 2002; Rauchhaus 2008). Dabei wurde als mögliche Quelle für die Lipopolysaccharide der Gastrointestinaltrakt vermutet (Rauchhaus 2008).

Lepper et al. vermuteten, dass LPS von Bakterien wie Chlamydia pneumonia, Heliobacter pylori oder Porphyromonas gingivalis stimulierend auf die Entzündungsreaktion bei der Pathogenese der Arteriosklerose wirken könnte (Lepper et al. 2007). Auch andere Studien befassten sich mit der Rolle des LPS bei der Progression der Herzinsuffizienz, wobei immer davon ausgegangen wurde, dass die gramnegativen Darmbakterien den Ursprung des LPS bilden (Anker et al. 1997; Niebauer et al. 1999; Charalambous et al. 2007). 
Bisher konnte jedoch nicht ausreichend geklärt werden, von welchen Bakterien das LPS, falls es wirklich eine Rolle bei der Entstehung der Herzinsuffizienz spielt, stammt. Die Tatsache, dass zum Zeitpunkt der Untersuchung bei keinem der Patienten eine entzündliche Darmerkrankung vorlag, schließt ein Vorhandensein von gramnegativen Darmbakterien am Herzen weitestgehend aus. Dies unterstützt die Hypothese, dass die Endotoxine am Myokard aus parodontopathogenen Mikroorganismen stammen könnten.

\subsection{Zusammenhang zwischen LBP und Schweregrad der Parodontitis}

Die statistische Auswertung der Ergebnisse ergab, dass für den Ventrikel ein Zusammenhang zwischen der Menge an LBP und dem Schweregrad der Parodontitis nachgewiesen werden konnte. Dieses Ergebnis bekräftigt die aufgestellte Hypothese, dass die Endotoxine parodontopathogener Mikroorganismen in der Lage sind, über den Blutkreislauf zum Myokardgewebe zu gelangen, dort zu binden und Entzündungsreaktionen zu stimulieren. Folgestudien sollten diesen Aspekt näher untersuchen. Für Atrium und Klappe konnte keine signifikante Korrelation mit dem Schweregrad der Parodontitis festgestellt werden.

\subsection{Ausblick}

Aufgrund der erlangten Erkenntnisse scheinen weiterführende Untersuchungen zu diesem Thema sinnvoll. Um aussagekräftigere Ergebnisse zu erhalten, wäre ein größeres Patientenkollektiv wünschenswert. Außerdem sollte eine ausreichend große Kontrollgruppe parallel untersucht werden, wobei sich hier zahnlose Patienten anbieten würden. Vor allem die beobachtete Assoziation von LBP am Ventrikel und dem Schweregrad der Parodontitis sollte in weiteren Studien umfassend analysiert und statistisch validiert werden.

Die vorliegenden Ergebnisse unterstützen die Empfehlung, die Zusammenarbeit zwischen Kardiologen und Zahnärzten zu intensivieren. Auch wenn bisher keine entsprechenden Leitlinien vorhanden sind, sollte die parodontale Gesundheit bei Prävention, Diagnostik und Therapie von Herzerkrankungen Berücksichtigung finden. 


\section{Zusammenfassung}

Ziel der vorliegenden Studie im Rahmen eines Pilotprojektes mit verschiedenen Einzelprojekten war es nachzuweisen, ob Lipopolysaccharide (LPS) parodontopathogener Mikroorganismen in der Lage sind, am menschlichen Myokard zu binden um dort Entzündungsreaktionen in den Myokardzellen auszulösen. Es wurde eine quantitative Bestimmung von Lipopolysaccharid-bindendem Protein (LBP) an Atrium, Ventrikel und Klappe durchgeführt und eine mögliche Assoziation zum Schweregrad der Parodontitis untersucht.

Als Probanden dienten Patienten, die sich aufgrund einer Aortenklappenstenose oder -insuffizienz einer Aortenklappenersatz-Operation unterziehen mussten. 30 Patienten (10 Frauen, 20 Männer) im Alter von 67,7 $\pm 9,3$ Jahren wurden untersucht.

Nach Patientenaufklärung, Einwilligung und Anamnese wurden der zahnärztliche Befund (DMFT und Papillen-Blutungs-Index) und der parodontale Status der Probanden erfasst. Anhand der Sondierungstiefen und des Attachmentlevels wurde der Schweregrad der Parodontitis bestimmt. Im Zuge der Operation entnahmen Thorax-Herz-Gefäßchirurgen Herzgewebe- und Blutproben.

Der mittlere DMFT betrug 21,6 $\pm 4,9$. Für den Papillen-Blutungs-Index ergab sich folgende Einteilung: Grad 0: n=11, Grad 1: n=11, Grad 2: n=6, Grad 3: n=2.

23 Patienten wiesen eine schwere Parodontitis auf, 5 Patienten eine leichte und 2 Patienten litten unter keiner oder milder Parodontitis.

Im Labor wurde das während der Aortenklappenersatz-Operation entnommene Herzgewebe mittels Proteinaufreinigung und Westernblot-Verfahren auf das Vorhandensein von LBP untersucht. Außerdem wurde DNA aus Blutproben extrahiert und auf einen IL-1-Polymorphismus (Genotyp) getestet.

LBP konnte bei allen Patienten am Herzen nachgewiesen werden. Die höchste big42LBP-Expression konnte für die Aortenklappe ermittelt werden. Die geringsten Werte wurden für den Ventrikel gemessen.

Bei acht Probanden lag ein Genotypmuster 1 (kein erhöhtes genetisches Parodontitisrisiko) vor, bei elf Patienten ein Genotypmuster 2 (erhöhtes genetisches Parodontitisrisiko), bei drei Patienten ein Genotypmuster 3 (stark erhöhtes genetisches Parodontitisrisiko) und bei acht Patienten ein Genotypmuster 4 (verminderte genetische Entzündungshemmung).

Die statistische Auswertung der Resultate ergab keine relevanten Einflüsse von Geschlecht und Rauchverhalten auf den Schweregrad der Parodontitis bzw. den Papillen-Blutungs-Index (PBI). Ebenfalls nicht signifikant waren die Ergebnisse für den 
Einfluss des IL-1-Genotyps auf den Schweregrad der Parodontitis $(p=0,259)$ bzw. den PBI $(p=0,167)$.

Die Menge an LBP stand in keinem Zusammenhang zu dem ermittelten PBI oder dem IL-1-Genotyp der Patienten, jedoch konnte eine Assoziation zwischen dem Vorhandensein von LBP am Ventrikel und dem Schweregrad der Parodontitis beobachtet werden ( $p=0,018)$. Für Atrium $(p=0,577)$ und Klappe $(p=0,198)$ konnte kein Zusammenhang zwischen LBP und dem Schweregrad der Parodontitis gezeigt werden. Die ermittelten Ergebnisse unterstützen die Arbeitshypothese, dass LPS parodontopathogener Mikroorganismen in der Lage ist, am Myokard zu binden und schädigenden Einfluss auszuüben. Zur Aufschlüsselung der verantwortlichen Mechanismen scheinen weiterführende Studien sinnvoll. 


\section{$7 \quad$ Anhang}

\subsection{Materiallisten}

\subsubsection{Untersuchung der Herzgewebeproben}

\begin{tabular}{|l|l|}
\hline Chemikalien & Hersteller, Ort, Land \\
\hline 1.Antikörper: big42 antibody to human LBP & Biometec GmbH, Greifswald, Deutschland \\
\hline 1-Butanol & Roth GmbH, Karlsruhe, Deutschland \\
\hline 2.Antikörper: goat anti mouse HRP & Thermo Fisher Scientific, Waltham, USA \\
\hline Acrylamid (Rotiphorese Gel) & Roth GmbH, Karlsruhe, Deutschland \\
\hline Ammoniumperoxidsulfat (APS) & Roth GmbH, Karlsruhe, Deutschland \\
\hline Bromphenolblau & Roth GmbH, Karlsruhe, Deutschland \\
\hline Dithiothreitol (DTT) & Merck KGaA, Darmstadt, Deutschland \\
\hline Glycerinaldehyd-3-phosphat-Dehydrogenase & Hy-Test Ltd., Turku, Finnland \\
\hline GAPDH) & \\
\hline Glycerol & $\begin{array}{l}\text { Sigma-Aldrich GmbH, Steinheim, } \\
\text { Deutschland }\end{array}$ \\
\hline Mercaptoethanol & Roth GmbH, Karlsruhe, Deutschland \\
\hline Methanol & chem solute \\
\hline Natriumchlorid (NaCl) & Roth GmbH, Karlsruhe, Deutschland \\
\hline Natriumdodecylsulfat (SDS) & Roth GmbH, Karlsruhe, Deutschland \\
\hline Natriumfluorid (NaF) & Roth GmbH, Karlsruhe, Deutschland \\
\hline Natriumpyrophosphat & Roth GmbH, Karlsruhe, Deutschland \\
\hline Ponceau S & Roth GmbH, Karlsruhe, Deutschland \\
\hline Starting Block (TBS) Blocking Buffer & Thermo Fisher Scientific, Waltham, USA \\
\hline Sucrose & $\begin{array}{l}\text { Sigma-Aldrich GmbH, Steinheim, } \\
\text { Deutschland }\end{array}$ \\
\hline Tetramethylethylendiamin (TEMED) & Roth GmbH, Karlsruhe, Deutschland \\
\hline Trichloressigsäure (20\%) & Roth GmbH, Karlsruhe, Deutschland \\
\hline Trishydroxymethylaminomethan (TRIS) & Roth GmbH, Karlsruhe, Deutschland \\
\hline Triton X-100 & Roth GmbH, Karlsruhe, Deutschland \\
\hline Tween20 & Roth GmbH, Karlsruhe, Deutschland \\
\hline
\end{tabular}

Tab. 22: Verwendete Chemikalien

\begin{tabular}{|l|l|}
\hline Hilfsmittel & Hersteller, Ort, Land \\
\hline BCA-Proteinassay-Kit & Thermo Fisher Scientific, Waltham, USA \\
\hline Eppendorf Tubes $(1,5 \mathrm{ml}$ und $2 \mathrm{ml})$ & Eppendorf AG, Hamburg, Deutschland \\
\hline Gelloadertips & Eppendorf AG, Hamburg, Deutschland \\
\hline $\begin{array}{l}\text { Glasplatten: Spacer Plate \& Short Plate } \\
(0,75 \mathrm{~mm})\end{array}$ & Bio-Rad GmbH, München, Deutschland \\
\hline
\end{tabular}




\begin{tabular}{|c|c|}
\hline Kaleidoscope (Proteingrößenmarker) & Bio-Rad GmbH, München, Deutschland \\
\hline Küvette: Uvette & Eppendorf AG, Hamburg, Deutschland \\
\hline Mini Trans-Blot Cell & Bio-Rad GmbH, München, Deutschland \\
\hline Mini-PROTEAN Tetra System & Bio-Rad GmbH, München, Deutschland \\
\hline Mörser & W. Haldenwanger, Waldkraiburg, Deutschland \\
\hline OrthoMedium Curix Screens (Filmkassette) & Agfa GmbH, Düsseldorf, Deutschland \\
\hline Pistillen & W. Haldenwanger, Waldkraiburg, Deutschland \\
\hline Protease Inhibitor Cocktail & Sigma-Aldrich GmbH, Steinheim, Deutschland \\
\hline Research Pipette 0,5-10 $\mu$ l & Eppendorf AG, Hamburg, Deutschland \\
\hline Research Pipette 10-100 $\mu$ l & Eppendorf AG, Hamburg, Deutschland \\
\hline SuperRX Fuji Medical X-Ray Film & Fujifilm GmbH, Düsseldorf, Deutschland \\
\hline $\begin{array}{l}\text { SuperSignal West Pico Chemiluminescent } \\
\text { Substrate }\end{array}$ & Thermo Fisher Scientific, Waltham, USA \\
\hline TipOne Filter Tips (Pipettenspitzen) & STARLAB GmbH, Ahrensburg, Deutschland \\
\hline 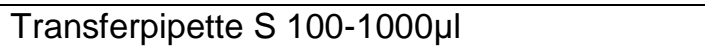 & Brand GmbH, Wertheim, Deutschland \\
\hline Whatman Filterpapier (3mm CHR) & Roth GmbH, Karlsruhe, Deutschland \\
\hline $\begin{array}{l}\text { Whatman PROTRAN Nitrocellulose Transfer } \\
\text { Membrane }\end{array}$ & Roth GmbH, Karlsruhe, Deutschland \\
\hline Zentrifugenröhrchen ECO & Karlsruhe, Deutschland \\
\hline
\end{tabular}

Tab. 23: Verwendete Hilfsmittel

\begin{tabular}{|l|l|}
\hline Geräte & Hersteller, Ort, Land \\
\hline Bio Doc Analyze & Biometra GmbH, Göttingen, Deutschland \\
\hline BioMate5 & Thermo Spectronic, Dreieich, Deutschland \\
\hline Centrifuge 5415 R & Eppendorf AG, Hamburg, Deutschland \\
\hline MS2 Minishaker & IKA GmbH, Staufen, Deutschland \\
\hline $\begin{array}{l}\text { Röntgenfilm-Entwicklungsmaschine: SRX- } \\
\text { 101A }\end{array}$ & Konica Minolta, Langenhagen, Deutschland \\
\hline Polymax 1040 (Plattformschüttler) & $\begin{array}{l}\text { Heidolph Instruments GmbH, Schwabach, } \\
\text { Deutschland }\end{array}$ \\
\hline Standard Power Pack P25 & Biometra GmbH, Göttingen, Deutschland \\
\hline ThermoStat plus & Eppendorf AG, Hamburg, Deutschland \\
\hline
\end{tabular}

Tab. 24: Verwendete Geräte

\begin{tabular}{|l|l|}
\hline Software & Hersteller, Ort, Land \\
\hline $\begin{array}{l}\text { BioDocAnalyze BDA U-205 } \\
\text { Ser.Nr.660748627-0 }\end{array}$ & Biometra GmbH, Göttingen, Deutschland \\
\hline VISIONlite Quant Version 1.0 & Thermo Spectronic, Dreieich, Deutschland \\
\hline
\end{tabular}

Tab. 25: Verwendete Software 


\subsubsection{Untersuchung der Blutproben}

\begin{tabular}{|l|l|}
\hline Chemikalien & Hersteller, Ort, Land \\
\hline Ethanol $(100 \%)$ & Merck KGaA, Darmstadt, Deutschland \\
\hline Ficoll-Lösung: Bicoll & Biochrom AG, Berlin, Deutschland \\
\hline PBS-Puffer & Invitrogen, Darmstadt, Deutschland \\
\hline
\end{tabular}

Tab. 26: Verwendete Chemikalien

\begin{tabular}{|l|l|}
\hline Hilfsmittel & Hersteller, Ort, Land \\
\hline Genotype IL-1 VER1.0 & Hain Lifescience GmbH, Nehren, Deutschland \\
\hline HotStarTaqPlus (DNA-Polymerase) & Qiagen GmbH, Hilden, Deutschland \\
\hline Pipette: Multipette plus & Eppendorf AG, Hamburg, Deutschland \\
\hline QIAamp DNA Mini Kit & Qiagen GmbH, Hilden, Deutschland \\
\hline Sarpette & Sarstedt AG, Nümbrecht, Deutschland \\
\hline Stabpipette & Sarstedt AG, Nümbrecht, Deutschland \\
\hline Zentrifugenröhrchen & Sarstedt AG, Nümbrecht, Deutschland \\
\hline
\end{tabular}

Tab. 27: Verwendete Hilfsmittel

\begin{tabular}{|l|l|}
\hline Geräte & Hersteller, Ort, Land \\
\hline MS2-Minishaker & IKA-Werke GmbH, Staufen, Deutschland \\
\hline $\begin{array}{l}\text { sterile Werkbank: } \\
\text { Airclean PCR Workstation }\end{array}$ & Airclean Systems, Raleigh, USA \\
\hline TwinCubator & Hain Lifescience GmbH, Nehren, Deutschland \\
\hline Zentrifuge: Heraeus Biofuge primo R & Thermo Scientific, Bonn, Deutschland \\
\hline Zentrifuge: Centrifuge 5415 R & Eppendorf AG, Hamburg, Deutschland \\
\hline
\end{tabular}

Tab. 28: Verwendete Geräte 


\subsection{Formulare}

\subsubsection{Patientenaufklärung}

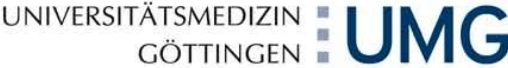

Prof. Dr. med. dent. Rainer F. Mausberg; Georg-August-Universität Göttingen, Zentrum Zahn-, Mundund Kieferheilkunde; Abteilung Zahnerhaltung und Präventive Zahnheilkunde und Parodontologie; Robert-Koch-Str. 40, 37075 Göttingen; Tel.: 0551/3922877

Prof. Dr. Dipl.-Phys. Friedrich Schöndube; Georg-August-Universität Göttingen, Zentrum Chirurgie der Universitätsmedizin; Abteilung der Thorax-, Herz- und Gefäß-Chirurgie; Robert- Koch-Str. 40, 37075 Göttingen; Telefon: 0551/396001

Patientenaufklärung - Studienteilnahme

„Klinisch - Experimentelle Studie zur möglichen Assoziation parodontaler Gesundheit und verschiedenen Herzerkrankungen“

Sehr geehrte Patientin, sehr geehrter Patient!

Hiermit möchten wir Sie um die freiwillige Teilnahme an der klinisch-wissenschaftlichen Untersuchung: „Klinisch Experimentelle Studie zur möglichen Assoziation parodontaler Gesundheit und verschiedenen Herzerkrankungen“ bitten.

Parodontitis ist eine Erkrankung von Zahnfleisch und zahnumgebenden Knochen, dem so genannten Zahnhalteapparat; bis hin zum Verlust des Zahnhalteapparates und Abbau des Kieferknochens. Als Folge können betroffene Zähne verloren gehen. Einer Entzündung des gesamten Zahnhalteapparates geht in der Regel eine Entzündung des Zahnfleisches voraus. Dabei spielen viele verschiedene Faktoren eine Rolle: Zahnbelag (Plaque), bestimmte Bakterien, körpereigene Abwehr, aber auch Allgemeinerkrankungen (z.B. Diabetes mellitus, HIV) oder Medikamente. Die Entzündung des Zahnhalteapparates lässt sich durch Messung von Zahnfleischtaschen und Beurteilung des Knochenabbaus aufzeigen und diagnostizieren. Zahnfleischbluten und zunehmende Lockerung des Zahnes können weitere Hinweise geben. Mikrobielle Untersuchungen zur Bestimmung der Menge und Art der in der Zahnfleischtasche befindlichen Bakterien können zudem eine genauere Auskunft über Krankheitszustand und den Verlauf geben.

Grund dieser Studie ist die Überprüfung der klinischen Zusammenhänge von Allgemeinerkrankungen (in diesem Fall Erkrankungen am Herzen) mit Erkrankungen des Zahnhalteapparates. Ziel dieser rein wissenschaftlichen Untersuchung soll es sein, Patienten mit Herzerkrankung hinsichtlich möglicher Zusammenhänge zwischen der Parodontitis und der Herzerkrankungen zu untersuchen. Mit Ihrer Teilnahme können Sie uns helfen herauszufinden ob und welche Zusammenhänge zwischen den beiden Erkrankungen existieren.

Um Aussagen über den jeweiligen Mundhygiene- und Entzündungszustand treffen zu können, werden spezielle Befunde erhoben, die sich aus einem Kariesbefund, der Messung der Entzündung des Zahnfleischs und aus Feststellung des Zustands des Zahnhalteapparates (Messung der Zahnfleischtaschen; Feststellung der Zahnlockerung) zusammensetzen. 


\section{UNIVERSITÄTSMEDIZIN $=\mathbf{U M G}$
GÖTTINGEN :}

Zusätzlich erfolgt eine Bestimmung von vorhandenen Bakterien aus der Zahnfleischtasche. Die Untersuchungen an Ihren Zähnen und an Ihrem Zahnfleisch führt ein Doktorand (9. Semester Zahnheilkunde) der Abt. Zahnerhaltung, Präventiven Zahnheilkunde und Parodontologie der Universitätsmedizin Göttingen nach Absprache mit Ihrem betreuendem Arzt durch.

Des Weiteren bitten wir Sie, einige Fragen zu Ihrem Allgemeinzustand, Lebensgewohnheiten und Mundgesundheitszustand zu beantworten. Bitte versuchen Sie diese Fragen wahrheitsgemäß und möglichst genau zu beantworten

Der Zeitraum der Untersuchung ist ein Tag vor oder nach der Operation geplant und wird bei Ihnen auf Station am Bett durchgeführt. Der Mehraufwand an Zeit pro Untersuchung beträgt ca. 15 Minuten; es entstehen für Sie keine zusätzlichen Kosten. Risiken und Nebenwirkungen bei der Durchführung der Untersuchung sind nicht zu erwarten bzw. bestehen nicht, da keine Medikamente, operative Eingriffe oder Anfertigungen von Röntgenaufnahmen notwendig sind; jedoch kann die Untersuchung ggf. unangenehm sein und möglicherweise geringfügige Blutungen provozieren. Um mögliche Unannehmlichkeiten zu verhindern, wird Ihr Zustand nach der Operation berücksichtigt und ggf. auf die Untersuchung verzichtet. Im Rahmen der postoperativen Maßnahmen sind Sie antibiotisch abgedeckt und es erübrigt sich eine eventuell notwendige Endokarditisprophylaxe.

Ihre personenbezogenen Daten unterliegen dem Datenschutz und werden vom Leiter der Prüfung nicht weitergegeben. Sie werden pseudonymisiert behandelt (anstelle von Namen und Geburtsdatum wird ein Zahlencode verwendet), nur zu Untersuchungszwecken verwendet und nach der Auswertung vernichtet.

Wir bitten um die freiwillige Teilnahme an der Studie. Sie können jederzeit die Teilnahme widerrufen, ohne Angabe von Gründen und ohne Nachteile erwarten zu müssen. Nach Ihrem Widerruf erfolgt unverzüglich die Vernichtung Ihrer personenbezogenen Daten.

Für Rückfragen stehen Ihnen der Studienleiter und der durchführende Zahnarzt unter o.g.

Telefonnummern zur Verfügung.

Vielen Dank für Ihre Teilnahme.

Ort und Datum Unterschrift 


\subsubsection{Einverständniserklärungen}

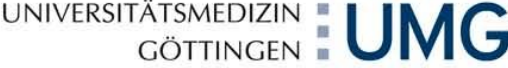

Prof. Dr. med. dent. Rainer F. Mausberg; Georg-August-Universität Göttingen, Zentrum Zahn-, Mundund Kieferheilkunde; Abteilung Zahnerhaltung; Präventive Zahnheilkunde und Parodontologie; RobertKoch-Str. 40, 37075 Göttingen; Tel.: 0551/3922877

Prof. Dr. Dipl.-Phys. Friedrich Schöndube; Georg-August-Universität Göttingen, Zentrum Chirurgie der Universitätsmedizin; Abteilung der Thorax-, Herz- und Gefäß-Chirurgie; Robert- Koch-Str. 40, 37075 Göttingen; Telefon: 0551/396001

\section{Einverständniserklärung - Teilnahme an Untersuchung}

„Klinisch - Experimentelle Studie zur möglichen Assoziation parodontaler Gesundheit und verschiedenen Herzerkrankungen

Ich, wurde von meinem Arzt vollständig über Wesen,

Bedeutung und Tragweite der klinischen Untersuchung mit dem Titel:

„Klinisch - Experimentelle Studie zur möglichen Assoziation parodontaler Gesundheit und verschiedenen Herzerkrankungen" aufgeklärt.

Mir ist bekannt, dass bei dieser Untersuchung personenbezogene Daten, insbesondere der medizinische Befund über mich erhoben, gespeichert und ausgewertet werden sollen. Die Verwendung der Angaben über meine Gesundheit erfolgt nach gesetzlichen Bestimmungen und setzt vor der Teilnahme an der Klinischen Prüfung die folgende freiwillig abgegebene Einwilligungserklärung voraus

Ich hatte ausreichend Zeit, mich zur Teilnahme an dieser Untersuchung zu entscheiden und weiß, dass die Teilnahme freiwillig ist.

Mir ist bekannt, dass ich jederzeit und ohne Angaben von Gründen diese Zustimmung widerrufen kann, ohne dass sich dieser Entschluss nachteilig auf meine weitere Behandlung auswirkt.

Ich habe eine Kopie der Patienteninformation und dieser Einwilligungserklärung erhalten.

Ich erkläre hiermit meine freiwillige Teilnahme an dieser Studie.

Ort und Datum

Unterschrift des Teilnehmers

Ort und Datum

Unterschrift des Prüfarzt

Universitätsmedizin Göttingen, Georg-August-Universität Stifftung Öffentlichen Rechts Vorstand Prof. Dr. Cornelius Frömmel (Forschung \& Lehre, Sprecher des Vorstands) Priv. Doz. Dr. Günther Bergmann (Krankenversorgung) Dipl.-Kffr. (FH) Barbara Schulte (Wirtschaftsführung \& Administration) Sparkasse Göttingen (260500 01) Kto:448 


\section{UNIVERSITÄTSMEDIZIN
GÖTTINGEN "}

Prof. Dr. med. dent. Rainer F. Mausberg; Georg-August-Universităt Göttingen, Zentrum Zahn-, Mund- und Kieferheilkunde; Abteilung Zahnerhaltung; Präventive Zahnheilkunde und Parodontologie; Robert-Koch-Str. 40, 37075 Göttingen; Tel. : 0551/3922877

Prof. Dr. Dipl.-Phys. Friedrich Schöndube; Georg-August-Universität Göttingen, Zentrum Chirurgie der Universitätsmedizin; Abteilung der Thorax-, Herz- und Gefäß-Chirurgie; Robert- Koch-Str. 40, 37075 Göttingen; Telefon: 0551/396001

\section{Einverständniserklärung}

Wissenschaftliche Verwendung von Blut und (Rest-)Gewebe.

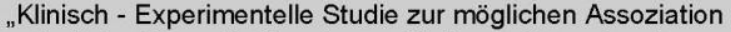

parodontaler Gesundheit und verschiedenen Herzerkrankungen"

Erklärung der Patientin, des Patienten nach dem Aufklärungsgespräch mit dem Arzt / Ärztin

Herr/Frau Dr.

hat mir anhand der Hinweise im Merkblatt den Zweck und die Vorgehensweise einer Blut-/ Gewebespende für die geplante wissenschaftliche Untersuchung ausführlich dargelegt. Ich wurde ebenfalls über den Umgang mit den erhobenen Daten und das Vorgehen bei der Verschlüsselung der Proben informiert. Alle Fragen wurden zu meiner Zufriedenheit beantwortet. Ich habe die zusätzlichen Hinweise (keine kommerzielle Verwendung des Gewebes, keine Genmanipulationen, Datenschutz, Recht auf Widerruf) zur Kenntnis genommen, das Aufklärungsblatt habe ich erhalten.

Hiermit erkläre ich mich einverstanden mit (Bei Zustimmung bitte bei ja ankreuzen)

- der wissenschaftlichen Verwendung vom Restgewebe (dabei wird lediglich das Gewebe verwendet, das aus medizinischen Gründen entnommen werden musste und nicht für weitere diagnostische Maßnahmen benötigt wird),

ja ( ) nein ()

- der Blutentnahme von insgesamt $5 \mathrm{ml}$ (dieses Blut wird im Rahmen einer medizinisch notwendiger Routineblutentnahme zusätzlich entnommen). , ja ( ) nein ( )

Besondere Bestimmungen für den Umgang mit den pseudonymisierten Blut-/Gewebeproben.

Ich bin damit einverstanden, dass die entnommene Blut-/Gewebeprobe in der ThoraxHerz- und Gefäßchirurgie Göttingen zeitlich uneingeschränkt aufbewahrt und in der Universitätsmedizin Göttingen für wissenschaftliche Untersuchungen verwendet wird. ja () nein ()

Die gegebene Einwilligung ist freiwillig und kann jederzeit ohne die Angabe von Gründen mündlich oder schriftlich bei: Anschrift- und Telefonnummer der Kontaktstelle widerrufen werden, ohne daß dies nachteilige Folgen für die weitere medizinische Behandlung hat.

Es gelten die im Aufklärungstext beschriebenen Maßnahmen zur Wahrung des Datenschutzes; eine Weitergabe von Proben oder Krankheitsdaten erfolgt ausschließlich in verschlüsselter (pseudonymisierter) Form.

Die unterschriebene Einwilligungserklärung wurde mir in Kopie ausgehändigt.

Göttingen,

den.......

Unterschrift der Patientin Unterschrift des Arztes

(Name in Blockbuchstaben) (Name in Blockbuchstaben) 


\subsubsection{Anamnesebogen}

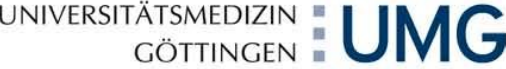

Prof. Dr. med. dent. Rainer F. Mausberg; Georg-August-Universität Göttingen, Zentrum Zahn-, Mundund Kieferheilkunde; Abteilung Zahnerhaltung und Präventive Zahnheilkunde und Parodontologie; Robert-Koch-Str. 40, 37075 Göttingen; Tel.: 0551/3922877

\section{Anamnesebogen}

„Klinisch - Experimentelle Studie zur möglichen Assoziation parodontaler Gesundheit und verschiedenen Herzerkrankungen"

Pat.-Nr.

Datum:

Bitte beantworten Sie die folgenden Fragen bzw. kreuzen Sie Zutreffendes an. Mehrfachantworten sind möglich. Die gewissenhafte Beantwortung ist eine Voraussetzung für den Erfolg der Studie!

1. Sind Sie in ständiger ärztlicher Behandlung?

ja nein Wenn ja, weswegen?

2. Leiden Sie an einer Herzerkrankung? (z.B. A. pectoris, Endokarditis, Klappenfehler)

3. Müssen Sie ständig Medikamente einnehmen? Wenn ja, welche?

z.B. zur Blutzuckersenkung; gegen Herzbeschwerden, Bluthochdruck; zur Hemmung der Blutgerinnung; Rheumamittel; Beruhigungs-/Schlaftabletten)

4. Sind Sie zur Zeit in ärztlicher Behandlung?

Wenn ja, weswegen?

Wann sind Sie zum letzten Mal zahnärztlich untersucht worden?

6. Sind Ihre Zähne temperaturempfindlich?

7. Blutet Ihr Zahnfleisch?

8. Bemerken Sie Stellungsveränderungen Ihrer Zähne?

9. Haben Sie manchmal einen schlechten Geschmack im Mund?

10. Haben Sie wegen Zahnlockerung bzw. Zahnfleischbeschwerden schon einmal einen Zahnarzt aufgesucht? Wenn ja, was wurde gemacht? Wenn ja, wann?

12. Rauchen Sie oder haben Sie geraucht?

13. Wie viel Zigaretten/Schachteln pro Tag etwa?
......... Zigaretten/ Tag, Schachteln/ Tag 


\subsection{Abbildungsverzeichnis}

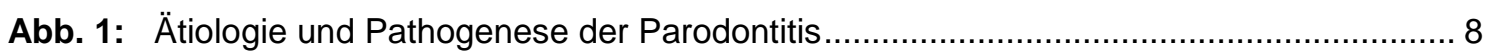

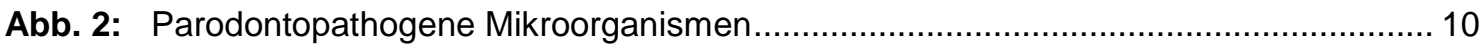

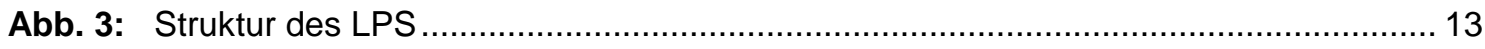

Abb. 4: Wirkmechanismus von Lipopolysacchariden ........................................................ 14

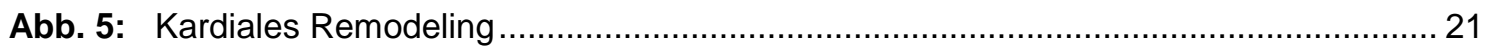

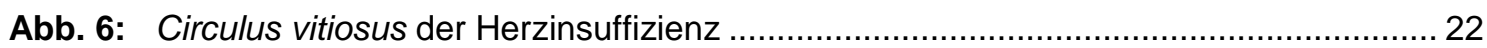

Abb. 7: Mögliche pathways der Assoziation zwischen Parodontitis und KHK ......................... 26

Abb. 8: Vorbereitung des Proteintransfers in der Mini Trans-Blot Cell .................................... 35

Abb. 9: Farbkopie der gefärbten Nitrocellulosemembran.................................................... 36

Abb. 10: Entwickelter Röntgenfilm nach 1 min. Belichtung ................................................... 38

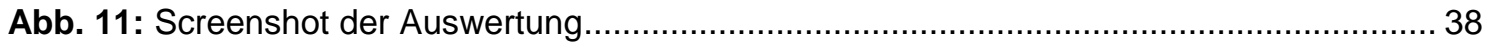

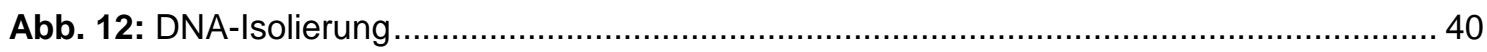

Abb. 13: Auswertung mit Schablone und Auswertungsbogen ................................................ 43

Abb. 14: Alters- und Geschlechtsstruktur des Patientenkollektivs ......................................... 45

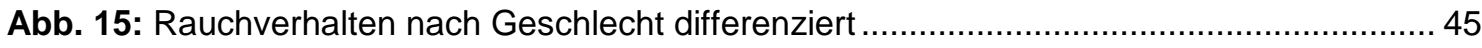

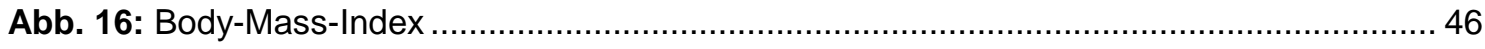

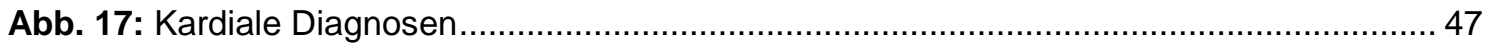

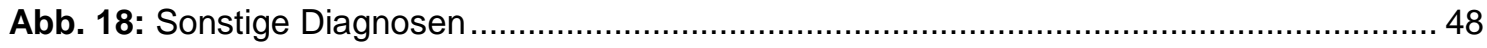

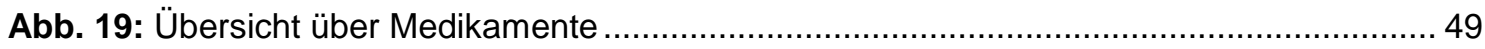

Abb. 20: Anteil der Einzelkomponenten des DMFT-Indexes (DT, MT und FT) am mittleren

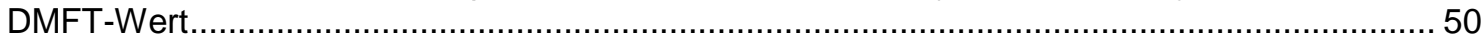

Abb. 21: Papillen-Blutungs-Index differenziert nach Geschlecht .............................................. 50

Abb. 22: Papillen-Blutungs-Index differenziert nach Rauchverhalten ....................................... 51

Abb. 23: Mittlere Sondierungstiefen differenziert nach Geschlecht ...................................... 51

Abb. 24: Mittlere Sondierungstiefen differenziert nach Rauchverhalten ................................. 52

Abb. 25: Schweregrad der Parodontitis differenziert nach Geschlecht.................................... 53

Abb. 26: Schweregrad der Parodontitis differenziert nach Rauchverhalten ............................ 53

Abb. 27: Verteilung der Genotypmuster differenziert nach Geschlecht ................................... 55

Abb. 28: Verteilung der Genotypmuster differenziert nach Rauchverhalten ............................... 55

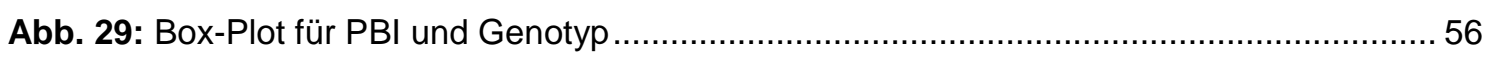

Abb. 30: Korrelation zwischen big42 für Ventrikel und Schweregrad der Parodontitis .............. 58

Abb. 31: Korrelation zwischen big42 Atrium und Schweregrad der Parodontitis ....................... 58

Abb. 32: Korrelation zwischen big42 für Klappe und Schweregrad der Parodontitis................. 59 


\subsection{Tabellenverzeichnis}

Tab. 1: Subklassifizierung der chronischen Parodontitis nach Ausbreitung des Attachmentverlustes

Tab. 2: Subklassifizierung der chronischen Parodontitis nach Ausmaß des

Attachmentverlustes 7

Tab. 3: Parodontitislast in Deutschland für ausgewählte Altersgruppen 8

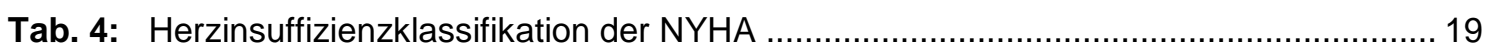

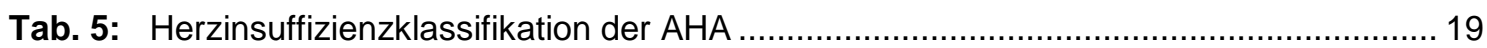

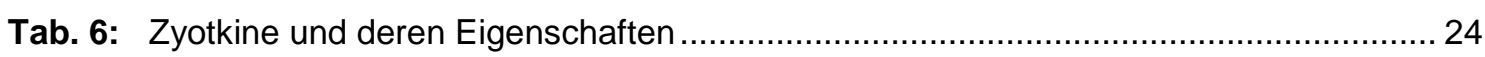

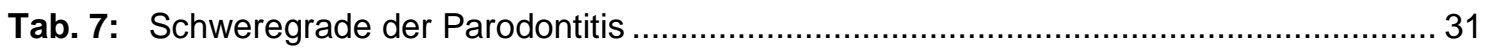

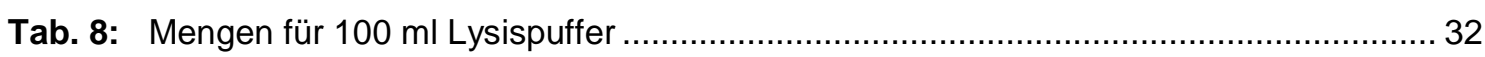

Tab. 9: Zugabe zu vorbereitetem Lysispuffer .................................................................. 32

Tab. 10: Herstellung der Standardreihe zur Bestimmung der Proteinkonzentration ................... 33

Tab. 11: Vier Phasen der Buffy-Coat-Aufreinigung …........................................................... 39

Tab. 12: Arbeitsschritte zur DNA-Isolierung und deren Effekte............................................... 40

Tab. 13: Protokoll für die Polymerase-Kettenreaktion .......................................................... 41

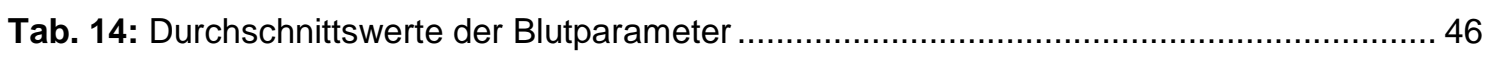

Tab. 15: Prozentuale Anteile positiver BOP-Befunde im Patientenkollektiv............................... 52

Tab. 16: Werte für big42 (absolut u. normiert auf das Expressionsniveau von GAPDH) an

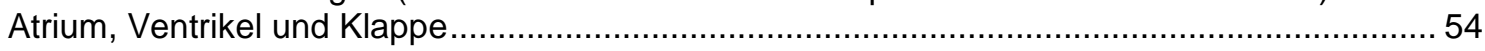

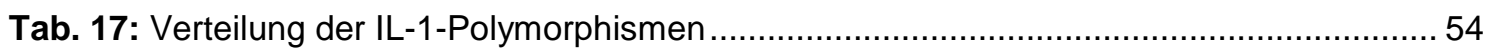

Tab. 18: Verteilung der Genotypmuster auf die Schweregrade der Parodontitis ...................... 57

Tab. 19: Ergebnisse der t-Tests für big42 und PBI für Atrium, Ventrikel und Klappe ................ 57

Tab. 20: Ergebnisse der t-Tests für big42 und Parodontitis für Atrium, Ventrikel und Klappe ... 59

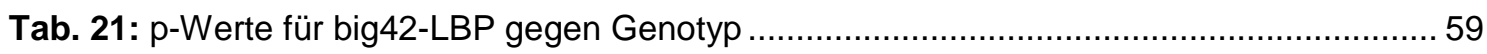

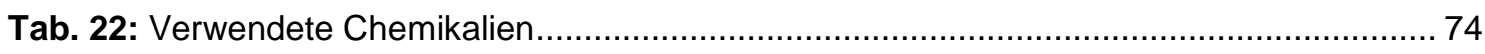

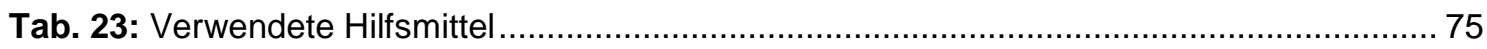

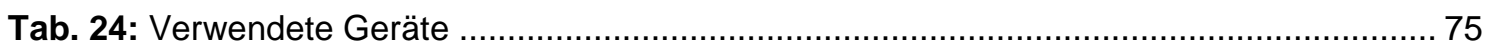

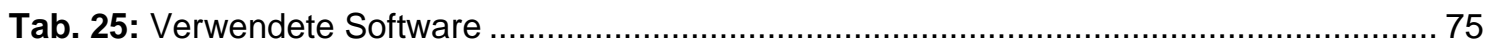

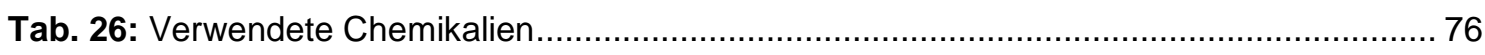

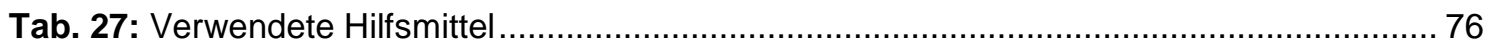

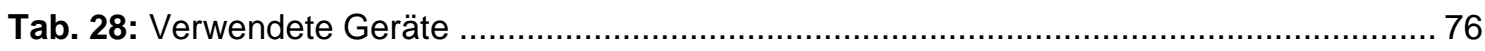




\subsection{Bisherige Veröffentlichungen der Ergebnisse}

Ziebolz D, Jahn C, Semper E, Rost C, Schmidt J, Hoch M, Waldmann-Beushausen R, Hornecker E, Schöndube F, Mausberg RF:

Systemische Effekte von Toxinen parodontalpathogener Bakterien auf humanes Myokard - Ergebnisse einer Pilotstudie. (Vortrag)

DGP-Jahrestagung; Baden-Baden 2011

Ziebolz D, Jahn C, Semper E, Rost C, Schmidt J, Hoch M, Waldmann-Beushausen R, Hornecker E, Schöndube F, Mausberg RF:

Systemic effects of toxins of periodontal pathogenic bacteria on human myocardium a possible route to elucidating the link between periodontitis and heart dysfunction.

(Vortrag)

Europerio; Wien 2012 


\section{Literaturverzeichnis}

Agrawal AA, Kapley A, Yeltiwar RK, Purohit HJ (2006):

Assessment of single nucleotide polymorphism at IL-1A+4845 and IL-1B+3954 as genetic susceptibility test for chronic periodontitis in Maharashtrian ethnicity.

J Periodontol $\underline{77}, 1515-1521$

Ainamo J, Barmes D, Beagrie G, Cutress T, Martin J, Sardo-Infirri J (1982):

Development of the World Health Organization (WHO) community periodontal index of treatment needs (CPITN).

Int Dent J 32, 281-291

Albandar JM, Kingman A (1999):

Gingival recession, gingival bleeding, and dental calculus in adults 30 years of age and older in the United States, 1988-1994.

J Periodontol $\underline{70}, 30-43$

Albandar JM, Streckfus CF, Adesanya MR, Winn DM (2000):

Cigar, pipe, and cigarette smoking as risk factors for periodontal disease and tooth loss.

J Periodontol $\underline{71}, 1874-1881$

Alexander MB, Damoulis PD (1994):

The role of cytokines in the pathogenesis of periodontal disease.

Curr Opin Periodontol 1994, 39-53

Anderson GB, Caffesse RG, Nasjleti CE, Smith BA (1991):

Correlation of periodontal probe penetration and degree of inflammation.

Am J Dent 4, 177-183

Andus T, Daig R, Vogl D, Aschenbrenner E, Lock G, Hollerbach S, Köllinger M, Schölmerich J, Gross, V (1997):

Imbalance of the interleukin 1 system in colonic mucosa-association with intestinal inflammation and interleukin 1 receptor agonist genotype 2 .

Gut $\underline{41}, 651-657$

Anker SD, Egerer KR, Volk HD, Kox WJ, Poole-Wilson PA, Coats AJ (1997):

Elevated soluble CD14 receptors and altered cytokines in chronic heart failure.

Am J Cardiol 79, 1426-1430

Arbes SJ, Slade GD, Beck JD (1999):

Association between extent of periodontal attachment loss and self-reported history of heart attack: an analysis of NHANES III data.

J Dent Res $\underline{78}, 1777-1782$

Attström R, Lindhe J:

Die Pathogenese plaquebedingter Parodontalerkrankungen in: Klinische

Parodontologie; hrsg. v. Lindhe J; Georg-Thieme-Verlag, Stuttgart 1986, 125-157

Ausschuss für Biologische Arbeitsstoffe (ABAS) 2005:

Irritativ-toxische Wirkungen von luftgetragenen biologischen Arbeitsstoffen am Beispiel der Endotoxine.

URL: http://www.baua.de/de/Themen-von-A-Z/Biologische-Arbeitsstoffe/ABAS/ausdem-ABAS/pdf/Endotoxinpapier.pdf?__blob=publicationFile 
Beck JD, Pankow J, Tyroler HA, Offenbacher S (1999):

Dental infections and atherosclerosis.

Am Heart J 138 Suppl 5, 528-533

Becker M, Weizenegger M, Bartel J (2000):

Grundlagenforschung in Sachen Parodontologie.

Zahnärztl Mitt 90(3), 38

Bergström J (1989):

Cigarette smoking as risk factor in chronic periodontal disease.

Community Dent Oral Epidemiol 17, 245-247

Bergström J (2004):

Tobacco smoking and chronic destructive periodontal disease.

Odontology $\underline{92}, 1-8$

Bergström J, Eliasson S, Dock J (2000):

A 10-year prospective study of tobacco smoking and periodontal health.

J Periodontol $\underline{71}, 1338-1347$

Birkedal-Hansen H (1993):

Role of cytokines and inflammatory mediators in tissue destruction.

J Periodontal Res 28, 500-510

Bogers RP, Bemelmans WJE, Hoogenveen RT, Boshuizen HC, Woodward M, Knekt P, van Dam RM, Hu FB, Visscher TLS, Menotti A (2007):

Association of overweight with increased risk of coronary heart disease partly independent of blood pressure and cholesterol levels: a meta-analysis of 21 cohort studies including more than 300000 persons.

Arch Intern Med 167, 1720-1728

Brown LJ, Löe H (1993):

Prevalence, extent, severity and progression of periodontal disease.

Periodontol 2000 2, 57-71

Buduneli E, Aksoy O, Köse T, Atilla G (2004):

Accuracy and reproducibility of two manual periodontal probes. An in vitro study.

J Clin Periodontol $\underline{31}, 815-819$

Burgemeister S, Schlagenauf U:

Chronische Parodontitis in: Parodontalerkrankungen; hrsg. v. Lang NP; Quintessenz

Verlag, Berlin 2003, 59-62

Bühling KJ:

Intensivkurs: Allgemeine und spezielle Pathologie, 2. Auflage; Urban \& Fischer, München 2000

Campbell NA, Reece JB, Markl J:

Biologie, 6. Auflage; Spektrum Akademischer Verlag, Heidelberg 2003

Charalambous BM, Stephens RCM, Feavers IM, Montgomery HE (2007):

Role of bacterial endotoxin in chronic heart failure: the gut of the matter.

Shock 28, 15-23 
Classen M, Diehl V, Kochsiek K:

Innere Medizin, 5. Auflage; Urban \& Fischer, München 2004

Cleland JGF, Swedberg K, Follath F, Komajda M, Cohen-Solal A, Aguilar JC, Dietz R, Gavazzi A, Hobbs R, Korewicki J (2003):

The EuroHeart Failure survey programme- a survey on the quality of care among patients with heart failure in Europe. Part 1: patient characteristics and diagnosis. Eur Heart J $\underline{24}, 442-463$

Cohn JN, Ferrari R, Sharpe N (2000):

Cardiac remodeling--concepts and clinical implications: a consensus paper from an international forum on cardiac remodeling. Behalf of an International Forum on Cardiac Remodeling.

J Am Coll Cardiol 35, 569-582

DeStefano F, Anda RF, Kahn HS, Williamson DF, Russell CM (1993):

Dental disease and risk of coronary heart disease and mortality.

BMJ $\underline{306}$, 688-691

DGP (Deutsche Gesellschaft für Parodontologie e.V.):

Parodontitis 2010 - Das Risikokompendium; Quintessenz-Verlag, Berlin 2011

Dickstein K, Cohen-Solal A, Filippatos G, McMurray JJV, Ponikowski P, Poole-Wilson PA, Strömberg A, van Veldhuisen DJ, Atar D, Hoes AW (2008):

ESC guidelines for the diagnosis and treatment of acute and chronic heart failure 2008: the Task Force for the diagnosis and treatment of acute and chronic heart failure 2008 of the European Society of Cardiology. Developed in collaboration with the Heart Failure Association of the ESC (HFA) and endorsed by the European Society of Intensive Care Medicine (ESICM).

Eur J Heart Fail 10, 933-989

Dietrich T, Jimenez M, Krall Kaye EA, Vokonas PS, Garcia RI (2008):

Age-dependent associations between chronic periodontitis/edentulism and risk of coronary heart disease.

Circulation 117, 1668-1674

Elsbach P, Weiss J (1993):

The bactericidal/permeability-increasing protein (BPI), a potent element in host-defense against gram-negative bacteria and lipopolysaccharide.

Immunobiology 187, 417-429

Engelberger T, Hefti A, Kallenberger A, Rateitschak KH (1983):

Correlations among Papilla Bleeding Index, other clinical indices and histologically determined inflammation of gingival papilla.

J Clin Periodontol $\underline{10}, 579-589$

Francis SE, Camp NJ, Dewberry RM, Gunn J, Syrris P, Carter ND, Jeffery S, Kaski JC, Cumberland DC, Duff GW (1999):

Interleukin-1 receptor antagonist gene polymorphism and coronary artery disease.

Circulation 99, 861-866

Gallay P, Barras C, Tobias PS, Calandra T, Glauser MP, Heumann D (1994):

Lipopolysaccharide (LPS)-binding protein in human serum determines the tumor necrosis factor response of monocytes to LPS.

$\mathrm{J}$ Infect Dis $\underline{170}$, 1319-1322 
Gore EA, Sanders JJ, Pandey JP, Palesch Y, Galbraith GM (1998):

Interleukin-1beta+3953 allele 2: association with disease status in adult periodontitis. J Clin Periodontol 25, 781-785

Granowitz EV, Clark BD, Vannier E, Callahan MV, Dinarello CA (1992):

Effect of interleukin-1 (IL-1) blockade on cytokine synthesis: I. IL-1 receptor antagonist inhibits IL-1-induced cytokine synthesis and blocks the binding of IL-1 to its type II receptor on human monocytes.

Blood 79, 2356-2363

Graves DT, Cochran D (2003):

The contribution of interleukin-1 and tumor necrosis factor to periodontal tissue destruction.

J Periodontol $\underline{74}, 391-401$

Grube BJ, Cochane CG, Ye RD, Green CE, McPhail ME, Ulevitch RJ, Tobias PS (1994):

Lipopolysaccharide binding protein expression in primary human hepatocytes and HepG2 hepatoma cells.

J Biol Chem 269, 8477-8482

Hamp SE, Nyman S, Lindhe J (1975):

Periodontal treatment of multirooted teeth. Results after 5 years.

J Clin Periodontol 2, 126-135

Haraszthy VI, Zambon JJ, Trevisan M, Zeid M, Genco RJ (2000):

Identification of periodontal pathogens in atheromatous plaques.

J Periodontol $\underline{71}, 1554-1560$

Haynes WG, Stanford C (2003):

Periodontal disease and atherosclerosis: from dental to arterial plaque.

Arterioscler Thromb Vasc Biol 23, 1309-1311

Heasman PA, Collins JG, Offenbacher S (1993):

Changes in crevicular fluid levels of interleukin-1 beta, leukotriene B4, prostaglandin $\mathrm{E} 2$, thromboxane B2 and tumour necrosis factor alpha in experimental gingivitis in humans.

J Periodontal Res $\underline{28}, 241-247$

Heath JK, Saklatvala J, Meikle MC, Atkinson SJ, Reynolds JJ (1985):

Pig interleukin 1 (catabolin) is a potent stimulator of bone resorption in vitro.

Calcif Tissue Int $\underline{37}, 95-97$

Hellwig E, Klimek J, Attin T:

Einführung in die Zahnerhaltung, 4. Auflage; Urban \& Fischer, München 2006

Hodge PJ, Riggio MP, Kinane DF (2001):

Failure to detect an association with IL1 genotypes in European Caucasians with generalised early onset periodontitis.

J Clin Periodontol 28, 430-436

Hoppe UC, Böhm M, Dietz R, Hanrath P, Kroemer HK, Osterspey A, Schmaltz AA, Erdmann E (2005):

Leitlinien zur Therapie der chronischen Herzinsuffizienz.

Z Kardiol 94, 488-509 
Hugoson A, Ljungquist B, Breivik T (2002):

The relationship of some negative events and psychological factors to periodontal disease in an adult Swedish population 50 to 80 years of age.

J Clin Periodontol 29, 247-253

Hujoel PP, Drangsholt M, Spiekerman C, DeRouen TA (2000):

Periodontal disease and coronary heart disease risk.

JAMA 284, 1406-1410

Huynh-Ba G, Lang NP, Tonetti MS, Salvi GE (2007):

The association of the composite IL-1 genotype with periodontitis progression and/or treatment outcomes: a systematic review.

$\mathrm{J}$ Clin Periodontol $\underline{34}, 305-317$

Jahn C:

Untersuchung zum Zusammenhang zwischen Herzinsuffizienz und chronischer Parodontitis mittels immunhistochemischem Nachweis der Makrophagenmarker CD68 und CD14.

Med. Diss. Göttingen 2012 (in Vorbereitung*)

Jandinski JJ, Stashenko P, Feder LS, Leung CC, Peros WJ, Rynar JE, Deasy MJ (1991):

Localization of interleukin-1 beta in human periodontal tissue.

J Periodontol $\underline{62}, 36-43$

Janeway CA:

Immunologie, 5. Auflage; Spektrum Akademischer Verlag, Heidelberg 2002

Jessup M, Brozena S (2003):

Heart failure.

N Engl J Med $\underline{348}$, 2007-2018

Joshipura KJ, Rimm EB, Douglass CW, Trichopoulos D, Ascherio A, Willett WC (1996): Poor oral health and coronary heart disease.

J Dent Res $\underline{75}, 1631-1636$

Kayser FH:

Medizinische Mikrobiologie, 10. Auflage; Georg-Thieme-Verlag, Stuttgart 2001

Keagle JG, Garnick JJ, Searle JR, King GE, Morse PK (1989):

Gingival resistance to probing forces. I. Determination of optimal probe diameter.

J Periodontol $\underline{60}, 167-171$

Kinane DF, Chestnutt IG (1997):

Relationship of diabetes to periodontitis.

Curr Opin Periodontol 4, 29-34

Kinane DF, Lindhe J:

Chronic Periodontitis in: Clinical periodontology and implant dentistry; hrsg. v. Lindhe J; Karring T; Lang NP; Blackwell Publishers, Oxford 2003, 209-215

*) mit freundlicher Genehmigung der Verfasserin 
Kocher T, Meisel P:

Genetik in: Parodontitis 2010; hrsg. v. Deutsche Gesellschaft für Parodontologie e.V.; Quintessenz-Verlag, Berlin 2011, 39-48

Kolenbrander PE, Andersen RN, Blehert DS, Egland PG, Foster JS, Palmer RJ (2002): Communication among oral bacteria.

Microbiol Mol Biol Rev $\underline{66}$, 486-505

Koolman J, Röhm K:

Taschenatlas Biochemie des Menschen, 4. Auflage; Georg-Thieme-Verlag, Stuttgart 2009

Kornman KS, di Giovine FS (1998):

Genetic variations in cytokine expression: a risk factor for severity of adult periodontitis. Ann Periodontol $\underline{3}, 327-338$

Kornman KS, Crane A, Wang HY, Di Giovine FS, Newman MG, Pirk FW, Wilson TG, Higginbottom FL, Duff GW (1997):

The interleukin-1 genotype as a severity factor in adult periodontal disease.

$\mathrm{J}$ Clin Periodontol 24, 72-77

Kornman KS, Pankow J, Offenbacher S, Beck J, Di Giovine F, Duff GW (1999):

Interleukin-1 genotypes and the association between periodontitis and cardiovascular disease.

J Periodontal Res $\underline{34}, 353-357$

Krejci CB, Bissada NF (2000):

Periodontitis--the risks for its development.

Gen Dent $\underline{48,}$ 430-436

Kuramitsu HK, Qi M, Kang IC, Chen W (2001):

Role for periodontal bacteria in cardiovascular diseases.

Ann Periodontol $\underline{6}, 41-47$

Laemmli UK (1970):

Cleavage of structural proteins during the assembly of the head of bacteriophage T4.

Nature 227, 680-685

Laine ML, Farré MA, González G, van Dijk LJ, Ham AJ, Winkel EG, Crusius JB, Vandenbroucke JP, van Winkelhoff AJ, Peña AS (2001):

Polymorphisms of the interleukin-1 gene family, oral microbial pathogens, and smoking in adult periodontitis.

J Dent Res 우, 1695-1699

Laine ML, Loos BG, Crielaard W (2010):

Gene polymorphisms in chronic periodontitis.

Int J Dent 2010, 324719

Lamping N, Hoess A, Yu B, Park TC, Kirschning CJ, Pfeil D, Reuter D, Wright SD, Herrmann F, Schumann RR (1996):

Effects of site-directed mutagenesis of basic residues (Arg 94, Lys 95, Lys 99) of lipopolysaccharide (LPS)-binding protein on binding and transfer of LPS and subsequent immune cell activation.

J Immunol 157, 4648-4656 
Lang NP:

Parodontalerkrankungen; Quintessenz Verlag, Berlin 2003

Larsen C, Barendregt DS, Slot DE, van der Velden U, van der Weijden F (2009):

Probing pressure, a highly undervalued unit of measure in periodontal probing: a systematic review on its effect on probing pocket depth.

J Clin Periodontol $\underline{36}, 315-322$

Lederhuber HC, Lange V:

Basics Kardiologie, 2. Auflage; Elsevier, Urban \& Fischer, München 2010

Lepper PM, Schumann C, Triantafilou K, Rasche FM, Schuster T, Frank H, Schneider EM, Triantafilou M, von Eynatten M (2007):

Association of lipopolysaccharide-binding protein and coronary artery disease in men. J Am Coll Cardiol 므, 25-31

Lindhe J, Ranney R, Lamster I, Charles A, Chung C, Flemming T, Kinane D, Listgarten M, Löe H, Schoor R (1999):

Consensus Report: Chronic Periodontitis.

Ann Periodontol $\underline{4}, 38$

Lip GY, Gibbs CR, Beevers DG (2000):

$A B C$ of heart failure: aetiology.

BMJ $\underline{320}, 104-107$

Listgarten MA (1980):

Periodontal probing: what does it mean?.

J Clin Periodontol $\underline{7}, 165-176$

Liu R, Desta T, Raptis M, Darveau RP, Graves DT (2008):

$P$. gingivalis and $E$. coli lipopolysaccharides exhibit different systemic but similar local induction of inflammatory markers.

J Periodontol $\underline{79}$, 1241-1247

Löe H, Theilade E, Jensen SB (1965):

Experimental Gingivitis in man.

J Periodontol $\underline{36}, 177-187$

López NJ, Jara L, Valenzuela CY (2005):

Association of interleukin-1 polymorphisms with periodontal disease.

J Periodontol $\underline{76}$, 234-243

López NJ, Quintero A, Llancaqueo M, Jara L (2009):

Effects of periodontal therapy on markers of systemic inflammation in patients with coronary heart disease risk.

Rev Med Chil 137, 1315-1322

Mann DL (2002):

Inflammatory mediators and the failing heart: past, present, and the foreseeable future. Circ Res 91, 988-998

Marra MN, Wilde CG, Collins MS, Snable JL, Thornton MB, Scott RW (1992):

The role of bactericidal/permeability-increasing protein as a natural inhibitor of bacterial endotoxin.

$\mathrm{J}$ Immunol $\underline{148}$, 532-537 
Marsh PD (2005):

Dental plaque: biological significance of a biofilm and community life-style.

J Clin Periodontol 32 Suppl 6, 7-15

Marsh PD, Bradshaw DJ (1995):

Dental plaque as a biofilm.

$\mathrm{J}$ Ind Microbiol 15, 169-175

Masada MP, Persson R, Kenney JS, Lee SW, Page RC, Allison AC (1990):

Measurement of interleukin-1 alpha and -1 beta in gingival crevicular fluid: implications for the pathogenesis of periodontal disease.

J Periodontal Res 25, 156-163

Matsuki Y, Yamamoto T, Hara K (1991):

Interleukin-1 mRNA-expressing macrophages in human chronically inflamed gingival tissues.

Am J Pathol 138, 1299-1305

Mattila KJ, Nieminen MS, Valtonen VV, Rasi VP, Kesäniemi YA, Syrjälä SL, Jungell PS, Isoluoma M, Hietaniemi K, Jokinen MJ (1989):

Association between dental health and acute myocardial infarction.

BMJ 298, 779-781

Mattila KJ, Valle MS, Nieminen MS, Valtonen VV, Hietaniemi KL (1993):

Dental infections and coronary atherosclerosis.

Atherosclerosis $103,205-211$

Mattila KJ, Valtonen VV, Nieminen M, Huttunen JK (1995):

Dental infection and the risk of new coronary events: prospective study of patients with documented coronary artery disease.

Clin Infect Dis 20, 588-592

McDevitt MJ, Wang HY, Knobelman C, Newman MG, Di Giovine FS, Timms J, Duff GW, Kornman KS (2000):

Interleukin-1 genetic association with periodontitis in clinical practice.

J Periodontol $\underline{71}, 156-163$

McGuire MK, Nunn ME (1999):

Prognosis versus actual outcome. IV. The effectiveness of clinical parameters and IL-1 genotype in accurately predicting prognoses and tooth survival.

J Periodontol $\underline{70}$, 49-56

McMurray JJ, Stewart S (2000):

Epidemiology, aetiology, and prognosis of heart failure.

Heart $\underline{83}, 596-602$

Meisel P, Siegemund A, Grimm R, Herrmann FH, John U, Schwahn C, Kocher T (2003):

The interleukin-1 polymorphism, smoking, and the risk of periodontal disease in the population-based SHIP study.

J Dent Res $\underline{82}, 189-193$

Mercado FB, Marshall RI, Bartold PM (2003):

Inter-relationships between rheumatoid arthritis and periodontal disease. A review. J Clin Periodontol $\underline{30}, 761-772$ 
Michalowicz BS (1994):

Genetic and heritable risk factors in periodontal disease.

J Periodontol 65 Suppl 5, 479-488

Michalowicz BS, Diehl SR, Gunsolley JC, Sparks BS, Brooks CN, Koertge TE, Califano JV, Burmeister JA, Schenkein HA (2000):

Evidence of a substantial genetic basis for risk of adult periodontitis.

J Periodontol 71, 1699-1707

Micheelis W:

Prävalenz in: Parodontitis 2010; hrsg. v. Deutsche Gesellschaft für Parodontologie e.V.; Quintessenz-Verlag, Berlin 2011, 11-21

Micheelis W, Schiffner U:

Vierte Deutsche Mundgesundheitsstudie (DMS IV). Institut der Deutschen Zahnärzte (Band 31); Deutscher Ärzte-Verlag, Köln 2006

Munger MA, Johnson B, Amber IJ, Callahan KS, Gilbert EM (1996):

Circulating concentrations of proinflammatory cytokines in mild or moderate heart failure secondary to ischemic or idiopathic dilated cardiomyopathy.

Am J Cardiol $\underline{77}$, 723-727

Murray PA (1994):

HIV disease as a risk factor for periodontal disease.

Compendium 15, 1052-1063

Niebauer J, Volk HD, Kemp M, Dominguez M, Schumann RR, Rauchhaus M, PooleWilson PA, Coats AJ, Anker SD (1999):

Endotoxin and immune activation in chronic heart failure: a prospective cohort study. Lancet $\underline{353}, 1838-1842$

Nikolopoulos GK, Dimou NL, Hamodrakas SJ, Bagos PG (2008):

Cytokine gene polymorphisms in periodontal disease: a meta-analysis of 53 studies including 4178 cases and 4590 controls.

$\mathrm{J}$ Clin Periodontol $\underline{35}, 754-767$

Nothwang HG, Strahm B, Denich D, Kübler M, Schwabe J, Gingrich JC, Jauch A, Cox A, Nicklin MJ, Kurnit DM (1997):

Molecular cloning of the interleukin-1 gene cluster: construction of an integrated

YAC/PAC contig and a partial transcriptional map in the region of chromosome 2q13. Genomics 41, 370-378

Offenbacher S (1996):

Periodontal diseases: pathogenesis.

Ann Periodontol 1, 821-878

Opal SM, Scannon PJ, Vincent JL, White M, Carroll SF, Palardy JE, Parejo NA, Pribble JP, Lemke JH (1999):

Relationship between plasma levels of lipopolysaccharide (LPS) and LPS-binding protein in patients with severe sepsis and septic shock.

$\mathrm{J}$ Infect Dis 180, 1584-1589

Page RC (1986):

Gingivitis.

J Clin Periodontol $\underline{13}, 345-359$ 
Page RC, Schroeder HE (1976):

Pathogenesis of inflammatory periodontal disease. A summary of current work.

Lab Invest 34, 235-249

Page RC, Kornman KS (1997):

The pathogenesis of human periodontitis: an introduction.

Periodontol 2000 14, 9-11

Page RC, Eke PI (2007):

Case definitions for use in population-based surveillance of periodontitis.

J Periodontol $\underline{78}$, 1387-1399

Paster BJ, Boches SK, Galvin JL, Ericson RE, Lau CN, Levanos VA, Sahasrabudhe A, Dewhirst FE (2001):

Bacterial diversity in human subgingival plaque.

J Bacteriol 183, 3770-3783

Persson GR (2006):

What has ageing to do with periodontal health and disease?

Int Dent J 트, 240-249

Pischon N, Heng N, Bernimoulin J, Kleber B, Willich SN, Pischon T (2007):

Obesity, inflammation, and periodontal disease.

J Dent Res $\underline{86}, 400-409$

Pistorius A, Krahwinkel T, Willershausen B, Boekstegen C (2002):

Relationship between stress factors and periodontal disease.

Eur J Med Res ㄱ, 393-398

Plagmann $\mathrm{H}$ :

Lehrbuch der Parodontologie; Hanser Verlag, München 1998

Preiss DS, Meyle J (1994):

Interleukin- 1 beta concentration of gingival crevicular fluid.

J Periodontol $\underline{65}, 423-428$

Pussinen PJ, Jousilahti P, Alfthan G, Palosuo T, Asikainen S, Salomaa V (2003):

Antibodies to periodontal pathogens are associated with coronary heart disease.

Arterioscler Thromb Vasc Biol 23, 1250-1254

QIAamp ${ }^{\circledR}$ DNA Mini and Blood Mini Handbook.

Second Edition, November 2007 (Fa. QIAGEN ${ }^{\circledR}$ )

Qureshi ST, Gros P, Malo D (1999):

Host resistance to infection: genetic control of lipopolysaccharide responsiveness by

TOLL-like receptor genes.

Trends Genet 15, 291-294

Raetz CR (1990):

Biochemistry of endotoxins.

Annu Rev Biochem 59, 129-170

Rateitschak KH, Rateitschak EM, Wolf HF:

Parodontologie, 2. Auflage; Georg-Thieme-Verlag, Stuttgart 1989 
Rauchhaus M:

Pathophysiologie der Herzinsuffizienz - traditionelle Paradigmen und innovative Konzepte. Med. Habil.-Schr., Berlin 2008

Rauchhaus M, Coats AJ, Anker SD (2000):

The endotoxin-lipoprotein hypothesis.

Lancet $\underline{356}$, 930-933

Ren L, Jin L, Leung WK (2004):

Local expression of lipopolysaccharide-binding protein in human gingival tissues.

J Periodontal Res $\underline{39}$, 242-248

Rickenbacher P (2001):

Herzinsuffizienz: Epidemiologie, Pathophysiologie.

Swiss Medical Forum 1(2), 4-9

Rietschel ET, Kirikae T, Schade FU, Mamat U, Schmidt G, Loppnow H, Ulmer AJ, Zähringer U, Seydel U, Di Padova F (1994):

Bacterial endotoxin: molecular relationships of structure to activity and function.

FASEB J $\underline{8}, 217-225$

Roger VL, Weston SA, Redfield MM, Hellermann-Homan JP, Killian J, Yawn BP, Jacobsen SJ (2004):

Trends in heart failure incidence and survival in a community-based population.

JAMA 292, 344-350

Sakellari D, Koukoudetsos S, Arsenakis M, Konstantinidis A (2003):

Prevalence of IL-1A and IL-1B polymorphisms in a Greek population.

$\mathrm{J}$ Clin Periodontol $\underline{30}, 35-41$

Sakellari D, Katsares V, Georgiadou M, Kouvatsi A, Arsenakis M, Konstantinidis A (2006):

No correlation of five gene polymorphisms with periodontal conditions in a Greek population.

J Clin Periodontol 33, 765-770

Salvi GE, Lawrence HP, Offenbacher S, Beck JD (1997):

Influence of risk factors on the pathogenesis of periodontitis.

Periodontol $2000 \underline{14}, 173-201$

Saxer UP, Mühlemann HR (1975):

Motivation und Aufklärung.

Schweiz Monatsschr Zahnmed 85, 905-919

Schütt S (2011):

Parodontitis - eine immunologische Erkrankung mit genetischer Komponente.

ZWR 120 (3), 94-101

Schütt C, Bröker B:

Grundwissen Immunologie, 3. Auflage; Spektrum Akademischer Verlag, Heidelberg 2011 
Schumann RR, Rietschel ET, Loppnow H (1994):

The role of CD14 and lipopolysaccharide-binding protein (LBP) in the activation of different cell types by endotoxin.

Med Microbiol Immunol 183, 279-297

Schumann RR, Kirschning CJ, Unbehaun A, Aberle HP, Knope HP, Lamping N, Ulevitch RJ, Herrmann F (1996):

The lipopolysaccharide-binding protein is a secretory class 1 acute-phase protein whose gene is transcriptionally activated by APRF/STAT/3 and other cytokine-inducible nuclear proteins.

Mol Cell Biol 16, 3490-3503

Seta Y, Shan K, Bozkurt B, Oral H, Mann DL (1996):

Basic mechanisms in heart failure: the cytokine hypothesis.

J Card Fail 2, 243-249

Sharma R, Bolger AP, Rauchhaus M, von Haehling S, Doehner W, Adcock IM, Barnes PJ, Poole-Wilson PA, Volk H, Coats AJS (2005):

Cellular endotoxin desensitization in patients with severe chronic heart failure.

Eur J Heart Fail 푸 865-868

Shiau HJ, Reynolds MA (2010):

Sex differences in destructive periodontal disease: a systematic review.

J Periodontol 81, 1379-1389

Sims JE, Giri JG, Dower SK (1994):

The two interleukin-1 receptors play different roles in IL-1 actions.

Clin Immunol Immunopathol $\underline{72}$, 9-14

Socransky SS, Haffajee AD (2002):

Dental biofilms: difficult therapeutic targets.

Periodontol $2000 \underline{28}, 12-55$

Socransky SS, Haffajee AD, Cugini MA, Smith C, Kent RL (1998):

Microbial complexes in subgingival plaque.

J Clin Periodontol 25, 134-144

Socransky SS, Haffajee AD, Smith C, Duff GW (2000):

Microbiological parameters associated with IL-1 gene polymorphisms in periodontitis patients.

J Clin Periodontol 27, 810-818

Sorsa T, Tjäderhane L, Konttinen YT, Lauhio A, Salo T, Lee H, Golub LM, Brown DL, Mäntylä P (2006):

Matrix metalloproteinases: contribution to pathogenesis, diagnosis and treatment of periodontal inflammation.

Ann Med 38, 306-321

Stashenko P, Dewhirst FE, Rooney ML, Desjardins LA, Heeley JD (1987):

Interleukin-1 beta is a potent inhibitor of bone formation in vitro.

J Bone Miner Res 2, 559-565

Statistisches Bundesamt (Destatis):

Todesursachen in Deutschland 2010. Fachserie 12, Reihe 4 - Todesursachenstatistik 2010, Wiesbaden 2011 
Staudt A, Landsberger M, Staudt Y, Felix SB (2002):

Die Rolle der Zytokine bei der Herzinsuffizienz.

Herz 27, 691-698

Syrjänen J (1990):

Vascular diseases and oral infections.

J Clin Periodontol $\underline{17}, 497-500$

Takahashi K, Takigawa M, Takashiba S, Nagai A, Miyamoto M, Kurihara H, Murayama Y (1994):

Role of cytokine in the induction of adhesion molecules on cultured human gingival fibroblasts.

J Periodontol $\underline{65}, 230-235$

Tang K, Lin M, Wu Y, Yan F (2011):

Alterations of serum lipid and inflammatory cytokine profiles in patients with coronary heart disease and chronic periodontitis: a pilot study.

$\mathrm{J}$ Int Med Res 39, 238-248

Tapping RI, Tobias PS (1997):

Cellular binding of soluble CD14 requires lipopolysaccharide (LPS) and LPS-binding protein.

J Biol Chem 272, 23157-23164

Theilade E, Wright WH, Jensen SB, Löe H (1966):

Experimental gingivitis in man. II. A longitudinal clinical and bacteriological investigation.

J Periodontal Res $\underline{1}, 1-13$

Tonetti MS (1998):

Cigarette smoking and periodontal diseases: etiology and management of disease.

Ann Periodontol $\underline{3}, 88-101$

van der Velden U (1979):

Probing force and the relationship of the probe tip to the periodontal tissues.

J Clin Periodontol $\underline{6}, 106-114$

van der Velden U (1980):

Influence of periodontal health on probing depth and bleeding tendency.

J Clin Periodontol $\underline{7}, 129-139$

van der Velden U, de Vries JH (1980):

The influence of probing force on the reproducibility of pocket depth measurements.

J Clin Periodontol $\underline{7}, 414-420$

van der Velden $U$, Abbas F, Armand $S$, Graaff $J$ de, Timmerman MF, van der Weijden GA, van Winkelhoff AJ, Winkel EG (1993):

The effect of sibling relationship on the periodontal condition.

J Clin Periodontol 20, 683-690

van Dyke TE, Serhan CN (2003):

Resolution of inflammation: a new paradigm for the pathogenesis of periodontal diseases.

J Dent Res 82, 82-90 
van Dyke TE, Sheilesh D (2005):

Risk factors for periodontitis.

J Int Acad Periodontol $\underline{7}, 3-7$

van Palenstein Helderman WH (1981):

Microbial etiology of periodontal disease.

J Clin Periodontol $\underline{8}, 261-280$

Weil J, Schunkert H (2006):

Pathophysiologie der chronischen Herzinsuffizienz.

Clin Res Cardiol 95 Suppl 4, 1-17

WHO (World Health Organization) 2006:

BMI classification.

URL: http://www.who.int/bmi/index.jsp?introPage=intro_3.html

WHO (World Health Organization) 2011:

The top 10 causes of death.

URL: http://www.who.int/mediacentre/factsheets/fs310/en/index2.html

Williams DM:

Pathology of periodontal disease; Oxford University Press, Oxford 1992

Wimmer G, Janda M, Wieselmann-Penkner K, Jakse N, Polansky R, Pertl C (2002):

Coping with stress: its influence on periodontal disease.

J Periodontol $\underline{73}$, 1343-1351

Wright SD, Ramos RA, Tobias PS, Ulevitch RJ, Mathison JC (1990):

CD14, a receptor for complexes of lipopolysaccharide (LPS) and LPS binding protein.

Science $\underline{249}, 1431-1433$

Yamazaki K, Honda T, Oda T, Ueki-Maruyama K, Nakajima T, Yoshie H, Seymour GJ (2005):

Effect of periodontal treatment on the C-reactive protein and proinflammatory cytokine levels in Japanese periodontitis patients.

J Periodontal Res $\underline{40}, 53-58$

Yeung SC, Stewart GJ, Cooper DA, Sindhusake D (1993):

Progression of periodontal disease in HIV seropositive patients.

J Periodontol $\underline{64}, 651-657$

Zweigner J, Gramm HJ, Singer OC, Wegscheider K, Schumann RR (2001):

High concentrations of lipopolysaccharide-binding protein in serum of patients with severe sepsis or septic shock inhibit the lipopolysaccharide response in human monocytes.

Blood $\underline{98}$, 3800-3808

1999 International Workshop for a Classification of Periodontal Diseases and Conditions. Papers. Oak Brook, Illinois, October 30-November 2, 1999.

Ann Periodontol 4 , i, 1-112 


\section{Danksagung}

Mein besonderer Dank gilt...

...Herrn Prof. Dr. R. F. Mausberg für die Überlassung des Dissertationsthemas, die freundliche Beratung und die konstruktive Kritik an meiner Arbeit,

...Herrn Dr. D. Ziebolz für die gute Betreuung und Unterstützung in allen Phasen dieser Dissertation,

...Frau M. Hoch und Frau R. Waldmann-Beushausen für die nette und kompetente Betreuung während der experimentellen Untersuchungen,

...den Mitarbeiterinnen und Mitarbeitern der Abteilung Thorax-, Herz- und Gefäßchirurgie der Universitätsmedizin Göttingen unter Leitung von Prof. Dr. F. A. Schöndube für die Ermöglichung der klinischen Untersuchungen und die Überlassung der Herzgewebeproben,

...den Mitarbeiterinnen und Mitarbeitern der Abteilung Medizinische Statistik der Universitätsmedizin Göttingen für die freundliche Unterstützung bei der statistischen Auswertung der Daten,

...den in die Studie einbezogenen Patientinnen und Patienten der Thorax-, Herz- und Gefäßchirurgie, die durch ihre freiwillige Teilnahme diese Arbeit ermöglicht haben. 